\title{
Interacción termal entre magmas graníticos laramídicos y rocas encajonantes mesoproterozoicas: Historia de enfriamiento de intrusivos de la Sierrita Blanca, NW Sonora
}

\author{
Mónica A. Enríquez-Castillo, ${ }^{1,2}$, Alexander Iriondo², Gabriel Chávez-Cabello ${ }^{1}$, \\ Michael J. Kunk ${ }^{3}$ \\ ${ }^{1}$ Facultad de Ciencias de la Tierra, Universidad Autónoma de Nuevo León, Apartado Postal 104, km 8, Carretera Linares-Cerro \\ Prieto, Linares, NL 67700, México. \\ ${ }^{2}$ Centro de Geociencias, Universidad Nacional Autónoma de México, Campus Juriquilla, Querétaro, Qro., 76230, México. \\ ${ }^{3}$ U.S. Geological Survey, MS 926A National Center, Reston, Virginia, 20192, USA. \\ *monicaenriquez4@gmail.com
}

\begin{abstract}
Resumen
Un estudio termocronológico semi-cuantitativo, combinando técnicas geocronológicas de U-Pb y ${ }^{40} \mathrm{Ar} /{ }^{39} \mathrm{Ar}$, permitió evaluar el fenómeno de cristalización y posterior enfriamiento del cuerpo intrusivo laramídico Sierrita Blanca, así como el efecto termal del mismo en las rocas encajonantes mesoproterozoicas $(\sim 1.1 \mathrm{Ga})$ denominadas granito Murrieta.

La disparidad en edades U-Pb en zircones para dos muestras del granito Sierrita Blanca (72.6 $\pm 1.2 \mathrm{Ma}$ y $69.7 \pm 1.0 \mathrm{Ma})$ pudiera estar asociada al enfriamiento más rápido del magma en la zona de contacto con el encajonante mesoproterozoico; pero no se puede descartar que esta unidad granítica esté compuesta por múltiples intrusiones de composición similar y relativamente espaciadas en el tiempo. Las edades de ${ }^{40} \mathrm{Ar} /{ }^{39} \mathrm{Ar}$ (biotita y feldespato potásico) de la muestra de granito más cercana al encajonante son también más antiguas que las de la roca recolectada en la zona más interna del intrusivo. El enfriamiento inicial del granito es relativamente rápido desde la temperatura de cierre del zircón hasta la de la biotita $\left(\sim 36-32^{\circ} \mathrm{C} / \mathrm{Ma}\right)$, para que posteriormente se pase a enfriamientos relativamente lentos desde la biotita hasta el feldespato potásico $\left(\sim 10-9^{\circ} \mathrm{C} / \mathrm{Ma}\right)$. Estos enfriamientos del granito Sierrita Blanca son comparables, aunque quizá un poco más lentos, a los estimados para otros granitoides laramídicos del NW de México.

Tres muestras del granito mesoproterozoico Murrieta, recolectadas a diferentes distancias del intrusivo laramídico, fueron fechadas por U-Pb en zircones $(\sim 1.1 \mathrm{Ga})$, reiterándose la resistencia de esta sistemática a los efectos termales. Sin embargo, se aprecia la presencia de zircones con pérdida evidente de $\mathrm{Pb}$, que se asocian a la exposición de estas rocas al calor y/o fluidos relacionados a la intrusión laramídica, siendo este efecto más pronunciado en la roca recolectada cerca del contacto con el granito. Este efecto de reajuste isotópico es mucho más marcado para la sistemática de ${ }^{40} \mathrm{Ar} /{ }^{39} \mathrm{Ar}$ en biotita y feldespato potásico, al encontrarse estos minerales totalmente reajustados a edades laramídicas. Las estimaciones de enfriamiento post-reajuste isotópico entre biotita y feldespato potásico $\left(\sim 18-15^{\circ} \mathrm{C} / \mathrm{Ma}\right)$ de las rocas encajonantes son, en cierto modo, armónicas con los enfriamientos estimados para estos mismos minerales en el granito laramídico. Esto sugiere que el enfriamiento general del área de la Sierrita Blanca, después de la intrusión granítica laramídica, fue coherente, finalizando este en las zonas más internas del intrusivo. Por último, destacar que el pulso magmático miocénico presente en la Sierrita Blanca no ha causado ningún efecto termal apreciable en las rocas graníticas cretácicas o mesoproterozoicas.
\end{abstract}

Palabras clave: Termocronología, Geocronología U-Pb y ${ }^{40} \mathrm{Ar} /{ }^{39} \mathrm{Ar}$, Laramídico, Mesoproterozoico, reajuste isotópico. 


\begin{abstract}
A semi-quantitative thermochronological study, combining $U-P b$ and ${ }^{40} \mathrm{Ar}{ }^{\beta 9} \mathrm{Ar}$ geochronology, has allowed assessment of the crystallization and cooling history of the Laramide Sierrita Blanca granite as well as the thermal effects resulting from the intrusion into the Mesoproterozoic host rocks ( 1.1 Ga Murrieta granite).

The U-Pb zircon age discrepancy between two samples of the Sierrita Blanca granite (72.6 $\pm 1.2 \mathrm{Ma}$ and $69.7 \pm 1.0 \mathrm{Ma})$ could be explained by a process of faster magma cooling in the contact zone with the host Murrieta granite. However, that the Sierrita Blanca granitic unit was made up of multiple intrusions of similar compositions emplaced relatively close in time cannot be discarded. The ${ }^{40} \mathrm{Ar}{ }^{\beta 9} \mathrm{Ar}$ ages of both biotite and $\mathrm{K}$-feldspar for the granite collected close to the contact are also significantly older than the ages for the sample collected in a more internal zone of the intrusion. The initial cooling of the Sierrita Blanca granite was fairly fast and monotonous from the closure temperature of zircon to that of biotite $\left(\sim 36-32^{\circ} \mathrm{C} / \mathrm{Ma}\right)$. Subsequently, the cooling of these Laramide rocks became relatively slow $\left(\sim 10-9^{\circ} \mathrm{C} / \mathrm{Ma}\right)$ between the closure temperature of biotite and $\mathrm{K}$-feldspar. These estimated cooling rates are similar, perhaps slightly slower, to the ones estimated for other Laramide granitoids in NW Mexico.

Three samples of the host Murrieta granite, collected at different distances from the Laramide intrusion, were dated by U-Pb zircon geochronology at $\sim 1.1 \mathrm{Ga}$, reiterating that the U-Pb zircon systematics are quite resistant to thermal effects inflicted by intrusions like the one in the Sierrita Blanca. However, close inspection of the U-Pb zircon data suggests the presence of Pb loss for some of the zircons. This Pb-loss phenomenon is most pronounced in the zircons from the sample collected at the contact with the Sierrita Blanca intrusive where heat and/or hydrothermal fluids are released by the Laramide intrusion. It is important to note that away from the intrusion-host contact there is a gradual decrease of such thermal effects in the rocks until samples with zircons that show no effects of resetting as suggested by their total U-Pb zircon concordance. This thermal resetting is more prominent in the ${ }^{40} \mathrm{Ar} /{ }^{\beta 0} \mathrm{Ar}$ systematics of biotite and K-feldspar, since they are totally reset to Laramide ages, including the sample collected the farthest away from the contact. The estimation of post-resetting cooling of biotite and $\mathrm{K}$-feldspar from the host rocks at $\sim 18-15^{\circ} \mathrm{C} / \mathrm{Ma}$ is, in a sense, coherent with the cooling estimates for the same minerals for the Sierrita Blanca granite. This suggests that the general cooling of the Sierrita Blanca after the Laramide intrusion was, for the most part, coherent for the entire area and ended, as expected, in the more internal zones of the Laramide intrusion. Lastly, it is important to point out that the Miocene magmatic pulse present in the Sierrita Blanca and adjacent areas has not caused any thermal disturbance to the Cretaceous or Mesoproterozoic igneous rocks studied in the area.
\end{abstract}

Keywords: Thermochronology, U-Pb and ${ }^{40} \mathrm{Ar}{ }^{\beta 9} \mathrm{Ar}$ Geochronology, Laramide, Mesoproterozoic, isotopic resetting.

\section{Introducción}

El término Laramide se ha utilizado para definir un evento orogénico de larga duración con características tectonomagmáticas, metamórficas y sedimentarias muy peculiares que sucedió durante el Cretácico superior y el Paleógeno en todo el SW de Norte América (ej., Damon et al., 1964; Coney, 1976; Dickinson et al., 1988). La orogenia Laramide tiene características específicas según la región y presenta diferentes estilos de deformación a lo largo de la cordillera Norteamericana, como son los estilos "thick skin" y "thin skin" (deformación de basamento y deformación de cobertura). Sin embargo, existe mucha controversia con respecto a la duración y la naturaleza de este evento contraccional en México (ej., Cerca, 2004; Iriondo et al., 2005; Chávez-Cabello, 2005). En este estudio, el término Laramide se maneja únicamente con una connotación temporal para definir un magmatismo de gran magnitud en el NW de México que se originó debido a la subducción de la placa oceánica Farallón debajo de la placa continental de Norte América entre 75-40 Ma.

La evolución termal de los intrusivos laramídicos asociados a la subducción, y sus efectos termales en las rocas encajonantes, son aspectos básicamente desconocidos en el NW de Sonora, y son de gran importancia para dilucidar la evolución del arco magmático continental del NW de México (ej., Ortega-Rivera, 2003; Valencia-Moreno et al., 2006; Ramos-Velázquez et al., 2008).

Para cuantificar la evolución termal de estos intrusivos y evaluar sus efectos termales en las rocas encajonantes, se seleccionó la zona de la Sierrita Blanca, ubicada a 25 $\mathrm{km}$ del poblado de Quitovac en el NW de Sonora (Figura 1). En esta zona existe un claro contacto intrusivo entre un granito, supuestamente laramídico, y su encajonante que permitió evaluar estos efectos. Es importante señalar que en las regiones aledañas a Sierrita Blanca muchos de los contactos de los granitos laramídicos son por cizalla dúctil asociada a cabalgaduras laramídicas como se ejemplifica en las zonas de Quitovac, Sonora (Iriondo et al., 2005) y Quitobaquito en Arizona (Haxel et al., 1984).

El objetivo principal de este estudio fue el de documentar el efecto termal de los magmas graníticos laramídicos en la roca encajonante mesoproterozoica. Para cumplir este objetivo se emplearon dos sistemáticas geocronológicas diferentes como lo son el U-Pb y el ${ }^{40} \mathrm{Ar} /{ }^{39} \mathrm{Ar}$ que, combinadas, permitieron obtener la edad de cristalización de los granitos laramídicos, su subsecuente enfriamiento y el efecto termal de estos en el encajonante granítico mesoproterozoico.

La hipótesis de trabajo sugiere que los enfriamientos de 


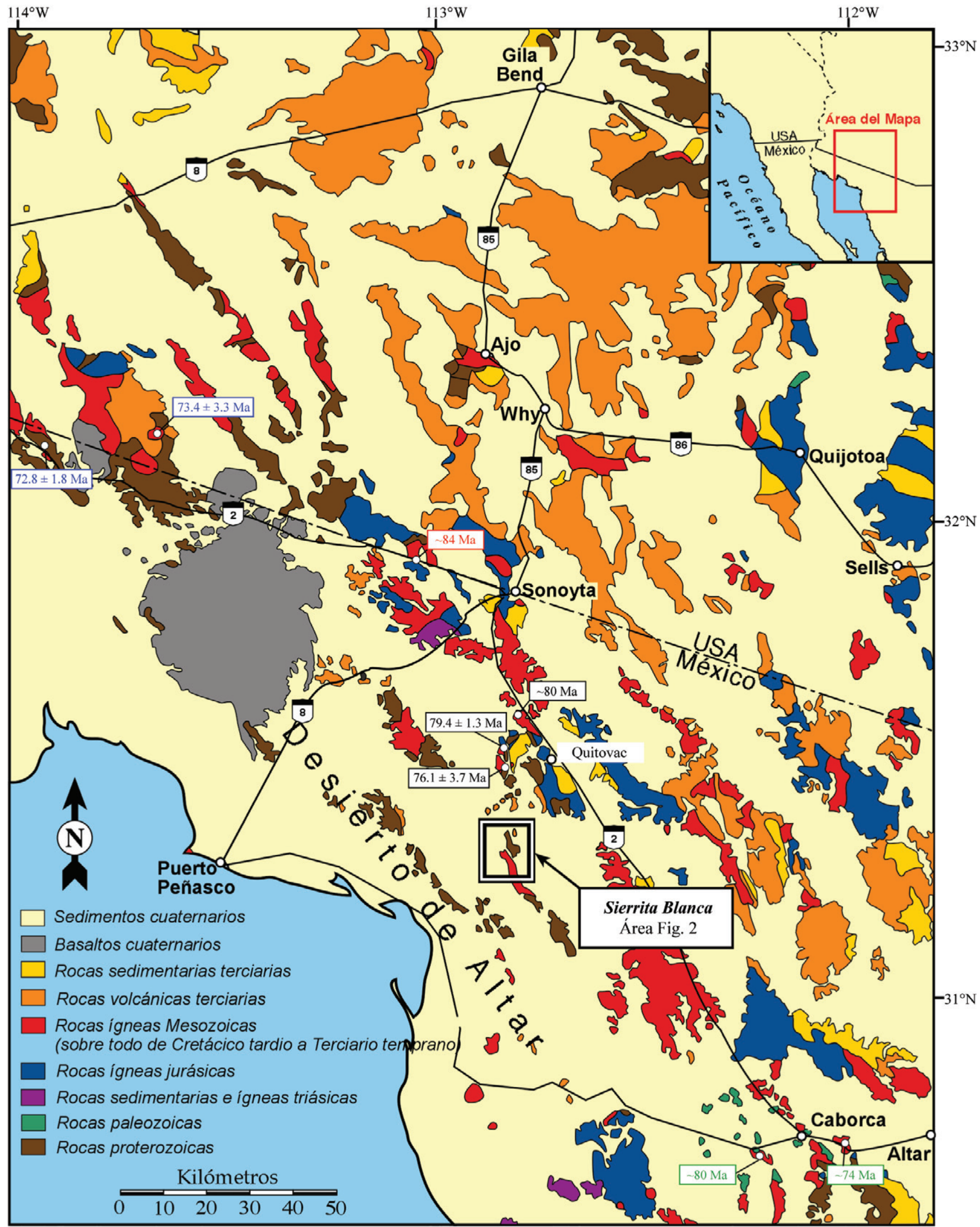

Figura 1. Mapa geológico regional del NW de Sonora y SW de Arizona, modificado de Iriondo et al. (2005). El área de estudio está mostrada en el recuadro negro. Se muestran algunas edades de U-Pb en zircones de rocas ígneas laramídicas reportadas para esta región del NW de Sonora. De color negro se presentan las edades reportadas por Iriondo (2001) en la zona de Quitovac. En rojo, la edad de un intrusivo en Sierra Los Tanques, reportado por Campbell y Anderson (2003). En color azul se muestran edades U-Pb de rocas graníticas reportadas por Nourse et al. (2005) para la zona Cabeza Prieta-Pinacate; y de color verde las edades reportadas por Jacques-Ayala et al. (2008) para los intrusivos graníticos de Pitiquito y del Cerro Proveedora. 
las rocas graníticas laramídicas en la Sierrita Blanca pudieron haber sido relativamente lentos desde su cristalización, quizá, en parte, por los grandes volúmenes magmáticos que representan estas rocas en el NW de México y por el largo periodo de tiempo que la región estuvo expuesta a flujo de calor asociado a los emplazamientos magmáticos generados por la subducción de la placa Farallón y el establecimiento del arco magmático laramídico. También, se sugiere que las rocas del basamento, consideradas como precámbricas en cartografías previas (SGM, 2002), deberían haber sido fuertemente afectadas por el evento termal laramídico asociado a los magmas de composición granítica, y que por lo tanto, los minerales de relativa baja retención de Argón, presentes en estas rocas (biotita y feldespato potásico), habrían sido isotópicamente reajustados e indicarían edades laramídicas de reajuste y/o enfriamiento. Para poner a prueba esta idea, se realizaron estudios de historia de enfriamiento $\mathrm{U}-\mathrm{Pb}$ y ${ }^{40} \mathrm{Ar} /{ }^{39} \mathrm{Ar}$ en dos muestras graníticas laramídicas y en tres muestras precámbricas metaígneas del encajonante. En ambos casos, el muestreo se realizó a diferentes distancias del contacto intrusivo-encajonante presente en la parte norte de la Sierrita Blanca (Figura 2).

\section{Trabajos previos en el NW de Sonora}

2.1. Geocronología y termocronología de rocas ígneas laramídicas en el NW de Sonora y áreas adyacentes

Los primeros estudios geocronológicos de rocas laramídicas en la región fueron realizados por Haxel et al. (1984) que estudiaron la parte sur de Arizona encontrando granitos laramídicos de dos micas, relacionados a un episodio orogénico ( $\sim 60-58 \mathrm{Ma}$; edades de enfriamiento $\mathrm{K}$-Ar en micas), los cuales representan una superposición de dos regímenes tectónicos; por un lado, acortamiento cortical relacionado a la orogenia Laramide, y por otro un pulso extensional de tipo complejo de núcleo metamórfico asociado al cese de la subducción en el borde del Pacífico. Posteriormente, Iriondo (2001) reportó edades U-Pb de zircones de $76.1 \pm 3.7 \mathrm{Ma}$ en dioritas de grano fino de la zona Campo Bustamante en el área de Quitovac en el NW de Sonora (Figura 1); también este autor, y en la misma zona, fechó granitos de dos micas y diques aplíticos en $79.4 \pm 1.3$ Ma utilizando la misma técnica geocronológica.

Campbell y Anderson (2003) realizaron un estudio en Sierra Los Tanques al NW de Sonora (a $\sim 50 \mathrm{~km}$ al NNW de Sierrita Blanca), a lo largo de la hipotética falla jurásica Mojave-Sonora, para ver las similitudes entre rocas cristalinas y su cubierta suprayacente prejurásica en el NW de Sonora. Estos autores fecharon una unidad granítica por $\mathrm{U}-\mathrm{Pb}$ en zircones en $\sim 84 \mathrm{Ma}$, considerándola como una unidad post-tectónica con respecto al desplazamiento de la supuesta megacizalla. La hipótesis de la megacizalla Mojave-Sonora sugiere la existencia de un sistema de fallas de corrimiento lateral izquierdo, con orientación NW-SE, que fue activo en el Jurásico Medio-Tardío. Se supone que su traza se extiende desde el Desierto de Mojave en el este de California, en los Estados Unidos, pasando por Sonora y todo el norte de México hasta llegar al Golfo de México (Anderson y Schmidt, 1983). Para tener una visión actual del estado de conocimiento sobre la megacizalla Mojave-Sonora se remite al lector a la síntesis presentada por Molina-Garza e Iriondo (2005) en la que se discuten aspectos a favor y en contra de esta controversial hipótesis.

Nourse et al. (2005) reportaron edades U-Pb en zircones de $73.4 \pm 3.3$ Ma y $72.8 \pm 1.7$ Ma para intrusivos de la zona de Cabeza Prieta ubicada al noroeste del Campo Volcánico Pinacate en el NW de Sonora. Jacques-Ayala et al. (2008) fecharon el granito Pitiquito en $\sim 74$ Ma por el método de $\mathrm{U}-\mathrm{Pb}$ en zircones. El granito Proveedora fue fechado por zircones por estos mismos autores con una edad similar de $\sim 74 \mathrm{Ma}$.

Por otro lado, existen estudios termocronológicos semi-cuantitativos en el NW de México como los de Ortega-Rivera et al. (1997) donde presentan información tectonotérmica de intrusivos para el área de San Pedro Mártir en Baja California. Estos estudios proponen velocidades de enfriamiento para estos intrusivos relativamente rápidas $\left(\sim 40^{\circ} \mathrm{C} / \mathrm{Ma}\right)$ entre el cierre isotópico del zircón y la biotita. También Ortega-Rivera (2003) realizó un estudio de termocronología para otros intrusivos de Baja California, obteniendo edades para los mismos que muestran una secuencia de enfriamiento que va de oeste hacia el este. Gans (1997) realizó estudios termocronológicos y estructurales en el área de Santa Rosa, al SE de Sonora, donde reporta rocas andesíticas-dacíticas de edad laramídica (60.0 \pm 0.5 $\mathrm{Ma} ;{ }^{40} \mathrm{Ar} /{ }^{39} \mathrm{Ar}$ en hornblenda). Para una granodiorita (San Nicolás) reporta velocidades de enfriamiento relativamente rápidas de $\sim 40^{\circ} \mathrm{C} / \mathrm{Ma}$ entre la hornblenda y la biotita; para posteriormente estimar un enfriamiento más lento entre la biotita y el feldespato potásico $\left(\sim 7^{\circ} \mathrm{C} / \mathrm{Ma}\right)$. Iriondo et al. (2003b) reportan edades ${ }^{40} \mathrm{Ar} /{ }^{39} \mathrm{Ar}$ de una tonalita en Baja California de la cual se fechó una hornblenda en $91.68 \pm 0.32$ Ma, una biotita en $89.39 \pm 0.11$ Ma y un feldespato potásico en $\sim 84.51 \mathrm{Ma}$. Estos fechamientos sugieren enfriamientos muy rápidos para esta tonalita entre hornblenda y biotita $\left(\sim 87^{\circ} \mathrm{C} / \mathrm{Ma}\right)$, y más lentos entre biotita y el feldespato potásico $\left(\sim 15-19^{\circ} \mathrm{C} / \mathrm{Ma}\right)$.

Recientemente, Ramos-Velázquez et al. (2008) realizaron un estudio termocronológico de rocas graníticas del batolito costero de Sonora utilizando las técnicas U-Pb en zircones y ${ }^{40} \mathrm{Ar} /{ }^{39} \mathrm{Ar}$ en biotita y feldespato potásico. Obtuvieron edades para el emplazamiento de los intrusivos graníticos a partir de zircones (U-Pb) entre 90-69 Ma, y edades de enfriamiento de biotita con ${ }^{40} \mathrm{Ar} /{ }^{39} \mathrm{Ar}$ de $\sim 74-67$ Ma y de feldespato potásico de $\sim 68-42 \mathrm{Ma}$. Las curvas de enfriamiento presentadas por estos autores indican enfriamientos de muy rápidos a relativamente rápidos de zircón a biotita $\left(\sim 85-36^{\circ} \mathrm{C} / \mathrm{Ma}\right)$, y enfriamientos muy lentos de biotita a feldespato de alta retención $\left(\sim 12-6^{\circ} \mathrm{C} /\right.$ $\mathrm{Ma})$, y algo más rápidos del feldespato de alta retención al 
feldespato de baja retención $\left(\sim 35-4.5^{\circ} \mathrm{C} / \mathrm{Ma}\right)$. Estos autores sugieren que estos enfriamientos parecen estar asociados a una importante exhumación de la región costera de Sonora durante el Paleoceno para explicar estas tasas de enfriamiento; también sugieren que este batolito costero pudiera representar la parte más occidental del evento magmático Laramide en Sonora.

\subsection{Basamento precámbrico en el NW de Sonora}

Cooper y Arellano (1946) fueron los primeros en reconocer el basamento precámbrico cristalino en

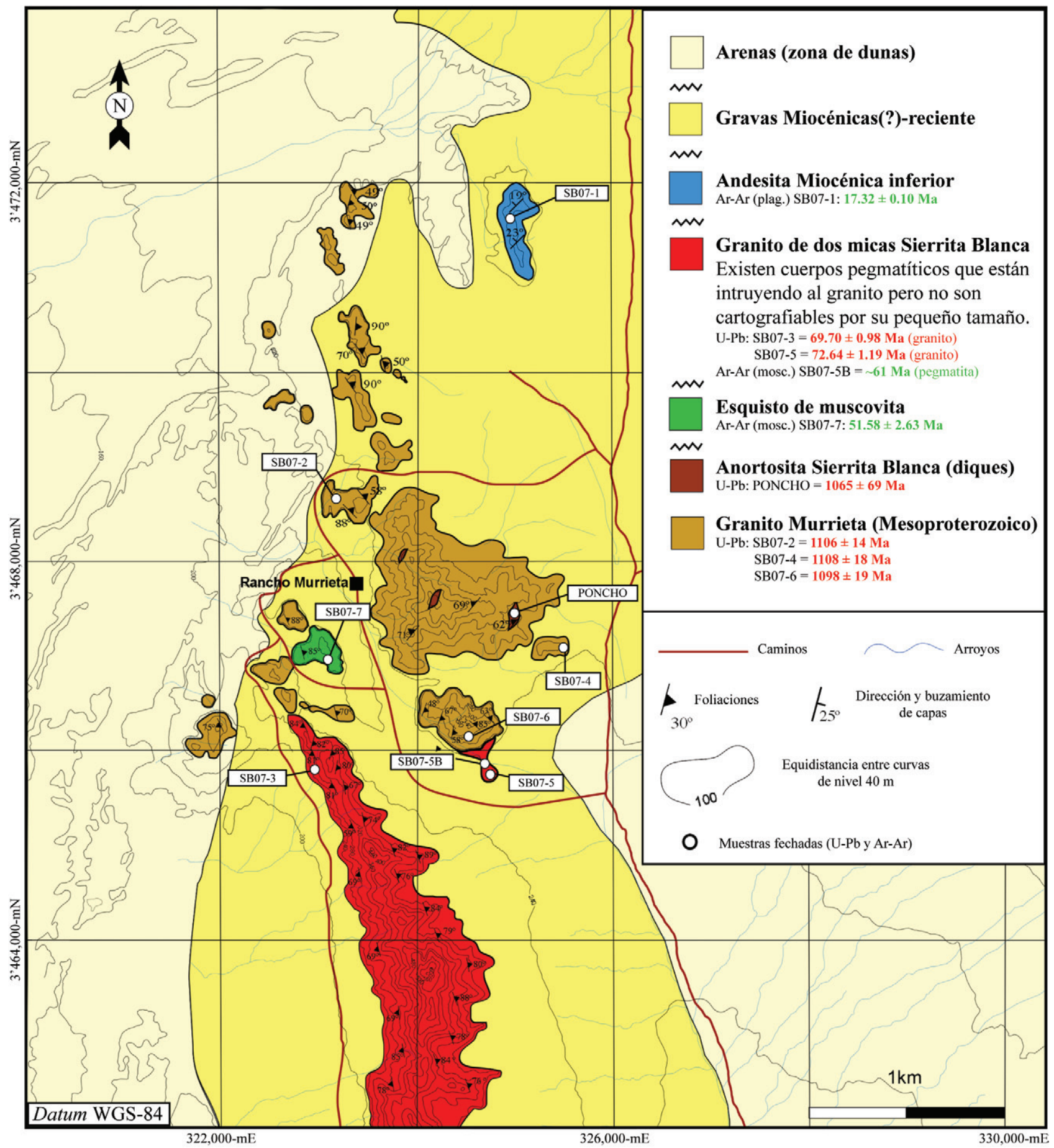

Figura 2. Mapa geológico del área de Sierrita Blanca, NW de Sonora, señalando los lugares donde se recolectaron las rocas para realizar los análisis geocronológicos, como también las vías de acceso al área de estudio. Información geográfica, curvas de nivel y arroyos a partir de carta topográfica H12A34 "El Tullido" escala 1:50,000 (INEGI, 2003). 
el NW de México al identificar fauna del Cámbrico Medio en la secuencia sedimentaria de la región de Caborca, sobreyaciendo a un basamento metaígneo. Posteriormente, Damon et al. (1962) reportaron los primeros fechamientos radiométricos (K-Ar) del basamento ígneo paleoproterozoico, identificando, en el NW de Sonora, la presencia de magmatismo de edad grenviliana $(\sim 1.1 \mathrm{Ga})$. Damon et al. $(1961,1962)$ correlacionaron las rocas antiguas de Sonora con las rocas precámbricas del SW de Estados Unidos. Anderson y Silver (1977) describieron el basamento paleoproterozoico como una serie metamórfica de gneises, metacuarzitas y esquitos (ca. 1.6-1.8 Ga) llamada Complejo Metamórfico Bámuri. Anderson y Silver (1978) reportaron edades de $1780 \pm 20$ Ma para este complejo metamórfico en la zona del Rancho Bámuri a $60 \mathrm{~km}$ al sur de la ciudad de Caborca, Sonora. Este complejo metamórfico lo interpretaron como una secuencia volcano-sedimentaria con metamorfismo en facies de esquistos verdes a anfibolita $(\sim 1.65 \mathrm{Ga})$ intrusionada posteriormente por granitoides de tipo anorogénico con edades de $\sim 1.4 \mathrm{y} \sim 1.1 \mathrm{Ga}$. El pulso magmático de $\sim 1.1$ Ga fue descrito inicialmente a partir de los estudios del granito Aibó, el cual aflora a $50 \mathrm{~km}$ al sur de la ciudad de Caborca, en el Rancho Aibó cerca del Cerro Los Indios. Este granito fue fechado por U-Pb en zircones por Anderson y Silver $(1979,2005)$ reportando una edad de $1091 \pm 54 \mathrm{Ma}$. Esta edad ha sido corroborada por otros fechamientos de $\mathrm{U}-\mathrm{Pb}$ en zircones por Iriondo et al. (2003a; $1074 \pm 5 \mathrm{Ma})$ y Farmer et al. $(2005 ; 1075 \pm 1$ $\mathrm{Ma}$ ) en muestras de granito recolectadas en las cercanías del Rancho Aibó.

Estudios geocronológicos, geoquímicos e isotópicos de Sm-Nd (Iriondo y Premo, 2010) revelaron que gran parte del basamento de la región noroeste de Sonora, al suroeste de la hipotética traza de la megacizalla Mojave-Sonora (bloque Caborca), contiene principalmente rocas con características similares a las de la provincia cortical paleoproterozoica Yavapai (provincia compuesta por rocas supracorticales de edades 1.75-1.71 Ga con grado metamórfico de moderado a alto que fueron intruidas por rocas plutónicas de composiciones máficas a intermedias y con edades de cristalización de 1.84-1.66 Ga). En menor mediada, como lo sugieren Iriondo y Premo (2010), en esta porción de Sonora también existen rocas con características similares a las de la provincia paleoproterozoica Mojave (esta provincia se encuentra, principalmente, al sur de Nevada, SE de California y SW de Arizona, y está compuesta por rocas de cobertura metasedimentaria de alto grado metamórfico con componentes neoarqueano-paleoproterozoicos $\sim 2.7-1.8$ $\mathrm{Ga})$.

Iriondo y Premo (2010) también sugieren que estas provincias (Yavapai y Mojave) son contrastantes con respecto al basamento expuesto al noreste de la supuesta megacizalla (bloque Norte América), que presenta rocas con características similares a las de la provincia paleoproterozoica Mazatzal (provincia localizada al sur de Arizona, compuesta por rocas supracorticales de bajo grado metamórfico e intrusiones hipobisales 1.75-1.62 Ga con características isotópicas juveniles; deformadas durante la orogenia Mazatzal entre 1.67-1.62 Ga).

\section{Geología de la parte Norte de la Sierrita Blanca}

En la parte norte de la Sierrita Blanca (Figura 2) aflora una unidad de granitos cartografiados por el Servicio Geológico Mexicano (SGM, 2002; hoja 1:250,000 Puerto Peñasco) como granitos del Proterozoico. Esta unidad se ha denominado en este estudio como granito Murrieta (Figuras 2 y 3 A) por su cercanía con el Rancho del mismo nombre. Debido a que estas rocas presentan una homogeneidad litológica y petrográfica, se justifica su agrupamiento en una sola unidad. La única excepción es la presencia de cuerpos aplíticos intruyendo al granito Murrieta que también se han considerado como de edad precámbrica (Figura 3B). El granito Murrieta debe de estar intruyendo a un basamento paleoproterozoico tipo Yavapai de una forma similar a lo que se observa en la zona de Quitovac (Iriondo 2001; Iriondo et al., 2004b). Este granito tiene un alto contenido en feldespato potásico (microclina) y también se observa abundante biotita y cuarzo; su textura general es de tipo inequigranular seriada (Tabla 1; EnríquezCastillo, 2008). Este granito presenta foliaciones con una orientación preferencial NW-SE y en menor medida NESW (Figuras 2 y 3D). El granito está intruido por diques de composición anortosítica con textura cumulítica y con orientación NE-SW (Figura 3C). Mineralógicamente, estas rocas se distinguen por su alto contenido en plagioclasa y pequeñas cantidades de piroxeno bien preservado. Rocas anortosíticas han sido reportadas en diferentes localidades en el basamento de Sonora con edades de entre $1095 \pm$ 28 y $1075 \pm 9$ Ma (Koenken, 1976; Espinoza et al., 2003; Izaguirre e Iriondo, 2007).

Dos muestras del granito laramídico Sierrita Blanca (Figuras 2 y 4A) se clasificaron por su composición modal como granito de feldespato alcalino y como una cuarzosienita de feldespato alcalino, ambos de dos micas, presentando generalmente una textura de tipo granular (Tabla 1; Enríquez-Castillo, 2008). Este cuerpo granítico se encuentra intruido por una serie de diques tardimagmáticos pegmatíticos y aplíticos (Figura 3A; Tabla 1) que son más abundantes a lo largo del contacto intrusivo entre el granito Sierrita Blanca y la roca encajonante (Figura 3A). Puntualmente, el granito Sierrita Blanca se encuentra cizallado y foliado con una orientación de foliación $\mathrm{N}-\mathrm{S}$, casi vertical, buzando hacia el este y al oeste (Figuras 2 y 4B). También se ha encontrado una unidad de esquisto de mica blanca que podría relacionarse al efecto de la deformación del granito precámbrico Murrieta durante la orogenia Laramide (Figura 3D). En lámina delgada, el esquisto presenta mica blanca bien orientada, apreciándose dos pulsos bien diferenciados de deformación al observarse un clivaje de crenulación desarrollado sobre una foliación 


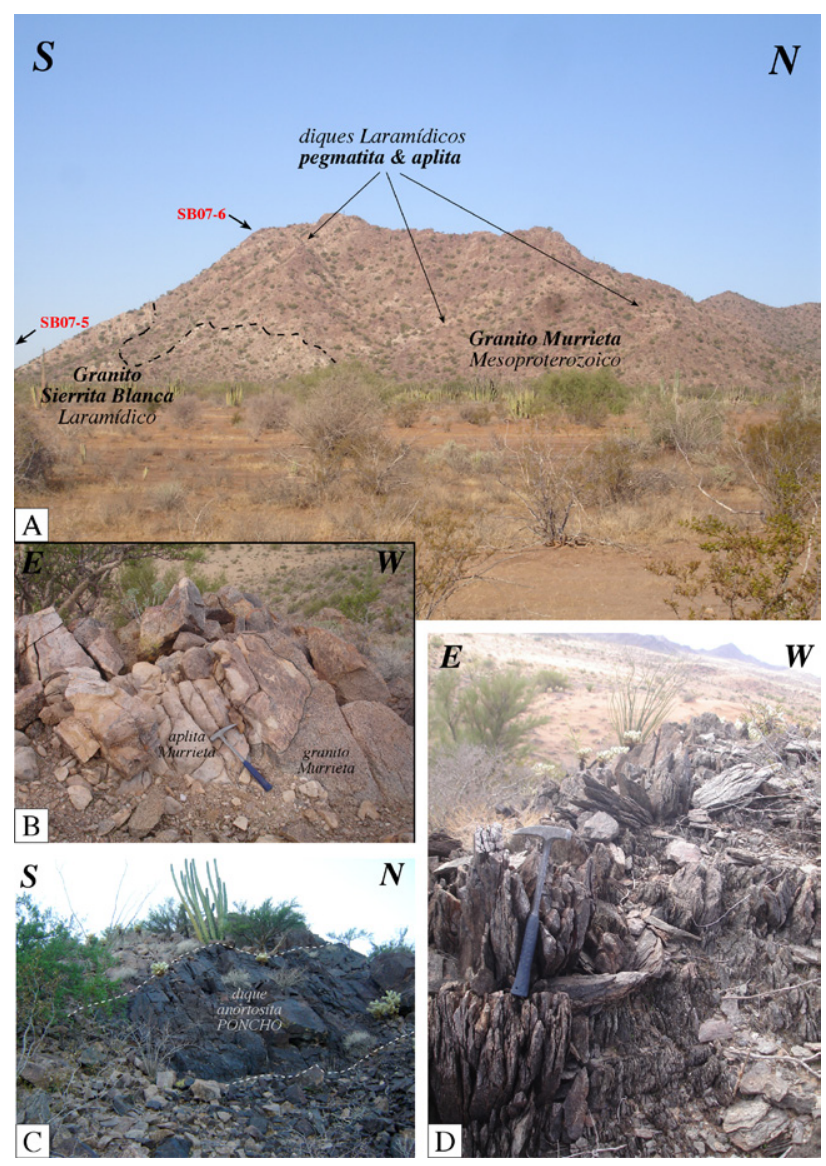

Figura 3. A) Vista panorámica del contacto entre el granito laramídico Sierrita Blanca y el granito mesoproterozoico Murrieta (línea negra punteada). Con flechas se muestran algunos de los diques pegmatíticos y aplíticos tardimagmáticos. B) Dique aplítico supuestamente mesoproterozoico cortando al granito Murrieta. C) Dique anortosítico mesoproterozoico intruyendo al granito Murrieta. D) Esquisto de moscovita con foliación subvertical, resultado posiblemente de la deformación laramídica del granito mesoproterozoico.

preexistente (Enríquez-Castillo, 2008).

$\mathrm{Al}$ norte de la Sierrita Blanca afloran rocas volcánicas andesíticas (Figura 2) que tienen alto contenido en plagioclasa, hornblenda y biotita (Tabla 1). Dentro de esta unidad volcánica se encontraron algunos xenolitos máficos con anfíboles muy alterados. La orientación principal aparente de las lavas es NE-SW con buzamientos de $19^{\circ}$ a $23^{\circ}$ hacia el NW.

Por último, y cubriendo gran parte del área de estudio, tenemos una unidad de gravas miocénicas y/o recientes, las cuales se encuentran en discordancia angular con respecto a las unidades descritas anteriormente (Figura 2). En los alrededores de la Sierrita Blanca se observan arenas finas de composición cuarzo-feldespática, las cuales forman dunas eólicas con actividad reciente.

\section{Muestreo y métodos analíticos}

Para obtener la edad de cristalización (geocronología $\mathrm{U}-\mathrm{Pb}$ ) y evaluar el enfriamiento de los granitos (geocronología ${ }^{40} \mathrm{Ar} /{ }^{39} \mathrm{Ar}$ ) presentes en la parte norte de la Sierrita Blanca, se recolectaron seis muestras, las cuales se tomaron a distintas distancias del contacto intrusivo-encajonante para evaluar al mismo tiempo los efectos termales del granito laramídico en el encajonante (Figura 2).

Se recolectaron aproximadamente de $2-4 \mathrm{~kg}$ de roca fresca para cada sitio seleccionado. Se realizaron separaciones minerales en el Centro de Geociencias de la UNAM usando técnicas estándar, que incluyeron separación magnética con un equipo Frantz y la separación por densidad utilizando líquidos pesados (bromoformo e ioduro de metileno). Para la separación final de los zircones se utilizó un microscopio binocular de luz reflejada y pinzas de precisión. Posteriormente, los zircones fueron montados en probetas de resina epoxi (probetas DM-1 y DM-2). Después se procedió a la desbastación (con lija de agua) y pulido de las probetas con pasta de diamante $(6$ y $1 \mu \mathrm{m})$. A partir de estas probetas pulidas y cubiertas con carbón se obtuvieron imágenes de cátodoluminiscencia (CL) de los zircones utilizando un microscopio electrónico de barrido (SEM-Scanning Electron Microscope) marca JEOL 5600 (U.S. Geological Survey, Denver, Colorado).

Los estudios geocronológicos de U-Pb en zircones se realizaron con un equipo de ICP-MS multicolector marca VG Isoprobe ubicado en el Laboratorio LaserChron de la Universidad de Arizona en Tucson, Arizona. Este espectrómetro está equipado con nueve colectores Faraday, un detector axial Daly y cuatro canales de contadores iónicos (Gehrels et al., 2006). El VG Isoprobe está conectado a un láser ArF Excimer, el cual tiene una emisión de longitud de onda de $193 \mathrm{~nm}$. Según la técnica, puede obtenerse un punto de análisis de diámetro en el intervalo de 10-75 $\mu \mathrm{m}$ con una producción de energía de $\sim 32 \mathrm{~mJ}$ y una repetición estimada de $10 \mathrm{~Hz}$. El tamaño de los puntos analizados en los experimentos fue de 30-35 $\mu \mathrm{m}$ de diámetro, aunque ocasionalmente se uso un tamaño de $\sim 15-20 \mu \mathrm{m}$ para zircones de la una muestra de anortosita. La profundidad de cada punto de ablación fue de $\sim 20 \mu \mathrm{m}$ y el tiempo total de análisis fue de $\sim 90$ segundos por punto. Se configuraron los canales para obtener medidas simultáneas de ${ }^{204} \mathrm{~Pb}$ en un contador iónico, como también para obtener el ${ }^{206} \mathrm{~Pb},{ }^{207} \mathrm{~Pb}$, ${ }^{208} \mathrm{~Pb},{ }^{232} \mathrm{Th}$ y ${ }^{238} \mathrm{U}$ en detectores Faraday.

Los datos generados de los análisis isotópicos fueron reducidos con un programa macro ("in house") de Microsoft Excel desarrollado por el Laboratorio LaserChron. Sin embargo, las edades y grados de concordia fueron calculados y graficados usando el programa ISOPLOT 3.0 (Ludwig, 2003), el cual permitió elegir los datos de zircones con un menor porcentaje de error y/o discordancia para calcular las edades de las rocas bajo estudio.

Los minerales utilizados para los estudios geocronológicos de ${ }^{40} \mathrm{Ar} /{ }^{39} \mathrm{Ar}$ fueron separados también 
Tabla 1. Resumen petrográfico y geocronológico de muestras de la Sierrita Blanca, NW Sonora, México.

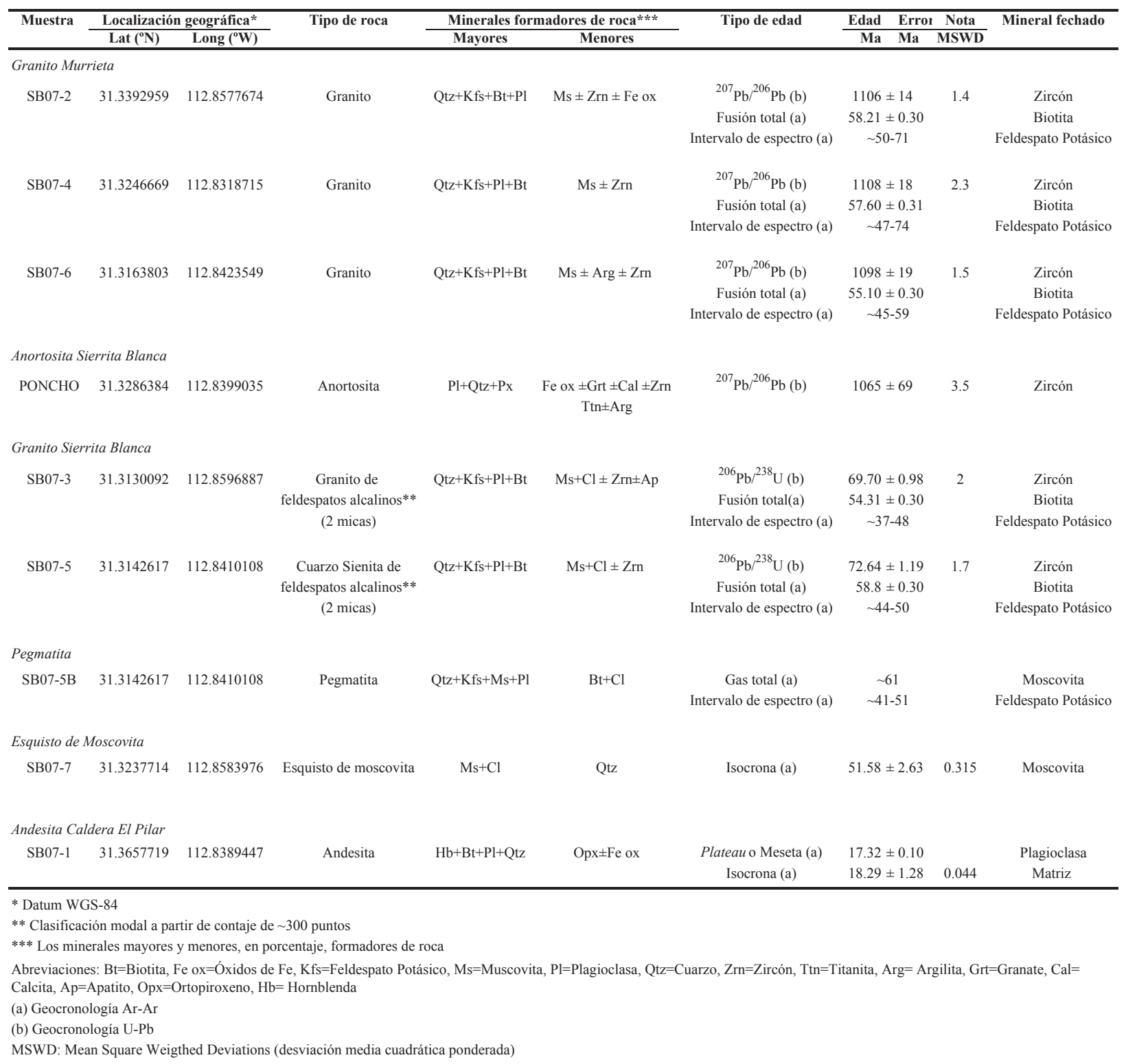

en el Centro de Geociencias (UNAM) utilizando métodos convencionales, incluida la separación por densidades a partir de líquidos pesados como el LST. Para obtener una pureza de los separados $>99 \%$, se utilizaron las pinzas de precisión bajo el microscopio binocular. Después de este proceso, las muestras se lavaron con acetona, alcohol y agua desionizada para limpiarlas y eliminar posibles residuos orgánicos.

Se tomaron alícuotas de separados de moscovita, biotita, feldespato potásico, matriz andesítica y plagioclasa para empaquetarlas en cápsulas de cobre selladas bajo vacío en tubos de cuarzo. Las muestras fueron irradiadas con neutrones rápidos (paquete de irradiación KD48; 20 horas) en la parte central del reactor nuclear TRIGA (GSTR) del
U.S. Geological Survey (Denver, Colorado). Las muestras estándar que se utilizaron fueron la sanidina de la toba Fish Canyon (FCT-3), la cual tiene una edad de 27.29 Ma obtenida por el método K-Ar (Kunk et al., 1985; Cebula et al., 1986), y el estándar de hornblenda MMhb-1 con una edad K-Ar de 519.4 $\pm 2.5 \mathrm{Ma}$ (Alexander et al., 1978; Dalrymple et al., 1981). Este último estándar se utilizó únicamente para la muestra de moscovita que fue irradiada en el mismo reactor pero en el paquete KD49 y por 40 horas. El valor J de irradiación se determinó a partir de las muestras estándar de edad conocida ya antes mencionadas.

Después de irradiadas, las muestras fueron analizadas en el Laboratorio de Termocronología ${ }^{40} \mathrm{Ar} /{ }^{39} \mathrm{Ar}$ del U.S Geological Survey (Reston, Virginia). Las muestras de 

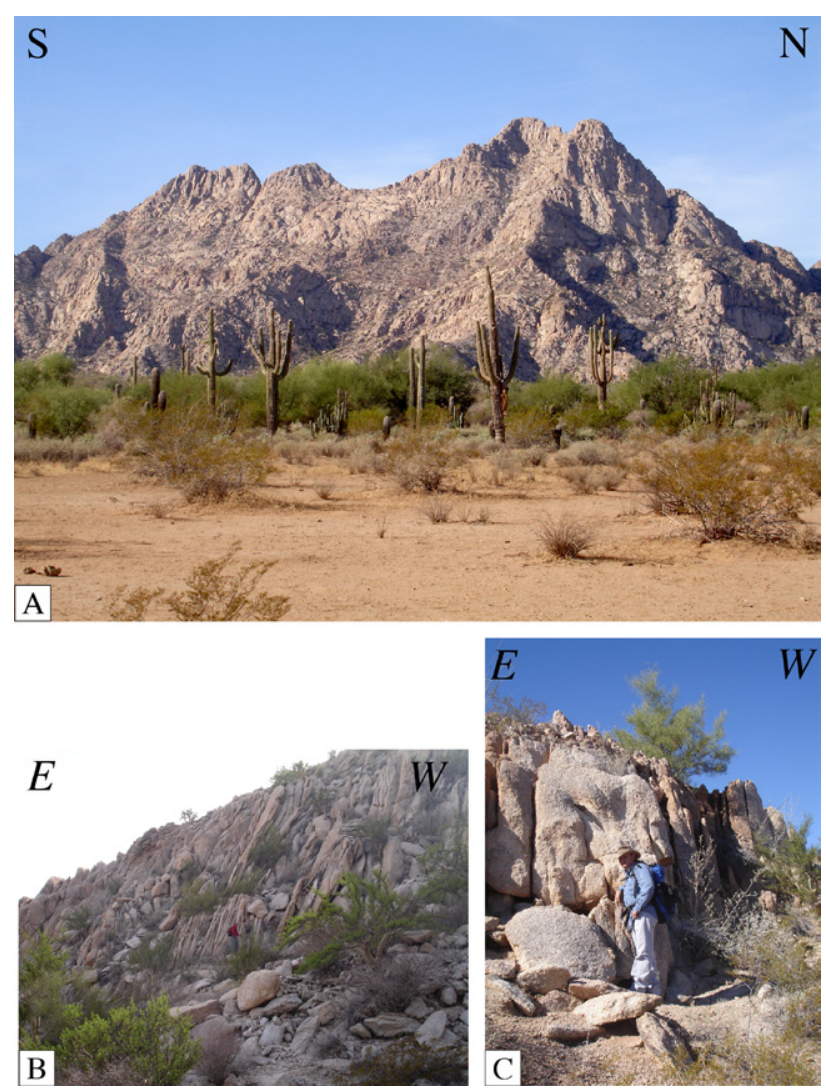

Figura 4. A) Vista panorámica hacia el W de la parte norte de la Sierrita Blanca con sus escarpes muy pronunciados y algo de su vegetación. B) Vista E-W mostrando la foliación verticalizada (buzando hacia el este) del granito Sierrita Blanca. C) El granito Sierrita Blanca mostrando la textura de grano grueso.

feldespato potásico fueron fechadas utilizando el método de calentamiento gradual por horno de tántalo de doble vacío y empleando un espectrómetro de masas tipo MAP 216, acoplado a un multiplicador de electrones. Con este mismo instrumento se fecharon muestras de biotita, las cuales se analizaron con el método de fusión total por horno. Una muestra de moscovita fue también analizada por calentamiento gradual por horno.

Los gases extraídos por el calentamiento y fusión de las muestras fueron purificados para obtener, única y exclusivamente, el gas Argón e introducirlo en el espectrómetro para medir los picos de sus diferentes masas $\left({ }^{40} \mathrm{Ar},{ }^{39} \mathrm{Ar},{ }^{38} \mathrm{Ar},{ }^{37} \mathrm{Ar} \mathrm{y}{ }^{36} \mathrm{Ar}\right)$.

Los separados de plagioclasa y matriz de la andesita SB07-1, y la moscovita del esquisto de moscovita SB077 , se analizaron por calentamiento gradual por horno de tántalo con el espectrómetro de masas VG 1200, también conectado a un multiplicador de electrones. Para más detalle sobre las técnicas geocronológicas de ${ }^{40} \mathrm{Ar} /{ }^{39} \mathrm{Ar}$ de ambos espectrómetros se remite al lector a Iriondo et al. (2003b, 2004a).

Los datos isotópicos de argón obtenidos para las muestras fechadas con el espectrómetro MAP 216 fueron reducidos utilizando el software Mass Spec (Deino, 2001). En el caso de las muestras analizadas en el espectrómetro VG1200 se utilizó el software $\mathrm{Ar} / \mathrm{Ar}^{*}$ (Haugerud y Kunk, 1988). En ambos casos se emplearon las constantes de decaimiento o desintegración isotópica propuestas por Steiger y Jäger (1977). La función general de estos programas es la sustracción de blancos analíticos y correcciones por interferencias isotópicas. Las edades de gas total representan la edad calculada sumando todos los picos de Argón medidos para todos los pasos de temperatura en el experimento para analizar la muestra. Las edades "plateau" o meseta se identifican cuando tres o más pasos contiguos del experimento de calentamiento gradual, conteniendo más del $50 \%$ del $^{39} \mathrm{Ar}_{\mathrm{k}}$, tienen la misma edad dentro de sus límites de error correspondientes a 1-sigma (Fleck et al., 1977).

\section{Resultados geocronológicos}

En este estudio se fecharon seis muestras de granitoides por el método $\mathrm{U}-\mathrm{Pb}$ a partir de zircones y nueve muestras por el método ${ }^{40} \mathrm{Ar} /{ }^{39} \mathrm{Ar}$, utilizando moscovita, biotita, feldespato potásico, matriz andesítica y plagioclasa. En la Tabla 1 se presenta un resumen de los resultados geocronológicos obtenidos por ambas técnicas.

\subsection{Geocronología U-Pb en zircones}

En las Figuras 5-7 se muestran diagramas de concordia (tipo Tera-Wasserburg y Wetherill) a partir de datos U-Pb obtenidos por ablación láser (LA-MC-ICPMS) en zircones de las rocas graníticas mesoproterozoicas (muestras SB072, SB07-4, SB07-6 y PONCHO) y laramídicas (muestras $\mathrm{SB} 07-3$ y SB07-5). Los datos analíticos de U-Pb se muestran en las Tablas 2 y 3. En las Figuras 8-11 se presentan imágenes de cátodoluminicencia, que muestran el nombre y la edad aparente del punto analizado. Como mejor edad aparente se considera la edad ${ }^{206} \mathrm{~Pb} /{ }^{238} \mathrm{U}$ para zircones de edades $<1000$ Ma y la edad ${ }^{207} \mathrm{~Pb} /{ }^{206} \mathrm{~Pb}$ para edades $>1000$ Ma.

\subsubsection{Muestras de encajonante mesoproterozoico (granito Murrieta)}

Los datos U-Pb de zircones de una muestra del granito Murrieta (SB07-2), recolectada a $1500 \mathrm{~m}$ del contacto con el granito laramídico Sierrita Blanca (Figura 2), se graficaron en un diagrama de concordia tipo Wetherill (Figura 5A). Únicamente, 36 de los 38 análisis realizados (elipses de color negro) fueron seleccionados para calcular la edad ${ }^{207} \mathrm{~Pb} / 206 \mathrm{~Pb}$ media ponderada de $1106 \pm 14 \mathrm{Ma}$ (2 sigma; $\mathrm{MSWD}=1.4$; Figura 5B) que se interpreta como la edad de cristalización de esta muestra del granito Murrieta. El criterio que se utilizó para descartar los otros dos análisis (elipses punteadas de color gris) fue un alto porcentaje de error en la edad ( $>5 \%)$ o también por presentar un alto porcentaje de discordancia $(>13 \%)$. 

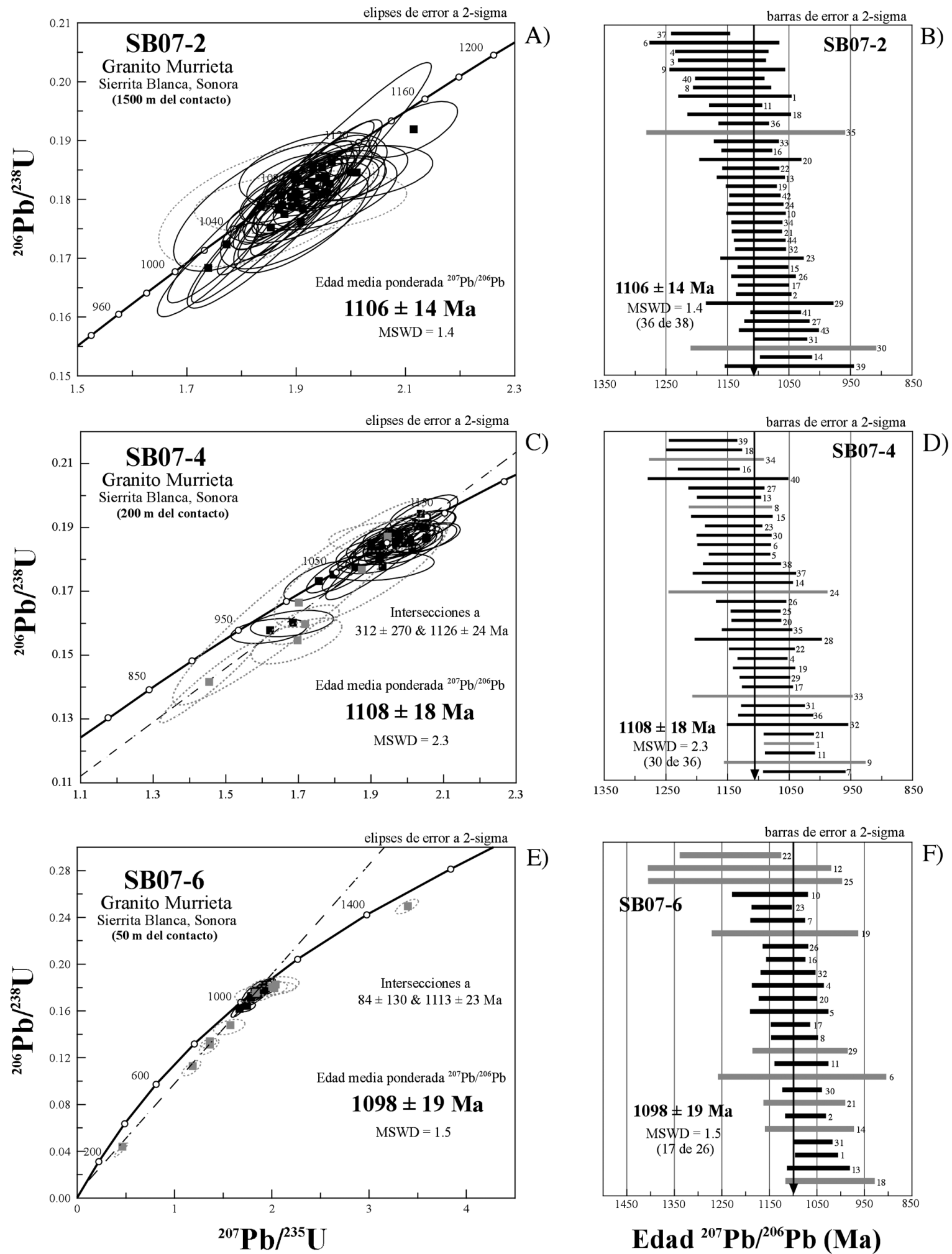

Figura 5. Información U-Pb obtenida por LA-MC-ICPMS en zircones de diferentes muestras del granito Murrieta de la parte norte de la Sierrita Blanca. A) Concordia de la muestra SB07-2 con todos los datos de zircones analizados. En todos los gráficos, los datos representados por las elipses de color negro muestran los análisis utilizados para obtener la edad; las elipses punteadas de color gris son los análisis descartados para el cálculo de la edad debido a su alto porcentaje de error (>5\%) o por su discordancia (>13\%). B) Diagrama de edad ${ }^{207} \mathrm{~Pb} / 206 \mathrm{~Pb}$ media ponderada de la muestra SB07-2. Los barras de error en color negro corresponden a los análisis empleados en el cálculo de la edad media ponderada; las barras de color gris son los análisis descartados. C) Concordia de la muestra SB07-4 con todos los datos de zircones; también se muestran las intersecciones de edad asociadas a la línea de discordia formada por la población de zircones de esta muestra. D) Diagrama de edad ${ }^{207} \mathrm{~Pb} /{ }^{206} \mathrm{~Pb}$ media ponderada de la muestra SB07-4. E) Concordia de la muestra SB07-6 con todos los datos de zircones; también se muestran las intersecciones de edad asociadas a la línea de discordia formada por la población de zircones de esta muestra. F) Diagrama de edad ${ }^{207} \mathrm{~Pb} /{ }^{206} \mathrm{~Pb}$ media ponderada de la muestra SB07-6. 


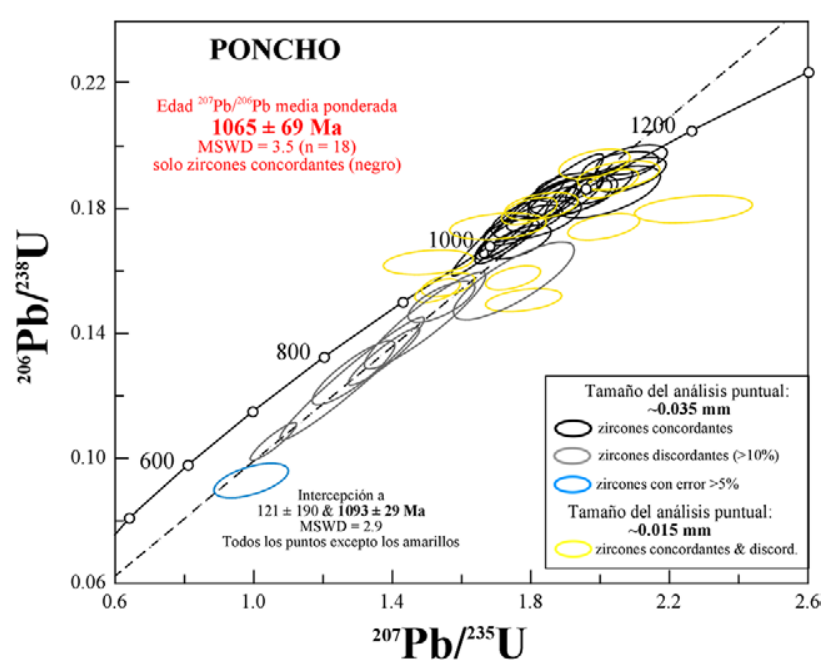

Figura 6. Información U-Pb obtenida por LA-MC-ICPMS en zircones de la muestra de anortosita (PONCHO). Las elipses de error color negro representan los datos empleados para el cálculo de la edad ${ }^{207} \mathrm{~Pb} /{ }^{206} \mathrm{~Pb}$ media ponderada. Los análisis asociados a las elipses de color gris fueron descartados del cálculo de edad por su alto porcentaje de discordancia $(>10 \%)$; el análisis con elipse de color azul se descarto por su alto porcentaje de error en su edad $(>5 \%)$. Las elipses de color amarillo son los análisis realizados por ablación láser a mayor resolución espacial (punto de análisis $\sim 0.015 \mathrm{~mm}$ ) de dos granos de zircón de esta anortosita empleados para evaluar los efectos de pérdida de $\mathrm{Pb}$; estos análisis no fueron utilizados para la obtención de la edad media ponderada ni tampoco para calcular las edades de las intersecciones de la línea de discordia formada por la población de zircones de esta muestra.

Los datos de una segunda muestra de este granito (SB074), recolectada a $200 \mathrm{~m}$ del contacto (Figura 2), se graficaron en un diagrama de concordia tipo Wetherill (Figura 5C). Un total de 30 análisis, representados por elipses de color negro, se tomaron en cuenta para calcular la edad ${ }^{207} \mathrm{~Pb} /{ }^{206} \mathrm{~Pb}$ media ponderada de $1108 \pm 18 \mathrm{Ma}$ (2 sigma; $\mathrm{MSWD}=2.3$; Figura 5D). Las 6 elipses restantes en color gris indican los datos descartados para el cálculo de la edad por su alto porcentaje de error en la edad ( $>5 \%)$ o por su alta discordancia $(>13 \%)$. En este gráfico se ilustra que existe algo de pérdida de $\mathrm{Pb}$ en alguno de los zircones que se fecharon, ya que se aprecia una línea de discordia formada por la población de zircones con una intersección inferior a una edad de $312 \pm$ $270 \mathrm{Ma}$ (supuesta edad del evento de pérdida de $\mathrm{Pb}$ ) y con una intercepción superior de $1126 \pm 24 \mathrm{Ma}$ (edad asociada a cristalización de los zircones magmáticos).

De otra muestra del granito Murrieta (SB07-6), recolectada a $50 \mathrm{~m}$ del contacto con el intrusivo laramídico (Figura 2), se graficaron en el diagrama de concordia tipo Wetherill (Figura 5E) los mejores 17 análisis, de un total de 26, permitiendo obtener una edad ${ }^{207} \mathrm{~Pb} /{ }^{206} \mathrm{~Pb}$ media ponderada de $1098 \pm 19 \mathrm{Ma}$ (2 sigma; $\mathrm{MSWD}=1.5$; Figura 5F). Los resultados isotópicos de algunos zircones de esta muestra son discordantes e indican una notable pérdida de $\mathrm{Pb}$. La intersección inferior generada por todos los zircones de esta muestra tiene una edad de $84 \pm 130$ Ma mientras que la intersección superior tiene una edad de $1113 \pm 23 \mathrm{Ma}$, indicando una edad comparable a la edad de cristalización de la roca. Esta intersección inferior permite suponer que hubo un reajuste isotópico de algunos zircones de esta muestra a esa edad mostrando, convincentemente, la pérdida de $\mathrm{Pb}$ experimentada por los mismos.

La Figura 6 muestra un diagrama de concordia tipo Wetherill para zircones de la anortosita (PONCHO). Las elipses de color negro muestran los datos que se tomaron en cuenta para calcular la edad ${ }^{207} \mathrm{~Pb} /{ }^{206} \mathrm{~Pb}$ media ponderada de $1065 \pm 69 \mathrm{Ma}(2$ sigma, MSWD = 3.5) que interpretamos como la edad de cristalización de la anortosita. Las elipses punteadas de color gris representan los zircones que se eliminaron por su alto porcentaje de discordancia (>10\%) y/o por su alto error en la edad. El análisis correspondiente a la elipse azul se eliminó por su alto porcentaje de error $(>5 \%)$ en la edad ${ }^{207} \mathrm{~Pb} /{ }^{206} \mathrm{~Pb}$. Las elipses de color amarillo muestran análisis de dos zircones (Pon-1 y Pon-2) a los cuales se les hicieron varios transectos de edad con perforaciones de $\sim 15 \mu \mathrm{m}$ para evaluar los efectos de pérdida de $\mathrm{Pb}$ (Figura 10). El transecto a lo largo del zircón Pon1 muestra el rejuvenecimiento, por pérdida de $\mathrm{Pb}$, de las edades del zircón al llegar a los dominios de color gris más oscuro en las imágenes de cátodoluminiscencia que representan dominios de zircón que han experimentado diferentes grados de pérdida de $\mathrm{Pb}$. Para el transecto del zircón Pon-2 se observa una complejidad adicional porque al acercarse al dominio del zircón de color gris más oscuro, se penetra en un dominio de zircón más viejo (ganancia de $\mathrm{Pb}$ ?), mostrando la complejidad del mismo e implicando la disrupción de la sistemática U-Pb.

\subsubsection{Muestras del granito laramídico Sierrita Blanca}

En los gráficos de concordia tipo Tera-Wasserburg (Figuras 7A y 7B) se presentan los análisis de U-Pb de zircones de la muestra SB07-3 recolectada a $\sim 300 \mathrm{~m}$ del contacto con el basamento mesoproterozoico (Figura 2). De las edades aparentes ${ }^{206} \mathrm{~Pb} /{ }^{238} \mathrm{U}, 20$ de 34 zircones arrojan una media ponderada de $69.70 \pm 0.98 \mathrm{Ma} \mathrm{(2}$ sigma; $\mathrm{MSWD}=2.0$; Figura $7 \mathrm{C}$ ) que se interpreta como la edad de cristalización de esta muestra del granito Sierrita Blanca. Los otros análisis de zircones, representados por elipses punteadas de color gris, se discriminaron por su porcentaje en el error en la edad o por su discordancia, o incluso por representar análisis de zircones con algún grado de herencia precámbrica. Se tienen herencias en algunos núcleos de zircones como se aprecia en las imágenes de cátodoluminiscencia (Figura 11). Estos zircones presentan un comportamiento relativamente concordante (Figura 7A y Tabla 3) y tienen edades ${ }^{207} \mathrm{~Pb} /{ }^{206} \mathrm{~Pb}$ del Paleoproterozoico de $\sim 2.3 \mathrm{Ga}$ y $\sim 1.64 \mathrm{Ga}$ y del Mesoproterozoico de $\sim 1.4 \mathrm{Ga}$ $\mathrm{y} \sim 1.1 \mathrm{Ga}$.

Los análisis de $\mathrm{U}-\mathrm{Pb}$ de zircones de una segunda muestra del granito laramídico SB07-5 (Figuras 7D y E), recolectada a $\sim 100 \mathrm{~m}$ del contacto con el encajonante mesoproterozoico (Figura 2), graficados en un diagrama tipo Tera-Wasserburg, resultaron en su mayoría muy discordantes (Figuras 7D y E; 

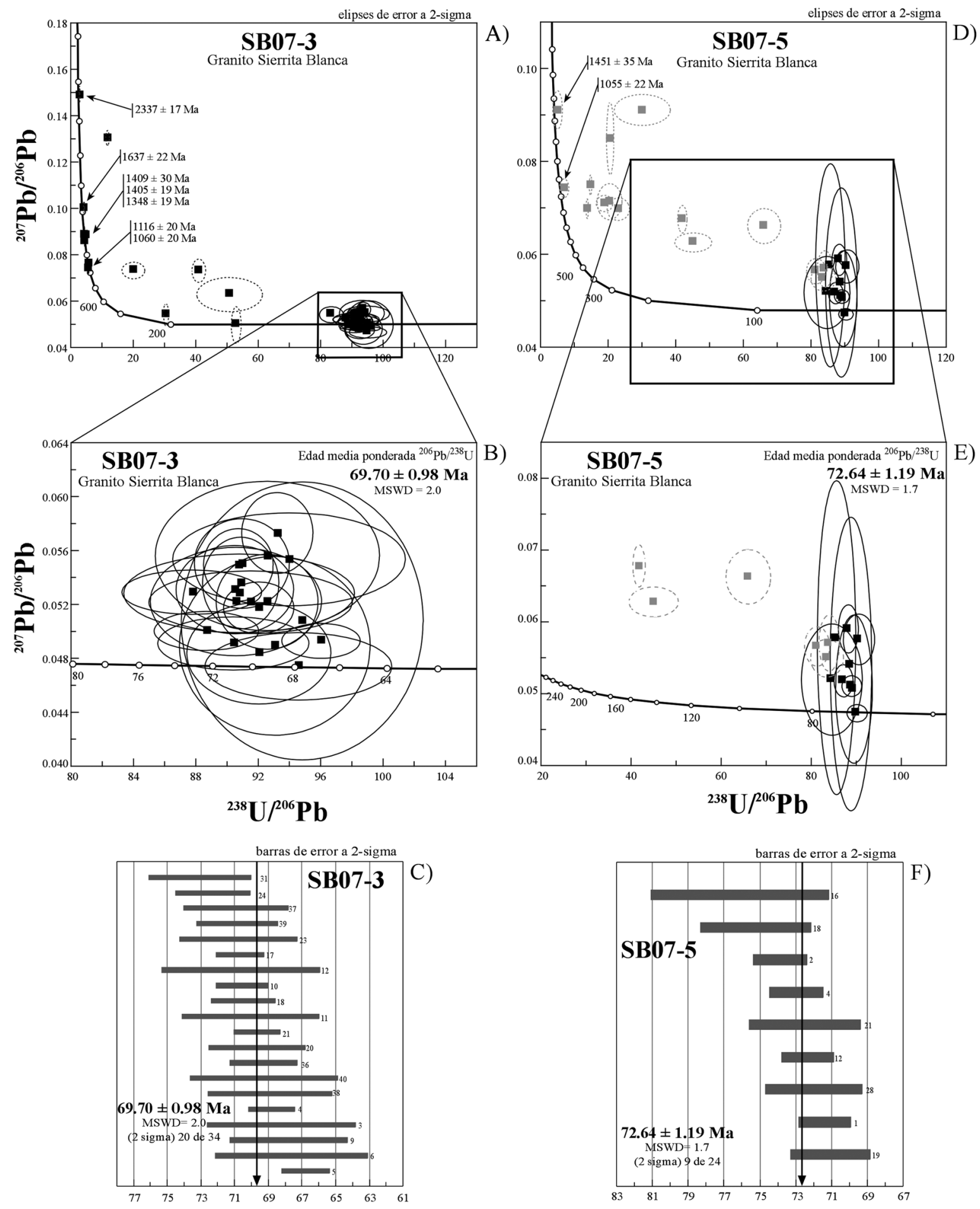

Edad ${ }^{206} \mathbf{P b} /{ }^{238} \mathbf{U}(\mathbf{M a})$

Edad ${ }^{200} \mathbf{P b} /{ }^{238} \mathbf{U}(\mathbf{M a})$

Figura 7. Información U-Pb obtenida por LA-MC-ICPMS en zircones de las rocas laramídicas del área de Sierrita Blanca. A) Concordia de la muestra SB07-3 donde se plotean todos los datos de los zircones analizados. B) Acercamiento al diagrama de concordia de la muestra SB07-3. C) Diagrama de edad ${ }^{206} \mathrm{~Pb} / 238 \mathrm{U}$ media ponderada de la muestra SB07-3. D) Concordia tipo Tera-Wasserburg de la muestra SB07-5 donde se plotearon todos los datos de los zircones analizados. E) Acercamiento al diagrama de concordia de la muestra SB07-3. Los datos correspondientes a las elipses de color negro fueron los utilizados para el cálculo de la edad; las elipses punteadas de color gris son los datos descartados por su alto porcentaje de error y/o discordancia. F) Diagrama de edad ${ }^{206} \mathrm{~Pb} /{ }^{238} \mathrm{U}$ media ponderada de la muestra SB07-5. 
Tabla 2. Datos analíticos de U-Th-Pb (LA-MC-ICPMS) de zircones de rocas graníticas mesoproterozoicas del granito Murrieta, NW de Sonora, México.

\begin{tabular}{|c|c|c|c|c|c|c|c|c|c|c|c|c|c|c|c|c|}
\hline \multicolumn{2}{|c|}{$\begin{array}{c}\text { Nombre del punto } \\
\text { de análisis }\end{array}$} & \multirow{2}{*}{$\begin{array}{c}\begin{array}{c}\text { Comentarios } \\
\text { Núcleo/Periferia }\end{array} \\
\underline{\text { Granito Murrieta }}\end{array}$} & \multirow{2}{*}{$\begin{array}{r}{ }^{206} \mathrm{~Pb} / \\
{ }^{204} \mathrm{~Pb} \\
\text { (Sierrit }\end{array}$} & \multirow{2}{*}{$\begin{array}{c}\mathbf{U} \\
\text { (ppm) }\end{array}$} & \multirow{2}{*}{$\begin{array}{c}\text { Th } \\
(\mathrm{ppm})\end{array}$} & \multirow{2}{*}{$\mathrm{Th} / \mathrm{U}$} & \multirow{2}{*}{$\begin{array}{c}{ }^{207} \mathrm{~Pb} / \\
{ }^{206} \mathrm{~Pb}{ }^{*} \\
\text { Montada en }\end{array}$} & \multirow{2}{*}{$\begin{array}{c}\begin{array}{c}\text { error } \\
(\mathbf{\%})\end{array} \\
\text { en Probeta }\end{array}$} & \multirow{2}{*}{\multicolumn{2}{|c|}{$\begin{array}{cc}{ }^{207} \mathbf{P b} / & \text { error } \\
{ }^{235} \mathbf{U}^{* *} & \mathbf{( \% )}\end{array}$}} & \multirow{2}{*}{$\begin{array}{l}{ }^{206} \mathrm{~Pb} / \\
{ }^{238} \mathbf{U}^{*}\end{array}$} & \multirow[t]{2}{*}{$\begin{array}{l}\text { error } \\
(\%)\end{array}$} & \multirow[t]{2}{*}{$\begin{array}{l}\text { error } \\
\text { correl. }\end{array}$} & \multirow[t]{2}{*}{$\begin{array}{c}\% \\
\text { discor. }\end{array}$} & \multirow[t]{2}{*}{$\begin{array}{c}{ }^{207} \mathrm{~Pb} /{ }^{206} \mathrm{~Pb} \\
\text { Edad (Ma) }\end{array}$} & \multirow[t]{2}{*}{$\begin{array}{l}\text { error } \\
\text { (Ma) }\end{array}$} \\
\hline Muestra & $\underline{S B 07-4}$ & & & & & & & & & & & & & & & \\
\hline SB4-7 & & Periferia & 8476 & 281 & 30 & 0.11 & 0.07345 & \pm 1.6 & 1.76 & \pm 2.19 & 0.1734 & \pm 1.4 & 0.66 & 0 & 1026 & \pm 33 \\
\hline SB4-9 & & Periferia; error $>5 \%$ & 14187 & 244 & 25 & 0.10 & 0.07401 & \pm 2.8 & 1.70 & \pm 8.25 & 0.1666 & \pm 7.8 & 0.94 & 5 & 1042 & \pm 57 \\
\hline SB4-11 & & Periferia & 45366 & 1414 & 116 & 0.08 & 0.07429 & \pm 1.0 & 1.80 & \pm 1.64 & 0.1754 & \pm 1.3 & 0.79 & 1 & 1049 & \pm 20 \\
\hline SB4-1 & & discord. $>15 \%$ & 27415 & 964 & 71 & 0.07 & 0.07435 & \pm 1.0 & 1.45 & \pm 3.70 & 0.1418 & \pm 3.6 & 0.96 & 23 & 1051 & \pm 20 \\
\hline SB4-21 & & Periferia & 46723 & 1249 & 128 & 0.10 & 0.07437 & \pm 1.0 & 1.90 & \pm 1.43 & 0.1853 & \pm 1.0 & 0.71 & -4 & 1051 & \pm 20 \\
\hline SB4-32 & & Núcleo & 71160 & 3572 & 883 & 0.25 & 0.07443 & \pm 2.4 & 1.62 & \pm 2.63 & 0.1579 & \pm 1.0 & 0.38 & 11 & 1053 & \pm 49 \\
\hline SB4-36 & & Periferia & 10587 & 238 & 36 & 0.15 & 0.07515 & \pm 1.5 & 1.89 & \pm 1.81 & 0.1823 & \pm 1.0 & 0.55 & -1 & 1072 & $\pm \mathbf{3 0}$ \\
\hline SB4-31 & & Núcleo & 12541 & 352 & 59 & 0.17 & 0.07532 & \pm 1.3 & 1.96 & \pm 1.63 & 0.1883 & \pm 1.0 & 0.62 & -3 & 1077 & \pm 26 \\
\hline SB4-33 & & Periferia; error $>5 \%$ & 8874 & 745 & 134 & 0.18 & 0.07535 & \pm 3.2 & 1.95 & \pm 3.37 & 0.1873 & \pm 1.0 & 0.30 & -3 & 1078 & \pm 65 \\
\hline SB4-17 & & Periferia & 19630 & 483 & 54 & 0.11 & 0.07564 & \pm 1.0 & 1.91 & \pm 1.65 & 0.1830 & \pm 1.3 & 0.78 & 0 & 1086 & \pm 21 \\
\hline SB4-29 & & Periferia & 12684 & 544 & 75 & 0.14 & 0.07580 & \pm 1.0 & 1.86 & \pm 1.97 & 0.1777 & \pm 1.7 & 0.86 & 3 & 1090 & \pm 20 \\
\hline SB4-19 & & Periferia & 25632 & 351 & 38 & 0.11 & 0.07585 & \pm 1.3 & 1.93 & \pm 1.63 & 0.1845 & \pm 1.0 & 0.64 & 0 & 1091 & \pm 25 \\
\hline SB4-4 & & - & 20453 & 477 & 52 & 0.11 & 0.07595 & \pm 1.0 & 1.92 & \pm 1.42 & 0.1830 & \pm 1.0 & 0.71 & 1 & 1094 & \pm 20 \\
\hline SB4-22 & & Núcleo & 21084 & 467 & 55 & 0.12 & 0.07599 & \pm 1.3 & 2.04 & \pm 1.66 & 0.1944 & \pm 1.0 & 0.60 & -4 & 1095 & \pm 27 \\
\hline SB4-28 & & Periferia & 21438 & 855 & 140 & 0.16 & 0.07622 & \pm 2.6 & 1.68 & \pm 2.77 & 0.1603 & \pm 1.0 & 0.37 & 15 & 1101 & \pm 51 \\
\hline SB4-35 & & Periferia & 16443 & 274 & 41 & 0.15 & 0.07629 & \pm 1.4 & 1.92 & \pm 1.74 & 0.1828 & \pm 1.0 & 0.57 & 2 & 1103 & \pm 29 \\
\hline SB4-20 & & Núcleo & 30167 & 456 & 57 & 0.12 & 0.07633 & \pm 1.0 & 1.98 & \pm 1.81 & 0.1879 & \pm 1.5 & 0.83 & -1 & 1104 & \pm 20 \\
\hline SB4-25 & & Núcleo & 17280 & 403 & 50 & 0.12 & 0.07638 & \pm 1.0 & 1.98 & \pm 1.82 & 0.1876 & \pm 1.5 & 0.83 & 0 & 1105 & \pm 20 \\
\hline SB4-26 & & Periferia & 39580 & 645 & 73 & 0.11 & 0.07665 & \pm 1.4 & 2.02 & \pm 2.33 & 0.1915 & \pm 1.8 & 0.79 & -2 & 1112 & \pm 28 \\
\hline SB4-24 & & Periferia; error $>5 \%$ & 14413 & 343 & 47 & 0.14 & 0.07685 & \pm 3.2 & 1.87 & \pm 5.21 & 0.1769 & \pm 4.1 & 0.79 & 6 & 1117 & \pm 64 \\
\hline SB4-14 & & Periferia & 14788 & 351 & 47 & 0.13 & 0.07688 & \pm 1.8 & 1.97 & \pm 2.27 & 0.1855 & \pm 1.3 & 0.59 & 2 & 1118 & \pm 37 \\
\hline SB4-37 & & Periferia & 48104 & 415 & 71 & 0.17 & 0.07708 & \pm 2.1 & 1.92 & \pm 2.41 & 0.1810 & \pm 1.2 & 0.49 & 5 & 1123 & \pm 42 \\
\hline SB4-38 & & Núcleo & 14692 & 347 & 50 & 0.14 & 0.07722 & \pm 1.6 & 1.97 & \pm 1.87 & 0.1849 & \pm 1.0 & 0.53 & 3 & 1127 & \pm 32 \\
\hline SB4-5 & & - & 19442 & 309 & 32 & 0.10 & 0.07737 & \pm 1.3 & 1.92 & \pm 3.08 & 0.1801 & \pm 2.8 & 0.91 & 6 & 1131 & \pm 25 \\
\hline SB4-6 & & Periferia & 23597 & 385 & 42 & 0.11 & 0.07771 & \pm 1.5 & 1.99 & \pm 2.13 & 0.1854 & \pm 1.5 & 0.71 & 4 & 1139 & $\pm \mathbf{3 0}$ \\
\hline SB4-30 & & Periferia & 11388 & 389 & 50 & 0.13 & 0.07771 & \pm 1.5 & 2.04 & \pm 1.83 & 0.1906 & \pm 1.0 & 0.55 & 1 & 1140 & $\pm \mathbf{3 0}$ \\
\hline SB4-23 & & Núcleo & 25912 & 289 & 34 & 0.12 & 0.07775 & \pm 1.2 & 2.00 & \pm 1.54 & 0.1868 & \pm 1.0 & 0.65 & 3 & 1140 & \pm 23 \\
\hline SB4-15 & & Núcleo & 12300 & 303 & 28 & 0.09 & 0.07785 & \pm 1.7 & 1.99 & \pm 1.94 & 0.1851 & \pm 1.0 & 0.52 & 4 & 1143 & \pm 33 \\
\hline SB4-8 & & Núcleo; discord. >15\% & 17374 & 676 & 79 & 0.12 & 0.07795 & \pm 1.7 & 1.72 & \pm 2.30 & 0.1598 & \pm 1.6 & 0.68 & 20 & 1145 & \pm 34 \\
\hline SB4-13 & & Periferia & 18928 & 343 & 36 & 0.11 & 0.07803 & \pm 1.3 & 2.05 & \pm 1.64 & 0.1904 & \pm 1.0 & 0.61 & 2 & 1148 & \pm 26 \\
\hline SB4-27 & & Periferia & 12587 & 296 & 46 & 0.15 & 0.07820 & \pm 1.6 & 2.01 & \pm 1.85 & 0.1861 & \pm 1.0 & 0.54 & 5 & 1152 & $\pm \mathbf{3 1}$ \\
\hline SB4-40 & & Periferia & 11307 & 284 & 42 & 0.15 & 0.07873 & \pm 2.9 & 1.93 & \pm 3.04 & 0.1779 & \pm 1.0 & 0.33 & 10 & 1165 & $\pm \mathbf{5 7}$ \\
\hline SB4-16 & & Periferia & 13084 & 299 & 30 & 0.10 & 0.07933 & \pm 1.3 & 2.01 & \pm 1.70 & 0.1840 & \pm 1.1 & 0.67 & 8 & 1180 & \pm 25 \\
\hline SB4-34 & & Periferia; discord. $>15 \%$ & 6325 & 408 & 57 & 0.14 & 0.07949 & \pm 2.3 & 1.70 & \pm 3.00 & 0.1548 & \pm 1.9 & 0.62 & 28 & 1184 & \pm 46 \\
\hline SB4-18 & & Periferia & 13843 & 269 & 31 & 0.12 & 0.07964 & \pm 1.6 & 2.05 & \pm 1.85 & 0.1870 & \pm 1.0 & 0.54 & 8 & 1188 & $\pm \mathbf{3 1}$ \\
\hline SB4-39 & & Periferia & 41395 & 536 & 93 & 0.17 & 0.07971 & \pm 1.4 & 2.05 & \pm 1.72 & 0.1866 & \pm 1.0 & 0.58 & 8 & 1190 & \pm 28 \\
\hline
\end{tabular}

Coordenadas Geográficas: Lat. 31.3246669—Long. 112.8318715: (Datum WGS-84)

$\operatorname{MSWD}=2.3 ;(\mathrm{n}=30$ de 36$)$

\begin{tabular}{|c|c|c|c|c|c|c|c|c|c|c|c|c|}
\hline Muestra & $\underline{\text { Granito Murrieta }}$ & (Sier & ta Blan & Sonor & & Montada en probet & $M-2(J l$ & unio 200 & & & & \\
\hline SB6-18 & Núcleo; discord. $>15 \%$ & 26667 & 827 & 102 & 0.12 & $0.07338 \pm 2.3$ & 1.36 & \pm 2.54 & $0.1342 \pm 1.2$ & 0.46 & 26 & $1024 \pm 46$ \\
\hline SB6-13 & Periferia & 11777 & 211 & 25 & 0.12 & $0.07426 \pm 1.6$ & 1.82 & \pm 2.68 & $0.1777 \pm 2.1$ & 0.80 & -1 & $1049 \pm 33$ \\
\hline SB6-1 & Periferia & 30068 & 565 & 88 & 0.16 & $0.07441 \pm 1.1$ & 1.66 & \pm 1.84 & $0.1622 \pm 1.5$ & 0.80 & 9 & $1053 \pm 22$ \\
\hline SB6-31 & Periferia & 98127 & 884 & 137 & 0.16 & $0.07468 \pm 1.0$ & 1.78 & \pm 1.59 & $0.1732 \pm 1.2$ & 0.77 & 3 & $1060 \pm 20$ \\
\hline SB6-14 & Núcleo; discord. >15\% & 25772 & 665 & 73 & 0.11 & $0.07496 \pm 2.3$ & 1.36 & \pm 3.07 & $0.1316 \pm 2.1$ & 0.67 & 34 & $1067 \pm 45$ \\
\hline SB6-2 & Periferia & 19312 & 459 & 75 & 0.16 & $0.07526 \pm 1.0$ & 1.82 & \pm 1.45 & $0.1756 \pm 1.0$ & 0.70 & 3 & $1075 \pm 21$ \\
\hline SB6-21 & Periferia; discord. $>15 \%$ & 41212 & 1143 & 34 & 0.03 & $0.07536 \pm 2.1$ & 0.46 & \pm 5.82 & $0.0442 \pm 5.4$ & 0.93 & 287 & $1078 \pm 42$ \\
\hline SB6-30 & Periferia & 38363 & 666 & 130 & 0.20 & $0.07552 \pm 1.0$ & 1.78 & \pm 1.63 & $0.1707 \pm 1.3$ & 0.78 & 7 & $1082 \pm 20$ \\
\hline SB6-6 & Periferia; error $>5 \%$ & 27235 & 395 & 67 & 0.17 & $0.07554 \pm 4.3$ & 1.83 & \pm 4.60 & $0.1759 \pm 1.6$ & 0.34 & 4 & $1083 \pm 87$ \\
\hline SB6-11 & Núcleo & 71805 & 728 & 136 & 0.19 & $0.07558 \pm 1.4$ & 1.86 & \pm 1.71 & $0.1784 \pm 1.0$ & 0.58 & 2 & $1084 \pm 28$ \\
\hline SB6-29 & Periferia; discord. $>15 \%$ & 33522 & 918 & 127 & 0.14 & $0.07569 \pm 2.4$ & 1.18 & \pm 3.36 & $0.1133 \pm 2.3$ & 0.69 & 57 & $1087 \pm 49$ \\
\hline SB6-8 & Periferia & 23354 & 538 & 82 & 0.15 & $0.07614 \pm 1.2$ & 1.87 & \pm 1.59 & $0.1785 \pm 1.0$ & 0.65 & 4 & $1099 \pm 24$ \\
\hline SB6-17 & Periferia & 23030 & 549 & 71 & 0.13 & $0.07646 \pm 1.0$ & 1.88 & \pm 1.71 & $0.1785 \pm 1.4$ & 0.81 & 5 & $1107 \pm 20$ \\
\hline SB6-5 & Periferia & 12262 & 447 & 69 & 0.15 & $0.07657 \pm 2.0$ & 1.74 & \pm 2.27 & $0.1648 \pm 1.0$ & 0.44 & 13 & $1110 \pm 41$ \\
\hline SB6-20 & Periferia & 15847 & 384 & 50 & 0.13 & $0.07665 \pm 1.5$ & 1.91 & \pm 2.45 & $0.1806 \pm 1.9$ & 0.79 & 4 & $1112 \pm 30$ \\
\hline SB6-4 & Periferia & 35118 & 533 & 98 & 0.18 & $0.07666 \pm 1.9$ & 1.88 & \pm 3.22 & $0.1776 \pm 2.6$ & 0.82 & 6 & $1112 \pm 37$ \\
\hline SB6-32 & Periferia & 10550 & 417 & 57 & 0.14 & $0.07667 \pm 1.4$ & 1.91 & \pm 2.04 & $0.1806 \pm 1.5$ & 0.72 & 4 & $1113 \pm 28$ \\
\hline SB6-16 & Núcleo & 32497 & 509 & 72 & 0.14 & $0.07684 \pm 1.0$ & 1.91 & \pm 1.43 & $0.1798 \pm 1.0$ & 0.70 & 5 & $1117 \pm 20$ \\
\hline SB6-26 & Periferia & 21428 & 458 & 68 & 0.15 & $0.07687 \pm 1.2$ & 1.85 & \pm 1.54 & $0.1742 \pm 1.0$ & 0.65 & 8 & $1118 \pm 23$ \\
\hline SB6-19 & Núcleo; discord. $>15 \%$ & 15726 & 834 & 95 & 0.11 & $0.07690 \pm 3.8$ & 1.57 & \pm 4.18 & $0.1481 \pm 1.8$ & 0.42 & 26 & $1119 \pm 76$ \\
\hline SB6-7 & Periferia & 16359 & 327 & 49 & 0.15 & $0.07750 \pm 1.4$ & 1.92 & \pm 2.54 & $0.1796 \pm 2.1$ & 0.83 & 6 & $1134 \pm 28$ \\
\hline SB6-23 & Núcleo & 22329 & 303 & 45 & 0.15 & $0.07799 \pm 1.0$ & 1.92 & \pm 1.48 & $0.1787 \pm 1.1$ & 0.72 & 8 & $1147 \pm 21$ \\
\hline SB6-10 & Periferia & 15994 & 317 & 43 & 0.14 & $0.07812 \pm 2.0$ & 1.93 & \pm 2.27 & $0.1796 \pm 1.1$ & 0.49 & 8 & $1150 \pm 39$ \\
\hline SB6-25 & Núcleo; discord. $>15 \%$ & 6303 & 557 & 92 & 0.17 & $0.08021 \pm 5.1$ & 2.00 & \pm 5.25 & $0.1807 \pm 1.2$ & 0.24 & 12 & $1202 \pm 100$ \\
\hline SB6-12 & Periferia; discord. $>15 \%$ & 15700 & 551 & 83 & 0.15 & $0.08068 \pm 4.8$ & 2.04 & \pm 5.10 & $0.1830 \pm 1.7$ & 0.33 & 12 & $1214 \pm 95$ \\
\hline SB6-22 & Periferia; discord. $>15 \%$ & 32349 & 684 & 107 & 0.16 & $0.08146 \pm 2.7$ & 2.02 & \pm 2.99 & $0.1800 \pm 1.4$ & 0.46 & 16 & $1233 \pm 52$ \\
\hline SB6-28 & Núcleo; discord. >15\% & 57590 & 1517 & 315 & 0.21 & $0.09847 \pm 1.0$ & 3.39 & \pm 1.41 & $0.2500 \pm 1.0$ & 0.71 & 11 & $1595 \pm 19$ \\
\hline
\end{tabular}


Tabla 2 (Continuación). Datos analíticos de U-Th-Pb (LA-MC-ICPMS) de zircones de rocas graníticas mesoproterozoicas del granito Murrieta, NW de Sonora, México.

\begin{tabular}{|c|c|c|c|c|c|c|c|c|c|c|c|c|c|c|c|}
\hline $\begin{array}{l}\text { Nombre del punto } \\
\text { de análisis }\end{array}$ & $\begin{array}{c}\text { Comentarios } \\
\text { Núcleo/Periferia }\end{array}$ & $\begin{array}{l}{ }^{206} \mathrm{~Pb} / \\
{ }^{204} \mathrm{~Pb}\end{array}$ & $\begin{array}{c}\mathrm{U} \\
(\mathrm{ppm})\end{array}$ & $\begin{array}{c}\text { Th } \\
\text { (ppm) }\end{array}$ & $\mathbf{T h} / \mathbf{U}$ & $\begin{array}{c}{ }^{207} \mathrm{~Pb} / \\
{ }^{206}{ }_{\mathrm{Pb}}{ }^{*}\end{array}$ & $\begin{array}{l}\text { error } \\
(\%)\end{array}$ & $\begin{array}{l}{ }^{207} \mathrm{~Pb} / \\
{ }^{235}{ }^{*}\end{array}$ & $\begin{array}{l}\text { error } \\
(\%)\end{array}$ & $\begin{array}{l}{ }^{206} \mathrm{~Pb} / \\
{ }^{238} \mathrm{U}^{*}\end{array}$ & $\begin{array}{l}\text { error } \\
(\%)\end{array}$ & $\begin{array}{l}\text { error } \\
\text { correl. }\end{array}$ & $\begin{array}{c}\% \\
\text { discor. }\end{array}$ & $\begin{array}{c}{ }^{207} \mathrm{~Pb} /{ }^{206} \mathrm{~Pb} \\
\text { Edad (Ma) }\end{array}$ & $\begin{array}{l}\text { error } \\
\text { (Ma) }\end{array}$ \\
\hline Muestra SBB07-2 & $\underline{\text { Granito Murrieta }}$ & (Sierrita Bla & nca Sonor & & Montada & en probeta & $D M-2\left(J_{l}\right.$ & unio 2007 & & & & & & & \\
\hline SB2-39 & Núcleo & 29874 & 580 & 73 & 0.13 & 0.07434 & \pm 2.6 & 1.83 & \pm 3.55 & 0.1790 & \pm 2.5 & 0.69 & -1 & 1051 & \pm 52 \\
\hline SB2-14 & Núcleo & 16884 & 543 & 91 & 0.17 & 0.07453 & \pm 1.0 & 1.77 & \pm 2.48 & 0.1724 & \pm 2.3 & 0.91 & 3 & 1056 & \pm 21 \\
\hline SB2-30 & Periferia; error $>5 \%$ & 18589 & 1048 & 147 & 0.14 & 0.07469 & \pm 3.7 & 1.84 & \pm 4.36 & 0.1791 & \pm 2.3 & 0.54 & 0 & 1060 & \pm 74 \\
\hline SB2-31 & Periferia & 46862 & 1508 & 162 & 0.11 & 0.07487 & \pm 1.1 & 1.74 & \pm 2.17 & 0.1684 & \pm 1.9 & 0.88 & 6 & 1065 & \pm 21 \\
\hline SB2-43 & Periferia & 78548 & 985 & 201 & 0.20 & 0.07496 & \pm 1.6 & 1.90 & \pm 1.88 & 0.1834 & \pm 1.0 & 0.53 & -2 & 1067 & \pm 32 \\
\hline SB2-27 & Periferia & 54247 & 1438 & 208 & 0.14 & 0.07507 & \pm 1.3 & 1.87 & \pm 1.63 & 0.1807 & \pm 1.0 & 0.61 & 0 & 1070 & \pm 26 \\
\hline SB2-41 & Periferia & 55006 & 1126 & 174 & 0.15 & 0.07516 & \pm 1.0 & 1.90 & \pm 1.42 & 0.1836 & \pm 1.0 & 0.71 & -1 & 1073 & \pm 20 \\
\hline SB2-29 & Periferia & 36210 & 501 & 70 & 0.14 & 0.07551 & \pm 2.5 & 1.93 & \pm 2.87 & 0.1854 & \pm 1.3 & 0.46 & -1 & 1082 & \pm 51 \\
\hline SB2-2 & Periferia & 12978 & 369 & 33 & 0.09 & 0.07587 & \pm 1.1 & 1.90 & \pm 2.24 & 0.1814 & \pm 2.0 & 0.87 & 2 & 1092 & \pm 22 \\
\hline SB2-17 & Núcleo & 32316 & 432 & 70 & 0.16 & 0.07589 & \pm 1.0 & 1.87 & \pm 1.95 & 0.1791 & \pm 1.7 & 0.85 & 3 & 1092 & \pm 20 \\
\hline SB2-26 & Periferia & 36882 & 804 & 95 & 0.12 & 0.07590 & \pm 1.3 & 1.87 & \pm 2.00 & 0.1786 & \pm 1.5 & 0.77 & 3 & 1092 & \pm 26 \\
\hline SB2-15 & Periferia & 19885 & 477 & 77 & 0.16 & 0.07592 & \pm 1.0 & 1.87 & \pm 1.43 & 0.1783 & \pm 1.0 & 0.71 & 3 & 1093 & \pm 20 \\
\hline SB2-23 & Periferia & 29256 & 845 & 138 & 0.16 & 0.07598 & \pm 1.7 & 1.89 & \pm 1.94 & 0.1804 & \pm 1.0 & 0.51 & 2 & 1095 & $\pm \mathbf{3 3}$ \\
\hline SB2-32 & Núcleo & 29854 & 485 & 60 & 0.12 & 0.07607 & \pm 1.0 & 1.89 & \pm 1.93 & 0.1805 & \pm 1.7 & 0.85 & 3 & 1097 & \pm 20 \\
\hline SB2-44 & Periferia & 27033 & 330 & 53 & 0.16 & 0.07612 & \pm 1.0 & 1.95 & \pm 1.43 & 0.1855 & \pm 1.0 & 0.70 & 0 & 1098 & \pm 20 \\
\hline SB2-21 & Periferia & 38759 & 755 & 94 & 0.12 & 0.07630 & \pm 1.0 & 1.92 & \pm 1.42 & 0.1826 & \pm 1.0 & 0.71 & 2 & 1103 & \pm 20 \\
\hline SB2-34 & Periferia & 40112 & 530 & 60 & 0.11 & 0.07630 & \pm 1.0 & 1.90 & \pm 3.08 & 0.1805 & \pm 2.9 & 0.94 & 3 & 1103 & \pm 20 \\
\hline SB2-10 & Núcleo & 23820 & 311 & 36 & 0.12 & 0.07635 & \pm 1.2 & 1.93 & \pm 4.64 & 0.1831 & \pm 4.5 & 0.97 & 2 & 1104 & \pm 24 \\
\hline SB2-24 & Periferia & 27027 & 492 & 60 & 0.12 & 0.07637 & \pm 1.1 & 1.91 & \pm 1.86 & 0.1809 & \pm 1.5 & 0.81 & 3 & 1105 & \pm 22 \\
\hline SB2-42 & Núcleo & 33452 & 428 & 68 & 0.16 & 0.07642 & \pm 1.0 & 1.96 & \pm 1.43 & 0.1864 & \pm 1.0 & 0.70 & 0 & 1106 & \pm 20 \\
\hline SB2-19 & Periferia & 25765 & 606 & 79 & 0.13 & 0.07663 & \pm 1.0 & 1.94 & \pm 2.41 & 0.1837 & \pm 2.2 & 0.91 & 2 & 1112 & \pm 20 \\
\hline SB2-13 & Periferia & 16917 & 418 & 50 & 0.12 & 0.07667 & \pm 1.4 & 1.85 & \pm 3.37 & 0.1753 & \pm 3.1 & 0.92 & 7 & 1113 & \pm 27 \\
\hline SB2-22 & Periferia & 11762 & 694 & 107 & 0.15 & 0.07668 & \pm 1.1 & 1.89 & \pm 1.51 & 0.1789 & \pm 1.0 & 0.66 & 5 & 1113 & \pm 23 \\
\hline SB2-20 & Periferia & 10138 & 449 & 88 & 0.20 & 0.07671 & \pm 2.0 & 1.88 & \pm 2.31 & 0.1775 & \pm 1.1 & 0.46 & 6 & 1114 & \pm 41 \\
\hline SB2-16 & Periferia & 25150 & 338 & 36 & 0.11 & 0.07692 & \pm 1.0 & 1.90 & \pm 2.35 & 0.1793 & \pm 2.1 & 0.90 & 5 & 1119 & \pm 20 \\
\hline SB2-33 & Núcleo & 32880 & 360 & 40 & 0.11 & 0.07695 & \pm 1.3 & 1.95 & \pm 1.79 & 0.1840 & \pm 1.2 & 0.69 & 3 & 1120 & \pm 26 \\
\hline SB2-35 & Núcleo; error $>5 \%$ & 35483 & 727 & 93 & 0.13 & 0.07699 & \pm 4.0 & 1.91 & \pm 4.16 & 0.1797 & \pm 1.2 & 0.29 & 5 & 1121 & \pm 79 \\
\hline SB2-36 & Periferia & 50809 & 521 & 57 & 0.11 & 0.07711 & \pm 1.0 & 1.93 & \pm 1.42 & 0.1819 & \pm 1.0 & 0.70 & 4 & 1124 & \pm 20 \\
\hline SB2-18 & Periferia & 34238 & 804 & 135 & 0.17 & 0.07739 & \pm 2.1 & 1.95 & \pm 2.31 & 0.1831 & \pm 1.0 & 0.43 & 4 & 1131 & \pm 41 \\
\hline SB2-11 & Periferia & 10505 & 330 & 40 & 0.12 & 0.07761 & \pm 1.1 & 1.93 & \pm 2.44 & 0.1805 & \pm 2.2 & 0.90 & 6 & 1137 & \pm 21 \\
\hline SB2-1 & Núcleo & 27321 & 456 & 50 & 0.11 & 0.07766 & \pm 2.3 & 1.91 & \pm 3.22 & 0.1785 & \pm 2.3 & 0.70 & 8 & 1138 & \pm 45 \\
\hline SB2-8 & Núcleo & 50465 & 530 & 41 & 0.08 & 0.07784 & \pm 1.6 & 1.96 & \pm 1.86 & 0.1827 & \pm 1.0 & 0.54 & 6 & 1143 & \pm 31 \\
\hline SB2-40 & Periferia & 21389 & 408 & 39 & 0.10 & 0.07799 & \pm 1.4 & 1.95 & \pm 1.85 & 0.1810 & \pm 1.2 & 0.66 & 7 & 1147 & \pm 28 \\
\hline SB2-9 & Núcleo & 48620 & 606 & 72 & 0.12 & 0.07815 & \pm 2.3 & 1.95 & \pm 2.71 & 0.1813 & \pm 1.4 & 0.51 & 7 & 1151 & \pm 46 \\
\hline SB2-3 & Núcleo & 24993 & 338 & 31 & 0.09 & 0.07849 & \pm 1.8 & 1.91 & \pm 2.63 & 0.1763 & \pm 1.9 & 0.74 & 11 & 1159 & \pm 35 \\
\hline SB2-4 & Núcleo & 34566 & 439 & 42 & 0.10 & 0.07850 & \pm 1.9 & 2.00 & \pm 2.14 & 0.1846 & \pm 1.0 & 0.48 & 6 & 1160 & \pm 37 \\
\hline SB2-6 & Núcleo & 20367 & 479 & 67 & 0.14 & 0.07897 & \pm 2.6 & 2.01 & \pm 2.82 & 0.1846 & \pm 1.0 & 0.36 & 7 & 1171 & \pm 52 \\
\hline SB2-37 & Periferia & 48593 & 715 & 82 & 0.11 & 0.07987 & \pm 1.2 & 2.11 & \pm 1.55 & 0.1920 & \pm 1.0 & 0.64 & 5 & 1194 & \pm 23 \\
\hline
\end{tabular}

Muestra Poncho $\quad \underline{\text { Anortosita }} \quad$ (Sierrita Blanca Sonora) Montada en probeta DM-1 (Junio 2007)

\begin{tabular}{|c|c|c|c|c|c|c|c|c|c|c|c|}
\hline & & & & & & & & & & & \\
\hline PON-39 & Núcleo & 38965 & 658 & 1530 & 2.33 & $0.07237 \pm 1.0$ & $1.74 \pm 3.90$ & $0.1741 \pm 3.8$ & 0.97 & -4 & $996 \pm 20$ \\
\hline PON-32 & Periferia & 18777 & 1057 & 448 & 0.42 & $0.07274 \pm 1.3$ & $1.73 \pm 21.67$ & $0.1730 \pm 31.0$ & 0.60 & -2 & $1007 \pm 27$ \\
\hline PON-23 & Periferia; discord. $>10 \%$ & 21060 & 942 & 733 & 0.78 & $0.07303 \pm 1.1$ & $1.06 \pm 2.59$ & $0.1048 \pm 2.4$ & 0.91 & 58 & $1015 \pm 21$ \\
\hline PON-20 & Periferia & 19512 & 539 & 1466 & 2.72 & $0.07344 \pm 1.1$ & $1.72 \pm 1.93$ & $0.1700 \pm 1.6$ & 0.83 & 1 & $1026 \pm 22$ \\
\hline PON-41 & Periferia & 13298 & 388 & 583 & 1.50 & $0.07352 \pm 1.6$ & $1.74 \pm 1.86$ & $0.1721 \pm 1.0$ & 0.54 & 0 & $1028 \pm 32$ \\
\hline PON-37 & discord. $>10 \%$ & 19954 & 496 & 1220 & 2.46 & $0.07358 \pm 1.9$ & $1.29 \pm 3.79$ & $0.1268 \pm 3.3$ & 0.87 & 34 & $1030 \pm 38$ \\
\hline PON-34 & Periferia & 17980 & 291 & 1043 & 3.59 & $0.07361 \pm 1.4$ & $1.83 \pm 3.98$ & $0.1804 \pm 3.7$ & 0.94 & -4 & $1031 \pm 28$ \\
\hline PON-14 & Periferia & 9862 & 343 & 881 & 2.57 & $0.07392 \pm 1.4$ & $1.79 \pm 3.38$ & $0.1752 \pm 3.1$ & 0.91 & 0 & $1039 \pm 28$ \\
\hline PON-18 & Periferia & 22960 & 451 & 482 & 1.07 & $0.07428 \pm 1.8$ & $1.91 \pm 2.08$ & $0.1863 \pm 1.0$ & 0.48 & -5 & $1049 \pm 37$ \\
\hline PON-35 & Periferia; discord. $>10 \%$ & 11542 & 355 & 757 & 2.13 & $0.07441 \pm 1.6$ & $1.28 \pm 6.64$ & $0.1250 \pm 6.4$ & 0.97 & 39 & $1052 \pm 32$ \\
\hline PON-15 & Periferia & 17543 & 358 & 723 & 2.02 & $0.07441 \pm 1.5$ & $1.81 \pm 1.82$ & $0.1765 \pm 1.0$ & 0.55 & 0 & $1053 \pm 31$ \\
\hline PON-25 & Periferia & 19261 & 327 & 210 & 0.64 & $0.07454 \pm 1.2$ & $1.86 \pm 1.61$ & $0.1814 \pm 1.1$ & 0.69 & -2 & $1056 \pm 24$ \\
\hline PON-38 & Periferia & 16989 & 307 & 188 & 0.61 & $0.07459 \pm 2.5$ & $1.82 \pm 2.92$ & $0.1765 \pm 1.6$ & 0.54 & 1 & $1058 \pm 49$ \\
\hline PON-33 & Periferia; discord. $>10 \%$ & 7599 & 246 & 461 & 1.87 & $0.07467 \pm 1.8$ & $1.54 \pm 2.56$ & $0.1496 \pm 1.8$ & 0.70 & 18 & $1060 \pm 37$ \\
\hline PON-40 & Periferia; discord. $>10 \%$ & 6861 & 483 & 1175 & 2.43 & $0.07541 \pm 1.9$ & $1.49 \pm 4.80$ & $0.1436 \pm 4.4$ & 0.92 & 25 & $1079 \pm 37$ \\
\hline PON-30 & Periferia; discord. $>10 \%$ & 6260 & 229 & 462 & 2.01 & $0.07548 \pm 1.1$ & $1.37 \pm 3.06$ & $0.1321 \pm 2.8$ & 0.93 & 35 & $1081 \pm 23$ \\
\hline PON-36 & Núcleo & 37684 & 532 & 936 & 1.76 & $0.07569 \pm 2.1$ & $1.91 \pm 2.57$ & $0.1833 \pm 1.4$ & 0.56 & 0 & $1087 \pm 43$ \\
\hline PON-26 & Periferia & 13428 & 187 & 383 & 2.05 & $0.07581 \pm 2.3$ & $1.92 \pm 2.71$ & $0.1840 \pm 1.4$ & 0.53 & 0 & $1090 \pm 46$ \\
\hline PON-22 & Periferia & 5658 & 450 & 802 & 1.78 & $0.07590 \pm 1.6$ & $1.77 \pm 2.11$ & $0.1689 \pm 1.3$ & 0.63 & 9 & $1092 \pm 33$ \\
\hline PON-19 & Núcleo & 30295 & 552 & 2103 & 3.81 & $0.07614 \pm 1.0$ & $1.93 \pm 1.78$ & $0.1834 \pm 1.5$ & 0.82 & 1 & $1099 \pm 20$ \\
\hline PON-16 & Periferia & 11952 & 198 & 86 & 0.43 & $0.07733 \pm 1.9$ & $2.06 \pm 2.17$ & $0.1931 \pm 1.0$ & 0.46 & -1 & $1130 \pm 38$ \\
\hline PON-24 & Núcleo & 30748 & 237 & 137 & 0.58 & $0.07753 \pm 1.5$ & $2.00 \pm 1.98$ & $0.1868 \pm 1.3$ & 0.65 & 3 & $1135 \pm 30$ \\
\hline PON-17 & Periferia & 14479 & 207 & 192 & 0.93 & $0.07774 \pm 1.7$ & $2.09 \pm 2.00$ & $0.1951 \pm 1.0$ & 0.50 & -1 & $1140 \pm 34$ \\
\hline PON-27 & Núcleo; discord. $>10 \%$ & 17296 & 2024 & 288 & 0.14 & $0.07787 \pm 3.7$ & $0.99 \pm 4.42$ & $0.0923 \pm 2.5$ & 0.55 & 101 & $1144 \pm 73$ \\
\hline PON-28 & Periferia & 12307 & 151 & 57 & 0.38 & $0.07936 \pm 2.4$ & $2.02 \pm 3.04$ & $0.1849 \pm 1.8$ & 0.60 & 8 & $1181 \pm 48$ \\
\hline PON-29 & Núcleo & 7874 & 131 & 59 & 0.45 & $0.07964 \pm 1.6$ & $2.09 \pm 1.95$ & $0.1904 \pm 1.2$ & 0.60 & 6 & $1188 \pm 31$ \\
\hline PON-31 & Núcleo; discord. $>10 \%$ & 5269 & 119 & 98 & 0.82 & $0.08116 \pm 2.4$ & $1.75 \pm 4.07$ & $0.1564 \pm 3.3$ & 0.80 & 31 & $1225 \pm 48$ \\
\hline
\end{tabular}


Tabla 2 (Continuación). Datos analíticos de U-Th-Pb (LA-MC-ICPMS) de zircones de rocas graníticas mesoproterozoicas del granito Murrieta, NW de Sonora, México.

\begin{tabular}{|c|c|c|c|c|c|c|c|c|c|c|c|c|c|c|c|}
\hline $\begin{array}{c}\text { Nombre del punto } \\
\text { de análisis }\end{array}$ & $\begin{array}{l}\text { Comentarios } \\
\text { Núcleo/Periferia }\end{array}$ & $\begin{array}{l}{ }^{206} \mathrm{~Pb} / \\
{ }^{204} \mathrm{~Pb}\end{array}$ & $\begin{array}{c}\mathrm{U} \\
(\mathrm{ppm})\end{array}$ & $\begin{array}{c}\text { Th } \\
\text { (ppm) }\end{array}$ & $\mathrm{Th} / \mathrm{U}$ & $\begin{array}{c}{ }^{207} \mathrm{~Pb} / \\
{ }^{206} \mathrm{~Pb}^{*}\end{array}$ & $\begin{array}{l}\text { error } \\
(\%)\end{array}$ & $\begin{array}{l}{ }^{207} \mathrm{~Pb} / \\
{ }^{235} \mathrm{U}^{*}\end{array}$ & $\begin{array}{l}\text { error } \\
(\%)\end{array}$ & $\begin{array}{l}{ }_{\mathrm{Pb} /}^{206}{ }_{\mathrm{U}} \\
{ }^{238}{ }^{*}\end{array}$ & $\begin{array}{l}\text { error } \\
(\%)\end{array}$ & $\begin{array}{l}\text { error } \\
\text { correl. }\end{array}$ & $\begin{array}{c}\% \\
\text { discor. }\end{array}$ & $\begin{array}{c}{ }^{207} \mathrm{~Pb} /{ }^{206} \mathrm{~Pb} \\
\text { Edad (Ma) }\end{array}$ & $\begin{array}{l}\text { error } \\
\text { (Ma) }\end{array}$ \\
\hline Muestra Pon-1 & Anortosita & (Sierrita Blanca & Sonora) & & ontada er & probeta D & M-1 (Juni & io 2007) & & & & & & & \\
\hline PON-6 & Periferia & 1491 & 22 & 58 & 2.68 & 0.07029 & \pm 1.5 & 1.48 & \pm 1.80 & 0.1530 & \pm 1.0 & 0.56 & 2 & $937=$ & \pm 31 \\
\hline PON-5 & Periferia & 1093 & 14 & 38 & 2.61 & 0.07089 & \pm 1.8 & 1.51 & \pm 2.07 & 0.1548 & \pm 1.0 & 0.48 & 3 & $954=$ & \pm 37 \\
\hline PON-3 & Núcleo & 1331 & 11 & 23 & 2.16 & 0.07097 & \pm 1.6 & 1.75 & \pm 1.88 & 0.1785 & \pm 1.0 & 0.53 & -10 & $957=$ & \pm 33 \\
\hline PON-1 & Periferia & 980 & 8 & 19 & 2.27 & 0.07254 & \pm 1.9 & 1.94 & \pm 2.17 & 0.1935 & \pm 1.0 & 0.46 & -12 & $1001=$ & \pm 39 \\
\hline PON-2 & Núcleo & 1741 & 12 & 27 & 2.33 & 0.07681 & \pm 1.3 & 1.98 & \pm 1.66 & 0.1871 & \pm 1.0 & 0.60 & 1 & 1116 & \pm 26 \\
\hline PON-4 & Núcleo & 1156 & 13 & 31 & 2.40 & 0.07851 & \pm 1.6 & 1.70 & \pm 1.90 & 0.1571 & \pm 1.0 & 0.53 & 23 & $1160=$ & \pm 32 \\
\hline Muestra Pon-2 & Anortosita & (Sierrita Blanca & Sonora) & Mon & tada en & robeta $D M$ & 1-1 (Junio & 2007) & & & & & & & \\
\hline PON-9 & Núcleo & 548 & 8 & 21 & 2.80 & 0.06515 & \pm 3.5 & 1.46 & \pm 3.63 & 0.1620 & \pm 1.0 & 0.28 & -20 & $779=$ & \pm 73 \\
\hline PON-11 & Núcleo & 549 & 7 & 23 & 3.44 & 0.06923 & \pm 3.3 & 1.66 & \pm 3.43 & 0.1736 & \pm 1.0 & 0.29 & -12 & $906=$ & \pm 68 \\
\hline PON-8 & Núcleo & 826 & 7 & 20 & 2.72 & 0.07182 & \pm 2.2 & 1.78 & \pm 2.43 & 0.1800 & \pm 1.0 & 0.41 & -8 & $981=$ & \pm 45 \\
\hline PON-7 & Periferia & 775 & 8 & 21 & 2.71 & 0.07661 & \pm 2.2 & 2.01 & \pm 2.42 & 0.1898 & \pm 1.0 & 0.41 & -1 & $1111=$ & \pm 44 \\
\hline PON-12 & Periferia & 880 & 7 & 23 & 3.46 & 0.08206 & \pm 1.9 & 1.96 & \pm 2.15 & 0.1734 & \pm 1.0 & 0.47 & 21 & $1247=$ & \pm 37 \\
\hline PON-13 & Periferia & 657 & 8 & 21 & 2.59 & 0.08374 & \pm 2.4 & 1.73 & \pm 2.59 & 0.1499 & \pm 1.0 & 0.39 & 43 & $1287=$ & \pm 46 \\
\hline PON-10 & Núcleo & 463 & 6 & 20 & 3.57 & 0.08995 & \pm 3.0 & 2.22 & \pm 3.13 & 0.1791 & \pm 1.0 & 0.32 & 34 & $1425=$ & \pm 57 \\
\hline
\end{tabular}

Tabla 3). Los nueve análisis más jóvenes, y relativamente concordantes, permiten calcular una edad ${ }^{206} \mathrm{~Pb} /{ }^{238} \mathrm{U}$ media ponderada de $72.64 \pm 1.19 \mathrm{Ma}$ ( 2 sigma; $\mathrm{MSWD}=1.7$; Figura 7F) que representa la mejor estimación de la edad de cristalización para esta muestra granítica laramídica. En el gráfico de concordia se observan otros análisis discordantes que se han descartado para el cálculo de la edad de la roca por su alto error en la edad o por su discordancia, pero también por representar granos de zircón con diferentes grados de herencia. Lo mismo se observó en el caso de los análisis 15 y 27 (Figura 7D y Tabla 3) que son relativamente concordantes y presentan edades ${ }^{207} \mathrm{~Pb} /{ }^{206} \mathrm{~Pb}$ del Mesoproterozoico de $\sim 1.4 \mathrm{Ga}$ y $\sim 1.1 \mathrm{Ga}$.

\subsection{Geocronología ${ }^{40} \mathrm{Ar} /{ }^{39} \mathrm{Ar}$}

Los resultados de ${ }^{40} \mathrm{Ar} /{ }^{39} \mathrm{Ar}$ son mostrados en las Figuras 12-14. Los datos analíticos del espectrómetro de masas MAP 216 se encuentran en la Tabla 4 y los datos analizados con el espectrómetro de masas VG 1200 se presentan en la Tabla 5. Mencionar que los análisis de biotita fueron realizados por fusión total en horno en un solo paso a $1450^{\circ} \mathrm{C}$ para evitar dificultades de interpretación de los espectros de ${ }^{40} \mathrm{Ar} /{ }^{39} \mathrm{Ar}$ que resultarían de experimentos realizados por calentamiento gradual. Estas complejidades en los espectros suelen estar asociadas a que la biotita se vuelve inestable durante el experimento de calentamiento gradual, en condiciones de vacío, al sufrir esta una desestabilización estructural por procesos de deshidroxilación y delaminación (ej., Hanson et al., 1975; Gaber et al., 1988). Este fenómeno hace que cualquier gradiente de difusión (dominios de retención de argón radiogénico), presente en la biotita, sea destruido durante el experimento de calentamiento gradual (McDougall y Harrison, 1999), produciéndose una homogenización del argón e imposibilitándose, generalmente, la interpretación de estos espectros ${ }^{40} \mathrm{Ar} /{ }^{39} \mathrm{Ar}$ en términos de distribución de argón radiogénico en los cristales de biotita.

\subsubsection{Muestras del granito laramídico Sierrita Blanca}

La biotita de la muestra SB07-3, recolectada a $\sim 300$ $\mathrm{m}$ del contacto intrusivo-encajonante (Figura 2), arroja una edad de fusión total de $54.31 \pm 0.30 \mathrm{Ma}$. La biotita de la segunda muestra de granito laramídico Sierrita Blanca (SB07-5), recolectada más cerca del contacto ( $\sim 100 \mathrm{~m}$; Fig. 2), arroja un edad de fusión total de biotita más antigua de $58.80 \pm 0.30 \mathrm{Ma}$ (Figuras 12A y D; Tabla 4), indicando que esta muestra de granito se enfrió por debajo de la temperatura de cierre de la biotita antes que la biotita de la muestra recolectada más alejada del contacto intrusivoencajonante.

El mismo efecto se observa en los espectros de ${ }^{40} \mathrm{Ar} /{ }^{39} \mathrm{Ar}$ de los feldespatos potásicos generados por calentamiento gradual (Tabla 4; Figura 12). Cabe aclarar que dentro de un cristal de feldespato potásico existen diferentes dominios de difusión del Argón radiogénico y que, en general, a mayor difusión, el feldespato presenta menor temperatura de cierre (menor retención) y a menor difusión, por consiguiente, se tiene una mayor retención del Argón y una temperatura de cierre más elevada. De esta manera, y de forma aproximada, estimamos la temperatura de cierre isotópico para dominios de feldespato de alta retención en $250 \pm 40^{\circ} \mathrm{C}$ y los de baja 
Tabla 3. Datos analíticos de U-Th-Pb (LA-MC-ICPMS) de zircones de rocas graníticas laramídicas de la Sierrita Blanca, NW de Sonora, México.



Muestra SB07-5 Granito de 2 micas $\quad$ (Sierrita Blanca, NW de Sonora) Montada en probeta DM-1 (Junio 2007)

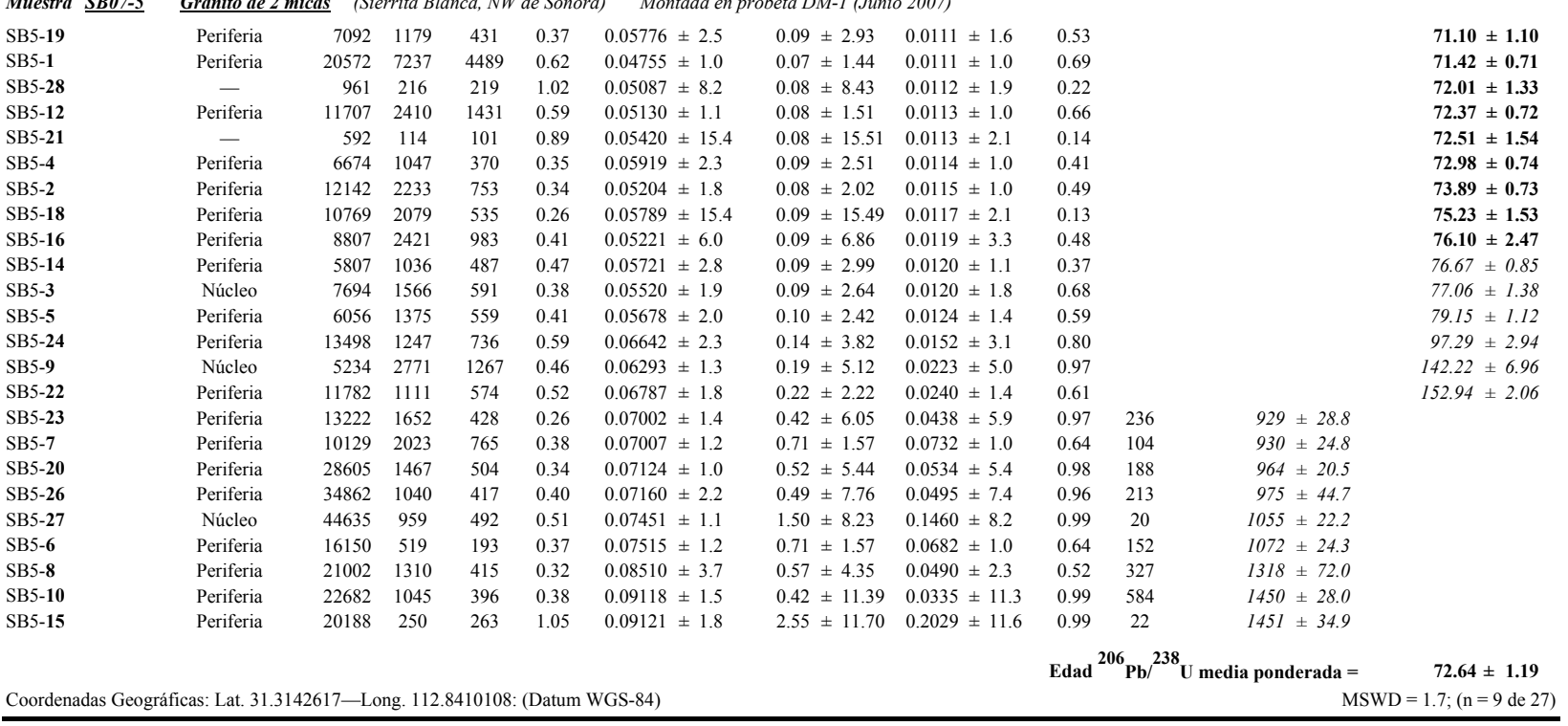

Relaciones atómicas corregidas para $\mathrm{Pb}$ inicial usando la cantidad de ${ }^{204} \mathrm{~Pb}$ y los valores terrestres promedio correspondientes de Stacey y Kramers (1975).

Todos los errores de relaciones isotópicas y edades están dados a 1 sigma con la excepcion de las edades ${ }^{206} \mathrm{~Pb} /{ }^{238}$ U medias ponderadas que se dan a 2 sigma.

Las edades individuales ${ }^{206} \mathrm{~Pb} /{ }^{238} \mathrm{U}$ en negrita son las empleadas para obtener la edad media ponderada.

\#El porcentaje de discordancia fue obtenido con la ecuación $\left(100^{*}\left[\left(\right.\right.\right.$ edad $\left.{ }^{207} \mathrm{~Pb} /{ }^{206} \mathrm{~Pb}\right) /\left(\right.$ edad $\left.\left.\left.{ }^{206} \mathrm{~Pb} /{ }^{238} \mathrm{U}\right)\right]-1\right)$. Los valores positivos son para las discordancias normales; valores negativos para las discordancias inversas.

MSWD: Mean Square Weigthed Deviations (desviación media cuadrática ponderada) 
SB07-2 Granito Murrieta
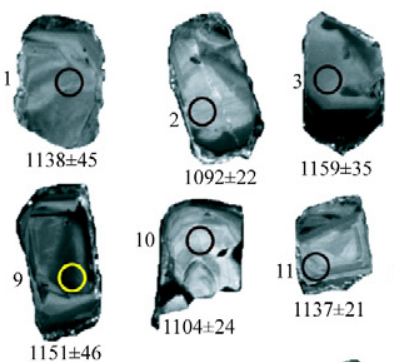

$1092 \pm 22$

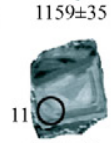

$1104 \pm 24$

$1137 \pm 21$
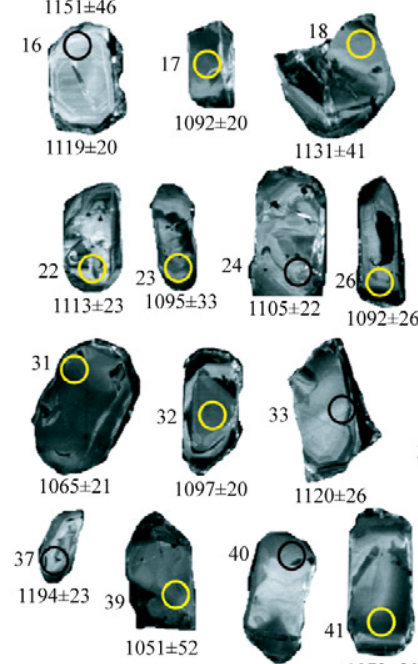

$0.1 \mathrm{~mm}$
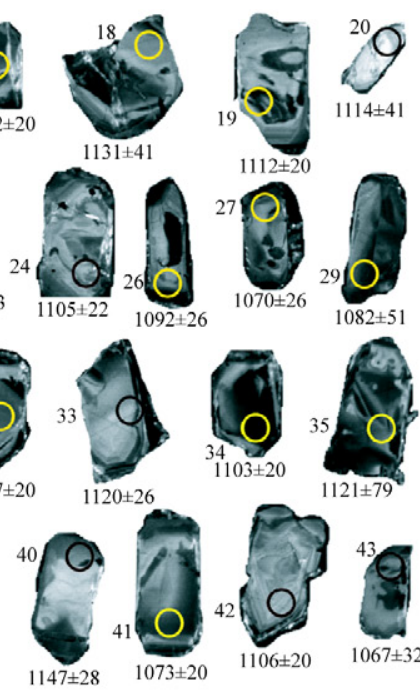
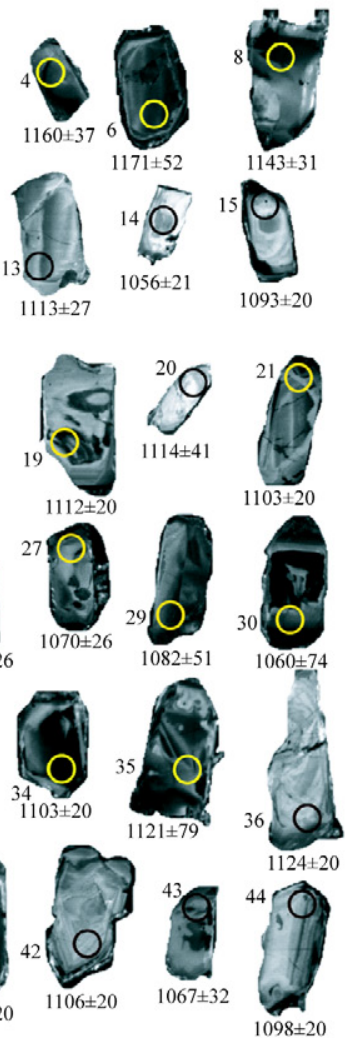

SB07-4 Granito Murrieta
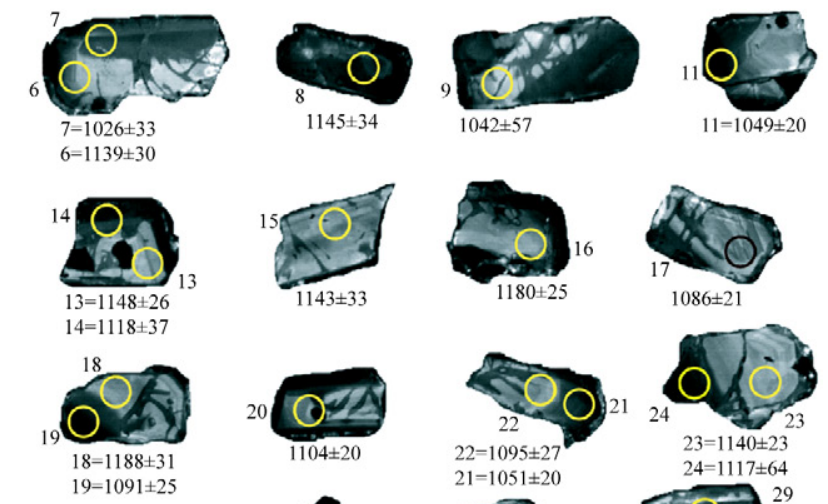
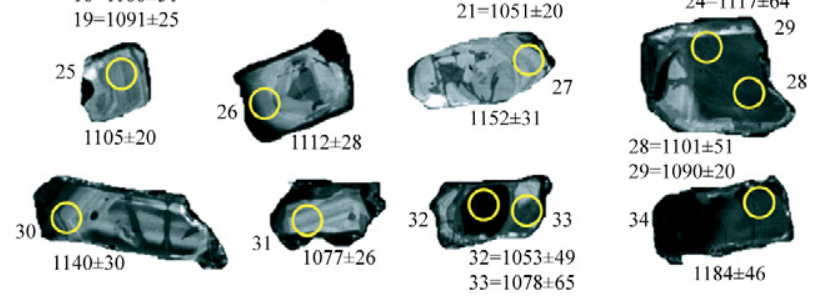

$28=1101 \pm 51$
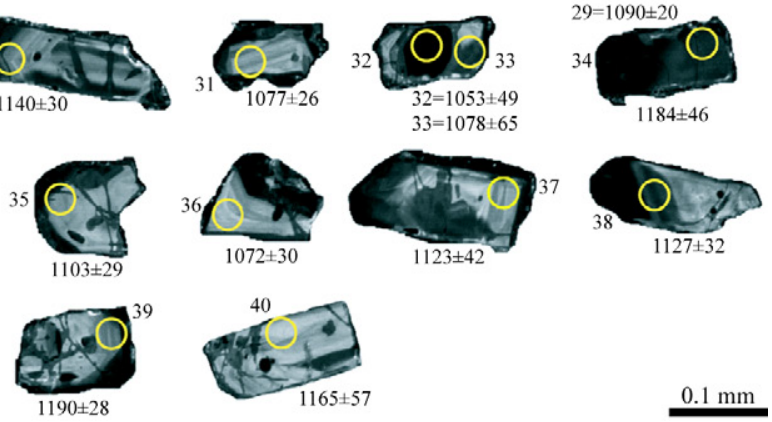

$0.1 \mathrm{~mm}$

Figura 8. Imágenes de cátodoluminiscencia de zircones a partir de microscopio electrónico de barrido (SEM-CL) para muestras del Mesoproterozoico $(\sim 1.1 \mathrm{Ga})$ del granito Murrieta (SB07-2 y SB07-4). Los círculos amarillos y negros representan los puntos de análisis de ablación láser de 35 micras. El número de análisis, y su edad en Ma, se muestra adjunto a cada zircón. Las edades individuales son edades ${ }^{207} \mathrm{~Pb} /{ }^{206} \mathrm{~Pb}$ reportadas a precisión de 1 -sigma.

retención en $150 \pm 40^{\circ} \mathrm{C}$. Destacar que estas estimaciones de temperatura de cierre isotópico son similares a las calculadas mediante el modelo matemático de Múltiples Dominios de Difusión (MDD) que muestra una variación de temperaturas de cierre para feldespatos potásicos entre $\sim 150-350^{\circ} \mathrm{C}$ (Lovera et al., 2003).

En el caso del feldespato potásico de la muestra granítica laramídica SB07-3, apreciamos que tiene un gradiente de edad (Figura 12A) desde $48 \mathrm{Ma}$ (feldespato de alta retención) hasta los $\sim 37 \mathrm{Ma}$ (feldespato de baja retención); mientras que el feldespato de la muestra SB07-5 presenta un gradiente de edad desde los $\sim 50$ Ma hasta los $\sim 44 \mathrm{Ma}$ (Figura 12B). El feldespato de la muestra de pegmatita tardimagmática (SB07-5B), que corta a estos granitos, cerca del contacto entre el intrusivo y la roca encajonante (Figura 2), presenta un espectro muy similar al feldespato de la muestra SB07-5 desde $\sim 51$ Ma hasta los $\sim 41 \mathrm{Ma}$ (Figura 12C). En general los espectros son relativamente coherentes para los tres feldespatos de las rocas ígneas laramídicas (Figura 12D). De la pegmatita se analizó también moscovita que muestra un comportamiento bastante homogéneo en el espectro de ${ }^{40} \mathrm{Ar}{ }^{39} \mathrm{Ar}$, aunque no llega a formar un "plateau" o meseta (Figura 12C). Debido a que la estadística de los datos no permite calcular una edad de isocrona confiable, se considera como la mejor estimación de la edad de moscovita la edad de gas total de $\sim 61 \mathrm{Ma}$ (Tabla 4)

\subsubsection{Muestras del encajonante mesoproterozoico (granito Murrieta)}

Los datos de Ar-Ar por fusión total de biotita para las diferentes muestras de granito Murrieta están reportados en la Tabla 4. Estas edades son edades laramídicas de reajuste isotópico, por lo que se puede decir que las muestras de granito Murrieta (rocas encajonantes) estuvieron expuestas por lo menos a temperaturas superiores a los $300 \pm 40^{\circ} \mathrm{C}$ (temperatura de cierre de la biotita) durante la intrusión de los granitos laramídicos en la Sierrita Blanca. Las diferencias de edades de biotita que se aprecian en el caso de los granitos laramídicos, en función de su distancia al contacto intrusivo-encajonante, también se aprecian para las muestras de rocas precámbricas, pero en este caso de manera inversa. Es decir, la biotita de la muestra recolectada más cerca del contacto (fuente de calor), a unos $50 \mathrm{~m}$ de este (SB07-6; Figura 2), tiene la edad de fusión total de biotita 
SB07-6 Granito Murrieta

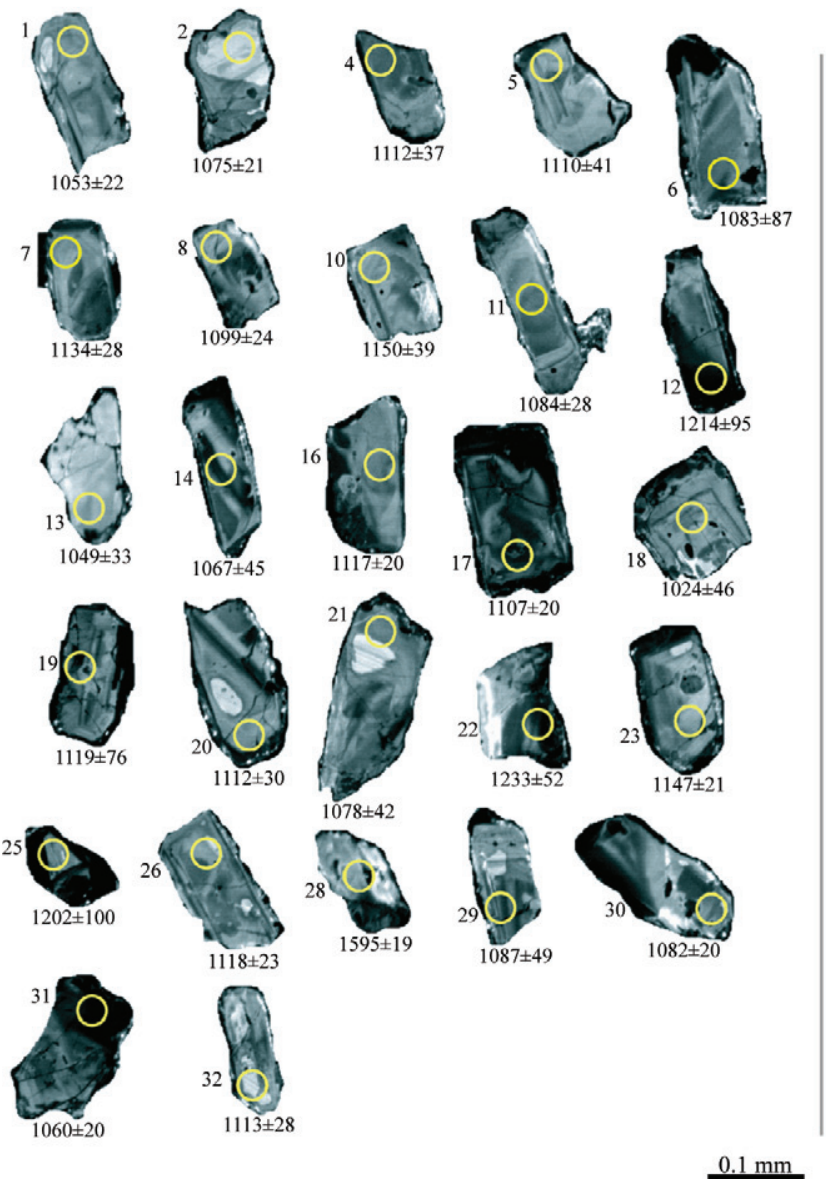

PONCHO Anortosita Sierrita Blanca
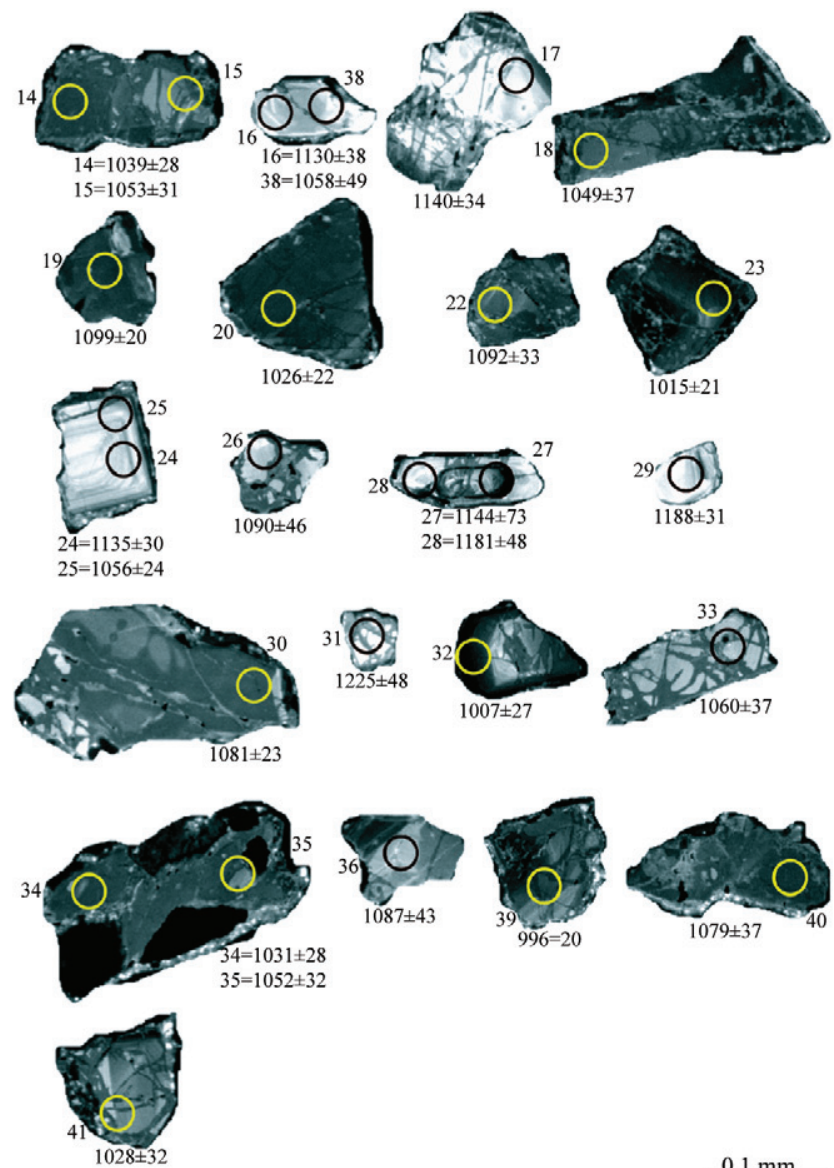

$0.1 \mathrm{~mm}$

Figura 9. Imágenes de cátodoluminiscencia de zircones a partir de microscopio electrónico de barrido (SEM-CL) para muestras del Mesoproterozoico del granito Murrieta (SB07-6) y de la anortosita Sierrita Blanca (PONCHO). Los círculos amarillos y negros representan los puntos de análisis de ablación láser de $\sim 35$ micras. El número de análisis, y su edad en Ma, se muestra adjunto a cada zircón. Las edades individuales son edades ${ }^{207} \mathrm{~Pb} /{ }^{206} \mathrm{~Pb}$ reportadas a precisión de 1-sigma.

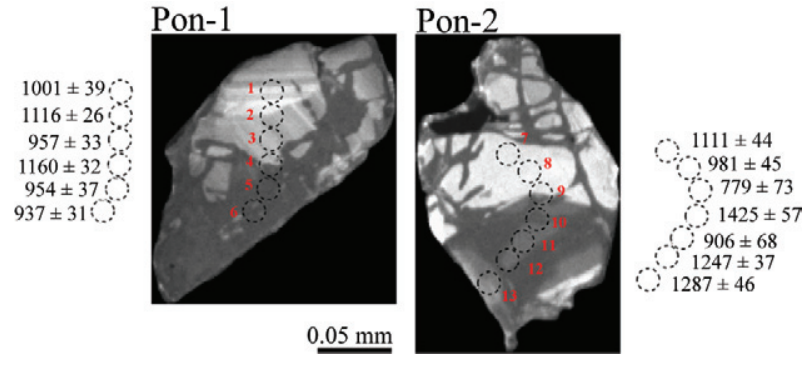

Figura 10. Imágenes de cátodoluminiscencia de dos zircones de la muestra de anortosita Sierrita Blanca (PONCHO). Los círculos punteados representan el tamaño del punto de análisis de la ablación láser ( $\sim 15$ micras $)$. El transecto de edades en el zircón Pon-1 muestra un rejuvenecimiento de las edades del zircón al llegar a los dominios de color gris más oscuro que representan dominios de zircón con perdida de $\mathrm{Pb}$. Las edades son edades individuales ${ }^{207} \mathrm{~Pb} /{ }^{206} \mathrm{~Pb}$ reportadas a precisión 1-sigma. En el transecto de edades para el zircón Pon-2 se presenta una complejidad adicional porque al acercarse al dominio de zircón de color gris, más oscuro, entramos en un dominio de zircón más viejo, mostrando la complejidad del mismo. más joven a $55.10 \pm 0.30 \mathrm{Ma}$, mientras que al alejarnos más del contacto ( $200 \mathrm{~m}$; muestra SB07-4), la muestra del granito Murrieta tiene una edad de biotita de $57.60 \pm 0.31$ Ma. Por último, la muestra SB07-2, recolectada a $\sim 1500 \mathrm{~m}$ del contacto (Figura 2), tiene la edad más antigua de biotita de las tres muestras a $58.21 \pm 0.31 \mathrm{Ma}$.

Este efecto de rejuvenecimiento de las edades hacia el contacto también se aprecia en los espectros de ${ }^{40} \mathrm{Ar} /{ }^{39} \mathrm{Ar}$ de los feldespatos potásicos de estas rocas (Figuras 12E, F y G). En este caso, existe una complicación adicional ya que los dominios de feldespato de alta retención de estas muestras proporcionan unos espectros más escalonados (Figura 12H). Estos escalones son más pronunciados cuanto mayor es la distancia a la fuente de calor de la muestra de feldespato, indicando que el proceso de reajuste isotópico para los mismos ha sido más profundo al acercarnos al contacto con la fuente de calor (intrusivo laramídico) como se observa en la muestra SB07-6 que presenta un gradiente 
SB07-3 Granito Sierrita Blanca
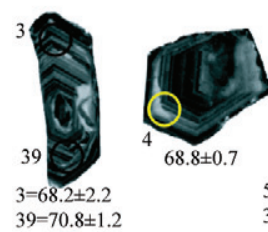

$9=70.8 \pm 1.2$
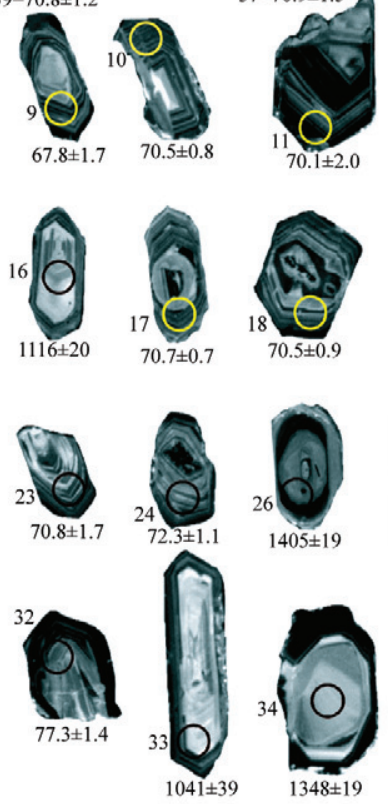

$0.1 \mathrm{~mm}$

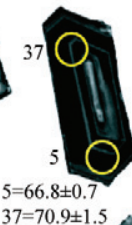

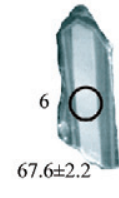
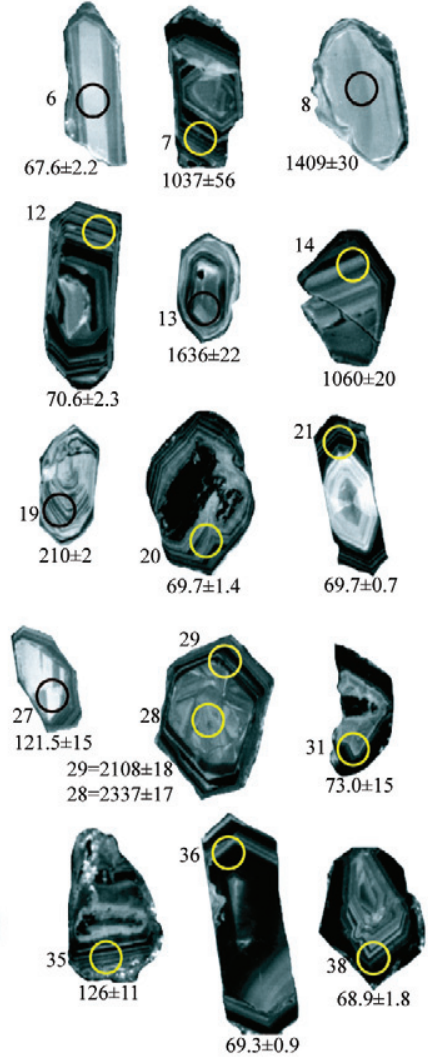

SB07-5 Granito Sierrita Blanca
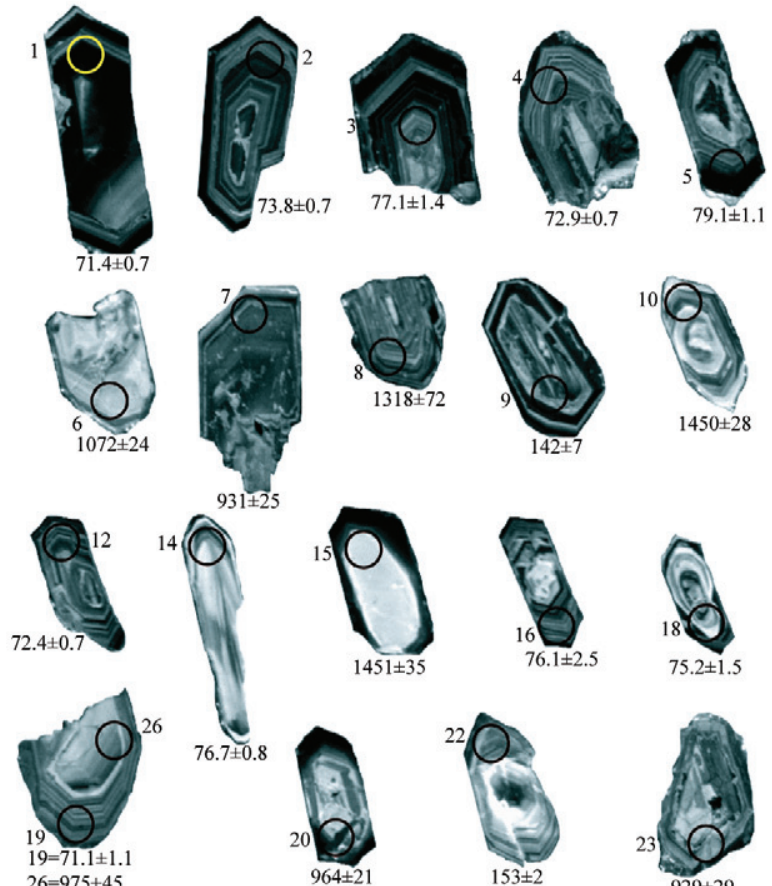
$76.7 \pm 0.8$
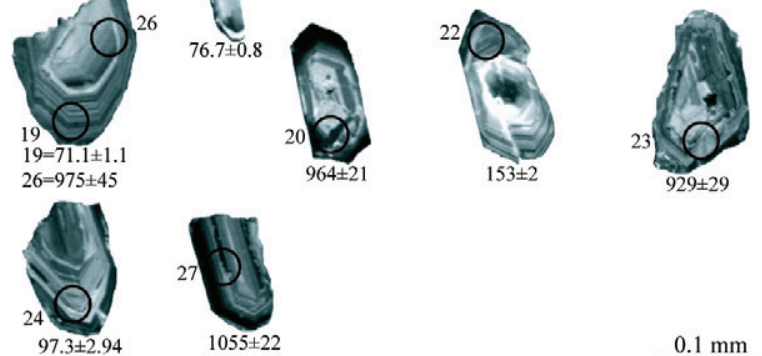

$0.1 \mathrm{~mm}$

Figura 11. Imágenes de cátodoluminiscencia de zircones a partir de microscopio electrónico de barrido (SEM-CL) de muestras laramídicas del granito Sierrita Blanca (SB07-3 y SB07-5). Los círculos amarillos y negros representan los puntos de análisis de ablación láser de $~ 35$ micras. El número de punto de análisis y su edad en Ma, se muestra adjunto a cada zircón. Las edades $<1000 \mathrm{Ma}$ son edades individuales ${ }^{206} \mathrm{~Pb} /{ }^{238} \mathrm{U}$ de zircón reportadas a precisión de 1-sigma; mientras que las $>1000 \mathrm{Ma}$ son edades individuales ${ }^{207} \mathrm{~Pb} / 206 \mathrm{~Pb}$, también reportadas a 1-sigma.

de edad muy similar al presentado por los feldespatos de las rocas graníticas laramídicas (Figura 12I). Por este motivo, se utilizan las edades mínimas (edades de los dominios de feldespato de baja retención) para estimar los enfriamientos de los feldespatos. Así, se observa que en el caso del feldespato de la muestra más cercana a la fuente de calor (SB07-6), ésta tiene una edad de $\sim 45 \mathrm{Ma}$ (Figura 12G). Esta edad gradualmente es más antigua al alejarse del contacto como se aprecia en la muestra SB07-4, la cual tiene una edad de $\sim 47 \mathrm{Ma}$ (Figura 12F). Por último, la edad más antigua de enfriamiento de feldespato (baja temperatura) se encuentra en la muestra del granito Murrieta recolectada más lejos del contacto (SB07-2; Figura 2), con una edad de feldespato de baja retención de $\sim 50 \mathrm{Ma}$.

Los estudios cartográficos en la Sierrita Blanca definieron una unidad de esquisto de moscovita (Figura 2) que se fechó para tener una referencia de la edad mínima del metamorfismo observado en esta zona de cizalla. Por su relación espacial, esta roca metamórfica pudiera ser el resultado de la deformación del granito mesoproterozoico Murrieta. La muestra de moscovita SB07-7 se fechó por
${ }^{40} \mathrm{Ar} /{ }^{39} \mathrm{Ar}$ por técnica de calentamiento gradual por horno con el espectrómetro de masas VG1200. Los datos se presentan en la Tabla 5. En el espectro de ${ }^{40} \mathrm{Ar} /{ }^{39} \mathrm{Ar}$ se aprecia que los datos no son muy homogéneos para los diferentes pasos de temperatura para poder formar un "plateau" o meseta (Figura 13A). La edad de isócrona a $51.58 \pm 2.63 \mathrm{Ma}\left({ }^{40} \mathrm{Ar} /{ }^{36} \mathrm{Ar}=296 \pm 7 ; \mathrm{MSWD}=0.315\right)$, mostrada en el diagrama de correlación isotópica inversa (Figura 13B), es la mejor estimación de la edad mínima del pulso de metamorfismo asociado a este esquisto. Por otro lado, cabe destacar que el error de los diferentes pasos de esta muestra es muy grande debido a que el separado de moscovita fue irradiado considerándolo como si fuera una muestra antigua (precámbrica); es decir, se utilizó una cantidad de mica muy pequeña $(5 \mathrm{mg}$ en vez de $30 \mathrm{mg}$ ) que no permitió obtener buenas señales en el espectrómetro de masas y que, por consiguiente, proporcionó errores muy elevados en la determinación de su edad. Sin embargo, a una resolución a nivel orogénico, se puede decir que esta edad de enfriamiento está asociada a la orogenia Laramide. 
Granitos Sierrita Blanca
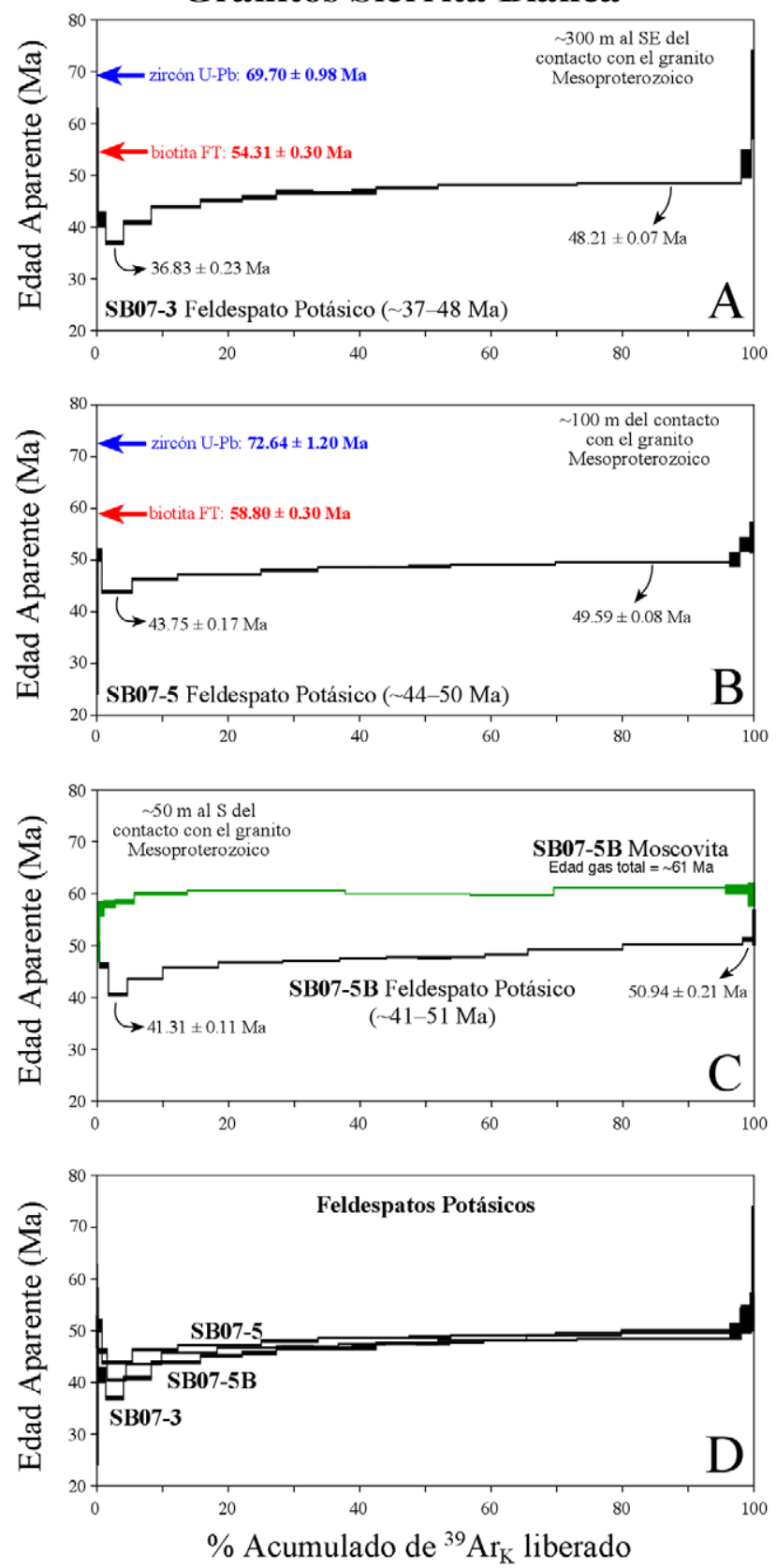

Granitos Murrieta
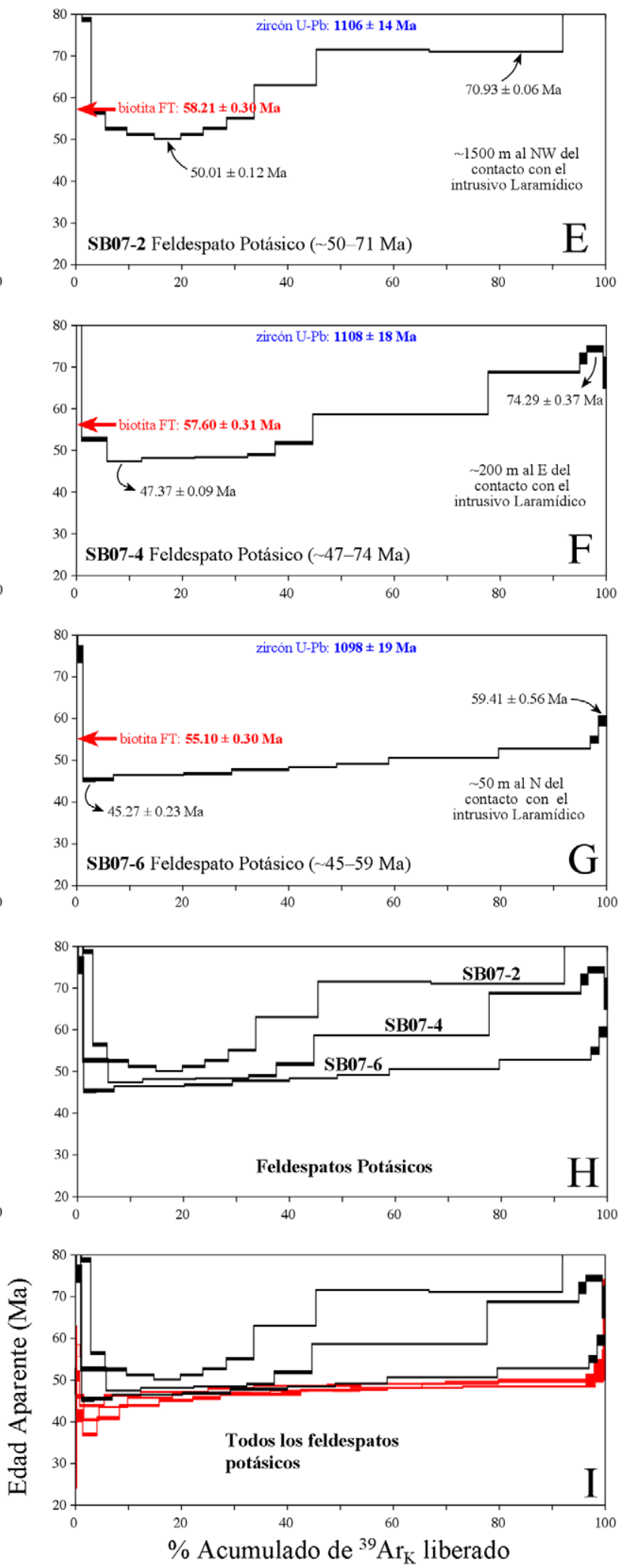

Figura 12. Espectros de ${ }^{40} \mathrm{Ar} /{ }^{39} \mathrm{Ar}$ a partir de datos obtenidos por calentamiento gradual de diferentes minerales de los granitos Sierrita Blanca (A, B, C y D) y Murrieta (E, F, G y H). El gráfico I muestra todos los espectros de ${ }^{40} \mathrm{Ar}{ }^{39} \mathrm{Ar}$ de feldespatos potásicos de las muestras laramídicas del granito Sierrita Blanca (espectros en color rojo) y las de las muestras mesoproterozoicas del granito Murrieta (espectros en color negro). Las fechas en color rojo representan las edades de ${ }^{40} \mathrm{Ar} /{ }^{39} \mathrm{Ar}$ de biotita obtenidas a partir de experimentos de fusión total por horno para las diferentes rocas. Las flechas en color azul representan las edades $\mathrm{U}-\mathrm{Pb}$ en zircones obtenidas para las rocas graníticas laramídicas. 

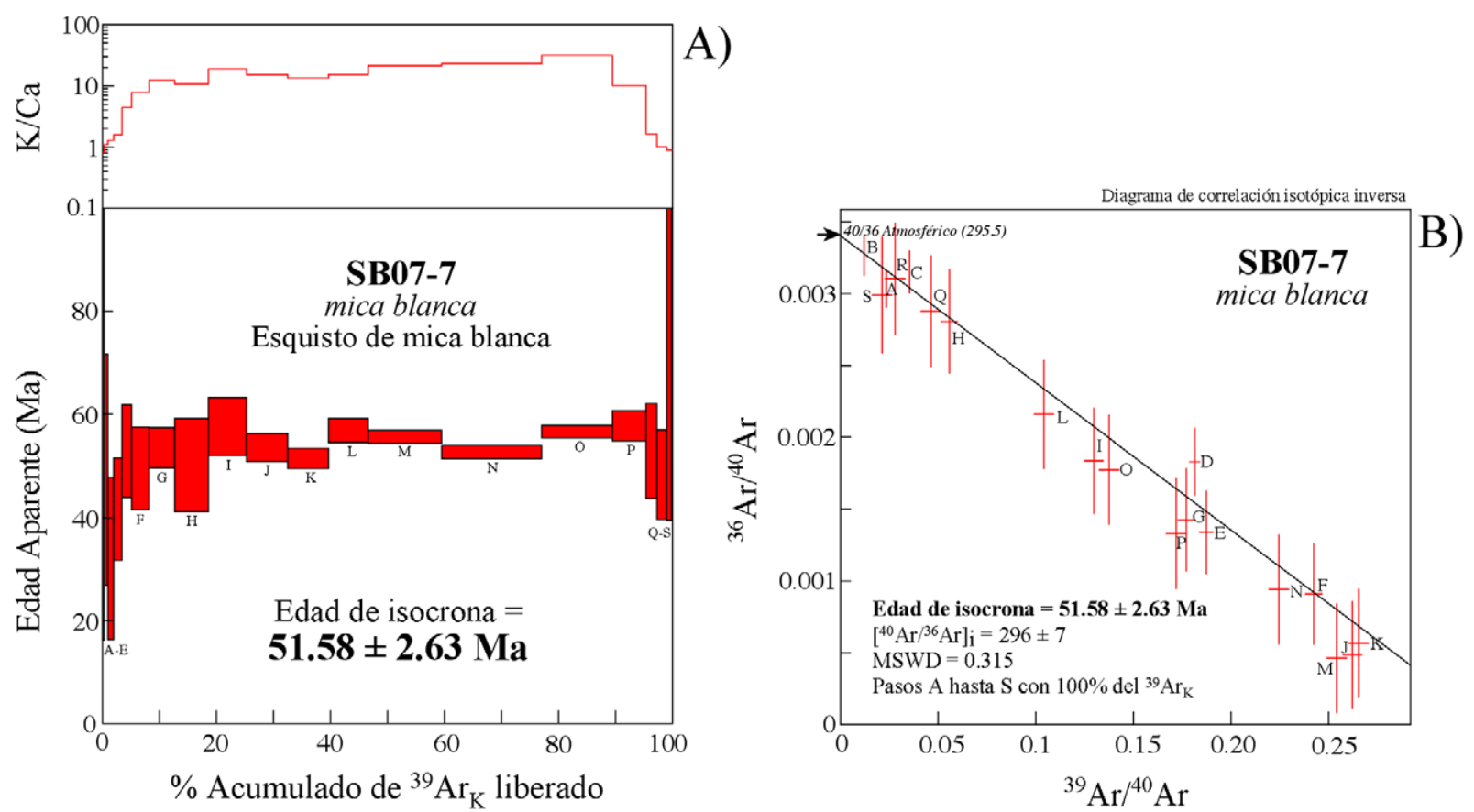

Figura 13. Datos de geocronología ${ }^{40} \mathrm{Ar}{ }^{39} \mathrm{Ar}$ de mica blanca obtenidos por calentamiento gradual por horno de la muestra de la unidad de esquisto de moscovita (SB07-7). A) Espectro de ${ }^{40} \mathrm{Ar} /{ }^{39} \mathrm{Ar}$, y B) su diagrama de correlación inversa con la edad de isócrona, su valor ${ }^{40} \mathrm{Ar} /{ }^{36} \mathrm{Ar}$ inicial y su MSWD (Mean Square of Weighted Deviates) que es una forma de cuantificar el encaje estadístico.

\subsubsection{Andesita miocénica}

La andesita de la parte norte de la Sierrita Blanca (SB07-1; Figura 2), que pudiera estar asociada a la Caldera El Pilar ubicada en la zona de Quitovac (Figura 1), justo al norte de la Sierrita Blanca, fue analizada por el método de calentamiento por pasos con el espectrómetro de masas VG1200 (Tabla 5). Se utilizó matriz volcánica y plagioclasa para evaluar la posibilidad de la existencia de Argón extraño en la muestra (Figura 14).

El espectro de ${ }^{40} \mathrm{Ar} /{ }^{39} \mathrm{Ar}$ de la matriz volcánica muestra un comportamiento no muy homogéneo que impide el cálculo de una edad "plateau" o meseta (Figura 14A). La edad de isócrona, mostrada en el diagrama de correlación isotópica inversa (Figura 14B), es de $18.29 \pm 1.28 \mathrm{Ma}$ $\left({ }^{40} \mathrm{Ar} /{ }^{36} \mathrm{Ar}=294 \pm 24 ; \mathrm{MSWD}=0.04 ;\right.$ con $67 \%$ del gas total). Se interpreta que la muestra de matriz volcánica ha sido afectada por la presencia de Argón extraño que ha tenido un efecto incrementando su edad. El espectro de la muestra de plagioclasa es algo más homogéneo (Figura 12C) permitiendo calcular una edad de meseta de 17.32 $\pm 0.10 \mathrm{Ma}$ utilizando los pasos de calentamiento $\mathrm{F}$ hasta el J, representando un $63 \%$ del total del gas extraído de la muestra (Tabla 5). La edad de isócrona a $16.86 \pm 0.40$ Ma (Figura 14D) apoya, dentro de los límites de error (1-sigma), la edad de meseta que tiene menor error, y que se ha interpretado como la edad de cristalización de la lava andesítica del norte de la Sierrita Blanca.

\section{Historia termal de rocas graníticas de la Sierrita Blanca}

La combinación de fechamientos por diferentes técnicas isotópicas es de vital importancia para realizar estudios de historia termal ya que permiten evaluar el concepto de evolución temperatura-tiempo de una región. Este concepto permite estimar la evolución termal (a partir de curvas de enfriamiento) de una roca durante su cristalización ígnea y/o durante el enfriamiento posterior de una roca que ha experimentado reajuste isotópico por efectos de metamorfismo (regional o de contacto).

En esta investigación de historia termal de rocas graníticas no se han calculado temperaturas de cierre isotópico para los minerales estudiados, únicamente se han utilizado valores aproximados de temperaturas de cierre que se consideran adecuados en función del gran número de estimaciones que existen en la literatura (ej., Heaman y Parrish, 1991; McDougall y Harrison, 1999). Además, destacar que los datos e interpretaciones que se presentan a continuación son de carácter semi-cuantitativo, en contraste con estudios termocronológicos cuantitativos que requieren de complejos modelos matemáticos con innumerables incógnitas y/o asunciones físico-químicas (ej., Harrison y McDougall, 1980a, 1980b).

Para el análisis de historia de enfriamiento que se presenta a continuación se generaron curvas de enfriamiento a partir de los siguientes valores de temperatura de cierre 


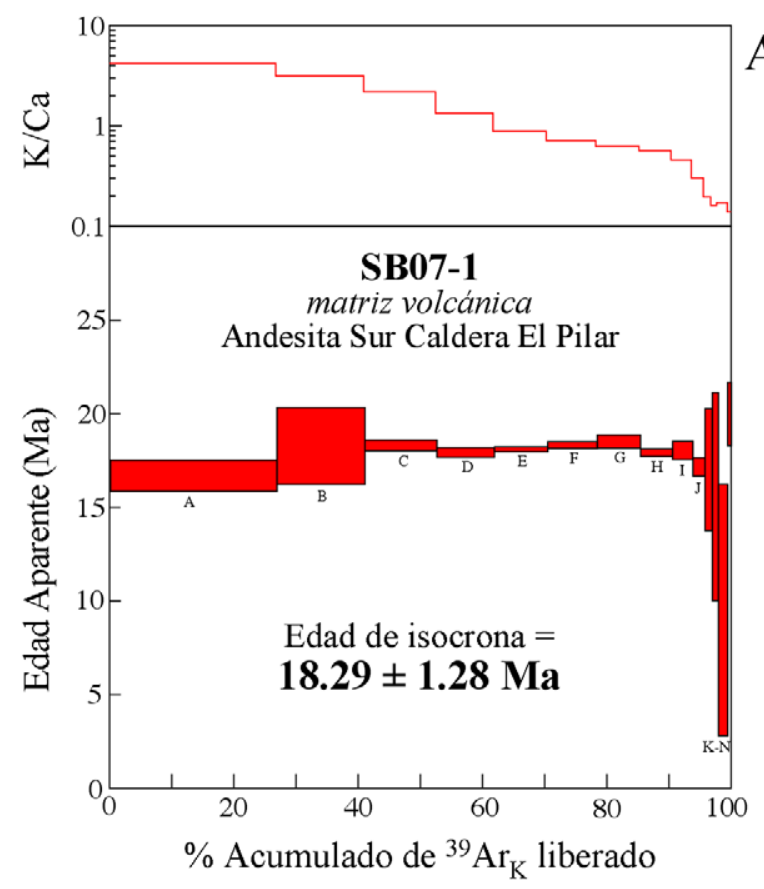

A)
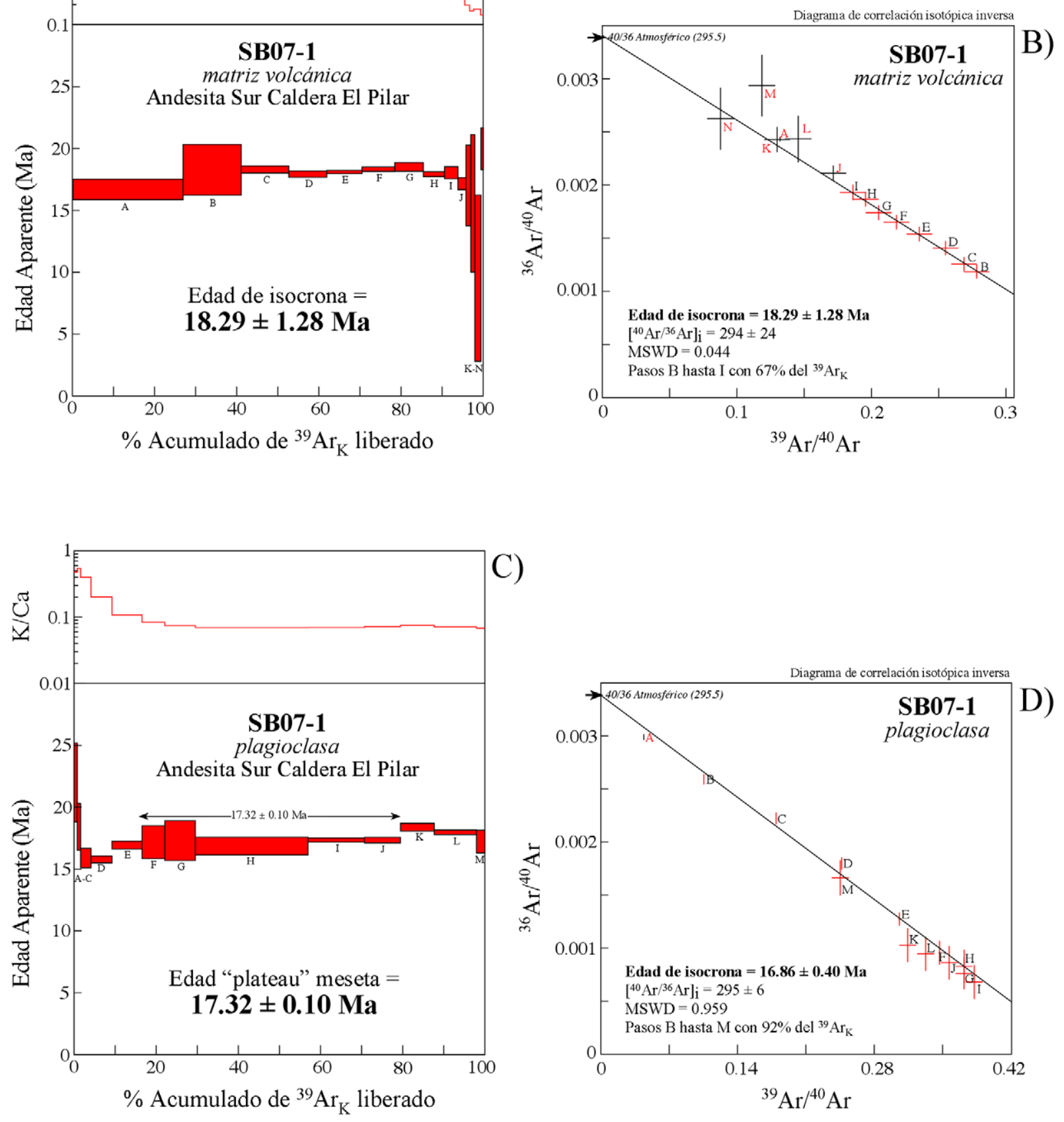

Figura 14. Datos de geocronología ${ }^{40} \mathrm{Ar} /{ }^{39} \mathrm{Ar}$ obtenidos por calentamiento gradual por horno de la muestra de andesita (SB07-1) a partir de matriz volcánica y plagioclasa. A) Espectro ${ }^{40} \mathrm{Ar} /{ }^{39} \mathrm{Ar}$ de matriz volcánica, y B) su diagrama de correlación inversa con la edad de isócrona, su valor ${ }^{40} \mathrm{Ar}{ }^{36} \mathrm{Ar}$ inicial y su MSWD. C) Espectro ${ }^{40} \mathrm{Ar} /{ }^{39} \mathrm{Ar}$ de plagioclasa mostrando la edad "plateau" o meseta de este mineral, y D) su diagrama de correlación inversa con la edad de isocrona, su valor ${ }^{40} \mathrm{Ar}{ }^{36} \mathrm{Ar}$ inicial y su MSWD. 
Tabla 4. Datos ${ }^{40} \mathrm{Ar} /{ }^{39} \mathrm{Ar}$ de calentamiento gradual y fusión total por horno en espectrómetro MAP-216.

\begin{tabular}{|c|c|c|c|c|c|c|c|c|c|}
\hline \multirow{2}{*}{$\begin{array}{r}\text { Paso } \\
\text { SB07-2 }\end{array}$} & \multirow{2}{*}{$\begin{array}{c}\text { Temp. } \\
{ }^{\circ} \mathrm{C} \\
\text { Sierrita Blanca }\end{array}$} & $\begin{array}{l}\%^{39} \mathrm{Ar} \\
\text { del total }\end{array}$ & \multirow[t]{2}{*}{$\begin{array}{c}\text { Radiogénico } \\
\text { Producido (\%) }\end{array}$} & \multirow{2}{*}{\multicolumn{2}{|c|}{$\begin{array}{cc}{ }^{39} \mathrm{Ar}_{\mathrm{k}} & { }^{40} \underline{\mathrm{Ar}^{*}} \\
(\text { Moles) } & { }^{39} \mathrm{Ar}_{\mathrm{k}} \\
J=0.004243 \pm 0.50 \%\end{array}$}} & $\begin{array}{c}\mathrm{K} / \mathrm{Ca} \\
\text { Aparente }\end{array}$ & $\begin{array}{c}\mathrm{K} / \mathrm{Cl} \\
\text { Aparente }\end{array}$ & $\begin{array}{r}\text { Edad } \\
\text { Aparente (Ma) }\end{array}$ & \multirow[t]{2}{*}{$\begin{array}{l}\text { Erro } \\
(\mathrm{Ma}) \\
\end{array}$} \\
\hline & & feldespato potásico & & & & \multicolumn{2}{|c|}{ peso $=2.19 \mathrm{mg}$} & $D 48$ & \\
\hline A & 700 & 0.1 & 15.8 & $8.80 \mathrm{E}-17$ & 36.441 & 1 & 6 & 259.37 & \pm 7.21 \\
\hline B & 800 & 0.2 & 52.5 & $1.82 \mathrm{E}-16$ & 52.691 & 2 & 11 & 364.01 & \pm 2.32 \\
\hline $\mathrm{C}$ & 900 & 1.0 & 75.9 & $8.87 \mathrm{E}-16$ & 29.763 & 6 & 44 & 214.55 & \pm 0.59 \\
\hline $\mathrm{D}$ & 950 & 1.7 & 78.6 & $1.52 \mathrm{E}-15$ & 10.511 & 12 & 112 & 78.72 & \pm 0.24 \\
\hline E & 1000 & 2.8 & 84.5 & $2.51 \mathrm{E}-15$ & 7.481 & 19 & 187 & 56.37 & \pm 0.15 \\
\hline F & 1050 & 4.0 & 87.9 & $3.68 \mathrm{E}-15$ & 6.949 & 21 & 304 & 52.42 & \pm 0.13 \\
\hline G & 1100 & 5.2 & 86.7 & 4.76E-15 & 6.779 & 28 & 388 & 51.16 & \pm 0.09 \\
\hline $\mathrm{H}$ & 1150 & 5.0 & 88.0 & $4.58 \mathrm{E}-15$ & 6.624 & 27 & 846 & 50.01 & \pm 0.12 \\
\hline I & 1200 & 4.3 & 88.9 & $3.92 \mathrm{E}-15$ & 6.765 & 14 & 545 & 51.05 & \pm 0.14 \\
\hline $\mathrm{J}$ & 1250 & 4.4 & 86.2 & 4.04E-15 & 6.959 & 9 & 451 & 52.50 & \pm 0.11 \\
\hline $\mathrm{K}$ & 1300 & 5.1 & 85.8 & $4.64 \mathrm{E}-15$ & 7.300 & 13 & 394 & 55.03 & \pm 0.09 \\
\hline $\mathrm{L}$ & 1350 & 11.8 & 78.9 & $1.07 \mathrm{E}-14$ & 8.362 & 19 & 59 & 62.90 & \pm 0.08 \\
\hline M & 1400 & 21.4 & 82.3 & $1.95 \mathrm{E}-14$ & 9.532 & 24 & 420 & 71.53 & \pm 0.08 \\
\hline $\mathrm{N}$ & 1450 & 25.0 & 85.9 & $2.28 \mathrm{E}-14$ & 9.451 & 35 & 397 & 70.93 & \pm 0.06 \\
\hline $\mathrm{O}$ & 1500 & 5.3 & 86.2 & $4.81 \mathrm{E}-15$ & 13.794 & 25 & 197 & 102.62 & \pm 0.13 \\
\hline $\mathrm{P}$ & 1550 & 2.3 & 75.2 & $2.05 \mathrm{E}-15$ & 12.799 & 12 & 33 & 95.41 & \pm 0.22 \\
\hline \multirow[t]{2}{*}{ Q } & 1650 & 0.5 & 52.6 & 4.84E-16 & 20.794 & 5 & 15 & 152.54 & \pm 1.13 \\
\hline & & & & & & \multicolumn{2}{|r|}{ Edad gas total $=$} & 69.50 & \\
\hline SB07-2 & Sierrita Blanca & $\underline{\text { biotita FT }}$ & \multicolumn{2}{|c|}{$J=0.004655 \pm 0.50 \%$} & \multicolumn{2}{|c|}{ peso $=0.65 \mathrm{mg}$} & $\# 85 K D 48$ & & \\
\hline A & 1450 & 100.0 & 68.7 & $1.07 \mathrm{E}-14$ & 7.045 & 19 & 31 & 58.21 & \pm 0.30 \\
\hline$S B 07-4$ & Sierrita Blanca & felde & pato potásico & $J=0.004208 \pm$ & $\pm 0.50 \%$ & peso $=2$. & $.80 \mathrm{mg}$ & $D 48$ & \\
\hline A & 800 & 0.2 & 65.3 & $1.38 \mathrm{E}-16$ & 46.293 & 3 & 20 & 321.09 & \pm 3.03 \\
\hline $\mathrm{B}$ & 950 & 0.9 & 71.6 & $5.19 \mathrm{E}-16$ & 16.683 & 12 & 42 & 122.40 & \pm 0.61 \\
\hline $\mathrm{C}$ & 1000 & 4.7 & 79.2 & $2.69 \mathrm{E}-15$ & 7.025 & 18 & 96 & 52.56 & \pm 0.19 \\
\hline $\mathrm{D}$ & 1050 & 6.6 & 87.0 & $3.78 \mathrm{E}-15$ & 6.322 & 35 & 254 & 47.37 & \pm 0.09 \\
\hline $\mathrm{E}$ & 1200 & 10.0 & 81.5 & $5.74 \mathrm{E}-15$ & 6.413 & 27 & 347 & 48.04 & \pm 0.08 \\
\hline F & 1250 & 10.0 & 86.1 & $5.76 \mathrm{E}-15$ & 6.453 & 22 & 481 & 48.34 & \pm 0.10 \\
\hline G & 1300 & 5.2 & 82.2 & $2.99 \mathrm{E}-15$ & 6.532 & 29 & 346 & 48.92 & \pm 0.12 \\
\hline $\mathrm{H}$ & 1350 & 7.1 & 69.5 & $4.06 \mathrm{E}-15$ & 6.916 & 19 & 183 & 51.76 & \pm 0.17 \\
\hline I & 1450 & 33.0 & 74.9 & $1.89 \mathrm{E}-14$ & 7.833 & 24 & 115 & 58.51 & \pm 0.08 \\
\hline $\mathrm{J}$ & 1500 & 17.3 & 82.3 & $9.87 \mathrm{E}-15$ & 9.222 & 68 & 378 & 68.68 & \pm 0.08 \\
\hline K & 1550 & 1.4 & 46.1 & $8.01 \mathrm{E}-16$ & 9.664 & 13 & 42 & 71.91 & \pm 0.68 \\
\hline $\mathrm{L}$ & 1650 & 3.1 & 36.6 & $1.80 \mathrm{E}-15$ & 9.990 & 26 & 38 & 74.29 & \pm 0.37 \\
\hline M & 1650 & 0.4 & 12.2 & $2.54 \mathrm{E}-16$ & 9.208 & 5 & 42 & 68.58 & \pm 1.87 \\
\hline & & & & & & & Edad gas total $=$ & 58.20 & \\
\hline$S B 07-4$ & Sierrita Blanca & $\underline{\text { biotit }}$ & $J=0.0$ & $4655 \pm 0.50 \%$ & peso $=$ & $0.70 \mathrm{mg}$ & $\# 81 K D 48$ & & \\
\hline A & 1450 & 100.0 & 62.5 & $1.01 \mathrm{E}-14$ & 6.967 & 2 & 22 & 57.60 & \pm 0.31 \\
\hline$S B 07-6$ & Sierrita Blanca & felde & pato potásico & $J=0.004239 \pm$ & $\pm 0.50 \%$ & peso $=2$. & $.23 \mathrm{mg}$ & $D 48$ & \\
\hline A & 800 & 0.2 & 4.3 & $9.68 \mathrm{E}-17$ & 12.693 & 3 & 3 & 94.55 & \pm 7.24 \\
\hline B & 900 & 0.9 & 34.9 & $4.33 \mathrm{E}-16$ & 10.066 & 10 & 20 & 75.38 & \pm 1.05 \\
\hline $\mathrm{C}$ & 950 & 2.3 & 73.3 & $1.07 \mathrm{E}-15$ & 5.995 & 18 & 77 & 45.27 & \pm 0.23 \\
\hline $\mathrm{D}$ & 1050 & 3.5 & 85.6 & $1.61 \mathrm{E}-15$ & 6.011 & 18 & 135 & 45.40 & \pm 0.19 \\
\hline $\mathrm{E}$ & 1100 & 13.3 & 88.0 & $6.06 \mathrm{E}-15$ & 6.126 & 50 & 309 & 46.25 & \pm 0.07 \\
\hline F & 1200 & 9.1 & 87.6 & 4.19E-15 & 6.195 & 52 & 501 & 46.77 & \pm 0.10 \\
\hline G & 1300 & 10.7 & 89.9 & $4.89 \mathrm{E}-15$ & 6.310 & 47 & 408 & 47.62 & \pm 0.09 \\
\hline $\mathrm{H}$ & 1350 & 9.0 & 73.6 & $4.11 \mathrm{E}-15$ & 6.405 & 41 & 27 & 48.33 & \pm 0.10 \\
\hline I & 1400 & 10.0 & 77.5 & 4.55E-15 & 6.499 & 27 & 341 & 49.03 & \pm 0.09 \\
\hline $\mathrm{J}$ & 1450 & 20.6 & 84.0 & $9.43 \mathrm{E}-15$ & 6.703 & 41 & 768 & 50.55 & \pm 0.07 \\
\hline K & 1500 & 17.5 & 83.2 & $7.98 \mathrm{E}-15$ & 6.989 & 87 & 747 & 52.67 & \pm 0.07 \\
\hline $\mathrm{L}$ & 1550 & 1.5 & 54.2 & $6.98 \mathrm{E}-16$ & 7.286 & 30 & 77 & 54.88 & \pm 0.43 \\
\hline M & 1650 & 1.4 & 38.2 & $6.23 \mathrm{E}-16$ & 7.898 & 12 & 12 & 59.41 & \pm 0.56 \\
\hline & & & & & & & Edad gas total $=$ & 49.60 & \\
\hline
\end{tabular}


Tabla 4 (Continuación). Datos ${ }^{40} \mathrm{Ar} /{ }^{39} \mathrm{Ar}$ de calentamiento gradual y fusión total por horno en espectrómetro MAP-216.

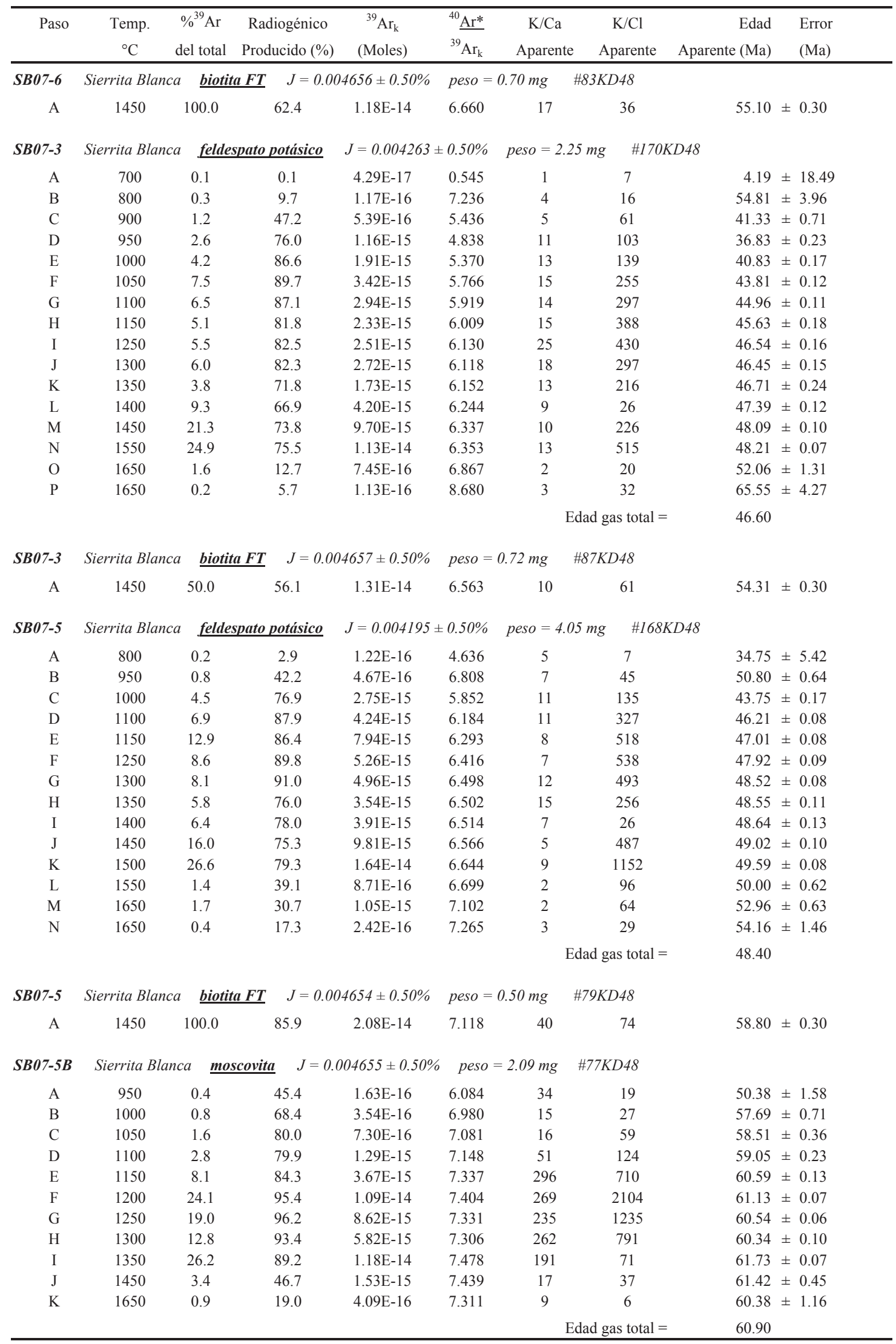


Tabla 4 (Continuación). Datos ${ }^{40} \mathrm{Ar} /{ }^{39} \mathrm{Ar}$ de calentamiento gradual y fusión total por horno en espectrómetro MAP-216.

\begin{tabular}{|c|c|c|c|c|c|c|c|c|c|}
\hline Paso & $\begin{array}{l}\text { Temp. } \\
{ }^{\circ} \mathrm{C}\end{array}$ & $\begin{array}{l}\%^{39} \mathrm{Ar} \\
\text { del total }\end{array}$ & $\begin{array}{c}\text { Radiogénico } \\
\text { Producido (\%) }\end{array}$ & $\begin{array}{l}{ }^{39} \mathrm{Ar}_{\mathrm{k}} \\
\text { (Moles) }\end{array}$ & ${ }^{40} \stackrel{\mathrm{Ar}^{*}}{\mathrm{Ar}_{\mathrm{k}}}$ & $\begin{array}{c}\mathrm{K} / \mathrm{Ca} \\
\text { Aparente }\end{array}$ & $\begin{array}{c}\mathrm{K} / \mathrm{Cl} \\
\text { Aparente }\end{array}$ & $\begin{array}{r}\text { Edad } \\
\text { Aparente }(\mathrm{Ma})\end{array}$ & $\begin{array}{l}\text { Error } \\
(\mathrm{Ma})\end{array}$ \\
\hline$S B 07-5 B$ & \multicolumn{2}{|c|}{ Sierrita Blanca } & feldespato potásico & \multicolumn{2}{|c|}{$J=0.004339 \pm 0.50 \%$} & \multicolumn{3}{|c|}{ peso $=3.19 \mathrm{mg} \quad \# 162 \mathrm{KD} 48$} & \\
\hline A & 800 & 0.2 & 12.2 & 2.34E-16 & 7.043 & 5 & 20 & 54.30 & \pm 1.88 \\
\hline $\mathrm{B}$ & 900 & 1.4 & 69.1 & $1.34 \mathrm{E}-15$ & 5.941 & 11 & 100 & 45.91 & \pm 0.25 \\
\hline $\mathrm{C}$ & 950 & 2.9 & 88.3 & $2.72 \mathrm{E}-15$ & 5.207 & 24 & 242 & 40.31 & \pm 0.11 \\
\hline $\mathrm{D}$ & 1000 & 5.3 & 94.3 & 4.99E-15 & 5.618 & 53 & 391 & 43.45 & \pm 0.08 \\
\hline $\mathrm{E}$ & 1050 & 8.6 & 96.6 & $8.14 \mathrm{E}-15$ & 5.895 & 71 & 1126 & 45.56 & \pm 0.07 \\
\hline $\mathrm{F}$ & 1100 & 9.7 & 96.3 & $9.18 \mathrm{E}-15$ & 6.016 & 86 & 820 & 46.49 & \pm 0.05 \\
\hline $\mathrm{G}$ & 1150 & 8.6 & 95.8 & $8.05 \mathrm{E}-15$ & 6.072 & 85 & 1186 & 46.92 & \pm 0.06 \\
\hline $\mathrm{H}$ & 1200 & 7.2 & 95.8 & $6.81 \mathrm{E}-15$ & 6.123 & 75 & 924 & 47.30 & \pm 0.06 \\
\hline I & 1250 & 4.8 & 94.9 & $4.51 \mathrm{E}-15$ & 6.156 & 98 & 647 & 47.56 & \pm 0.08 \\
\hline $\mathrm{J}$ & 1300 & 5.0 & 91.3 & $4.76 \mathrm{E}-15$ & 6.139 & 46 & 460 & 47.43 & \pm 0.10 \\
\hline $\mathrm{K}$ & 1350 & 5.1 & 78.9 & 4.84E-15 & 6.158 & 42 & 37 & 47.57 & \pm 0.10 \\
\hline $\mathrm{L}$ & 1400 & 6.6 & 82.9 & $6.17 \mathrm{E}-15$ & 6.212 & 27 & 204 & 47.98 & \pm 0.08 \\
\hline M & 1450 & 14.3 & 89.0 & $1.35 \mathrm{E}-14$ & 6.346 & 52 & 968 & 49.00 & \pm 0.07 \\
\hline $\mathrm{N}$ & 1500 & 18.3 & 88.0 & $1.73 \mathrm{E}-14$ & 6.484 & 134 & 1175 & 50.05 & \pm 0.06 \\
\hline $\mathrm{O}$ & 1550 & 1.7 & 70.7 & $1.58 \mathrm{E}-15$ & 6.600 & 19 & 123 & 50.94 & \pm 0.21 \\
\hline \multirow[t]{2}{*}{$\mathrm{P}$} & 1650 & 0.2 & 19.9 & $1.95 \mathrm{E}-16$ & 6.900 & 3 & 5 & 53.22 & \pm 1.70 \\
\hline & & & & & & \multicolumn{2}{|c|}{ Edad gas total $=$} & 47.50 & \\
\hline
\end{tabular}

Edades calculadas asumiendo un valor inicial $\mathrm{de}^{40} \mathrm{Ar}{ }^{36} \mathrm{Ar}=295.5$.

Las estimaciones de precisión en la edad son al nivel 1-sigma.

Las edades de los pasos individuales no incluyen error en el parametro de irradiación J.

No se calcula error para la edad de gas total.

FT: Fusión total

J: Parámetro de irradiación para cuantificar el campo neutrónico al que se han expuesto las rocas dentro del reactor nuclear.

isotópico de minerales: zircón $800 \pm 50^{\circ} \mathrm{C}(\mathrm{U}-\mathrm{Pb})$, moscovita $350 \pm 25^{\circ} \mathrm{C}$ y biotita $300 \pm 40^{\circ} \mathrm{C}$. Por otro lado, y como se mencionó anteriormente, la temperatura de cierre isotópico del feldespato potásico se maneja asumiendo dos miembros finales de retención del Argón en función de sus diferentes dominios de difusión (retención); un miembro de alta retención con $250 \pm 40^{\circ} \mathrm{C}$ y otro de baja retención de 150 $\pm 40^{\circ} \mathrm{C}$.

\subsection{Historia termal del granito laramídico Sierrita Blanca}

La muestra SB07-3, recolectada a $300 \mathrm{~m}$ del contacto con el granito Murrieta (Figura 2), tiene una edad de cristalización de $69.70 \pm 0.98 \mathrm{Ma}$ (Figuras 7A, B y C) y presenta un enfriamiento relativamente rápido desde la temperatura de cierre del zircón hasta la de biotita $\left(\sim 32^{\circ} \mathrm{C} /\right.$ Ma; Figura 15A). Posteriormente, el enfriamiento fue relativamente lento $\left(\sim 9^{\circ} \mathrm{C} / \mathrm{Ma}\right)$ desde la temperatura de cierre de la biotita hasta el cierre del feldespato potásico de alta retención; siendo básicamente la misma tasa de enfriamiento $\left(\sim 9^{\circ} \mathrm{C} / \mathrm{Ma}\right)$ entre el feldespato potásico de alta y de baja retención.

Una segunda muestra de granito laramídico SB075 , que se recolectó a $100 \mathrm{~m}$ del contacto con el granito mesoproterozoico Murrieta (Figura 2), tiene una edad de cristalización U-Pb de zircones de $72.64 \pm 1.20 \mathrm{Ma}$ (Figuras $7 \mathrm{D}, \mathrm{E}$ y F), y muestra un enfriamiento relativamente rápido $\left(\sim 36^{\circ} \mathrm{C} / \mathrm{Ma}\right)$ desde la temperatura de cierre del zircón hasta la de biotita (Figura 15B). El enfriamiento desde la biotita al feldespato potásico de alta retención es bastante lento $\left(\sim 5^{\circ} \mathrm{C} / \mathrm{Ma}\right)$. Por último, el enfriamiento desde el feldespato potásico de alta al de baja retención se vuelve a incrementar hasta los $\sim 17^{\circ} \mathrm{C} / \mathrm{Ma}$.

Se observa que los enfriamientos para ambas muestras laramídicas son bastante parecidos (Figuras $15 \mathrm{~A} \mathrm{y} \mathrm{B)} \mathrm{pero}$ observamos que la biotita de la muestra SB07-5, que se encuentra más cerca del contacto con el encajonante, cierra su sistemática antes, como cabría esperar, obteniendo una edad más antigua (58.80 $\pm 0.30 \mathrm{Ma})$ para esta muestra, en contraste con la biotita que se encuentra más alejada del contacto (SB07-3) que tiene una edad de $54.31 \pm 0.13 \mathrm{Ma}$.

La muestra de pegmatita SB07-5B tiene un enfriamiento de $\sim 9^{\circ} \mathrm{C} / \mathrm{Ma}$ desde el cierre isotópico de la moscovita hasta el cierre del feldespato potásico de alta retención y una misma tasa de enfriamiento entre el feldespato de alta y baja retención (Figura 15C). Esto indicaría que la pegmatita tuvo un enfriamiento lento similar al enfriamiento estimado para los granitos laramídicos que corta. 
Tabla 5. Datos ${ }^{40} \mathrm{Ar} /{ }^{39} \mathrm{Ar}$ de calentamiento gradual por horno en espectrómetro VG-1200.

\begin{tabular}{|c|c|c|c|c|c|c|c|c|c|c|}
\hline \multirow{2}{*}{$\begin{array}{c}\text { Paso } \\
\text { SB07-7 }\end{array}$} & $\begin{array}{c}\text { Temp. } \\
{ }^{\circ} \mathrm{C}\end{array}$ & $\begin{array}{c}\%^{39} \mathrm{Ar} \\
\text { del total }\end{array}$ & $\begin{array}{c}\text { Radiogénico } \\
\text { Producido (\%) }\end{array}$ & $\begin{array}{c}{ }^{39} \mathrm{Ar}_{\mathrm{k}} \\
\text { (Moles) }\end{array}$ & ${ }^{30}{ }^{30} \mathrm{Ar}_{\mathrm{k}}$ & $\begin{array}{c}\mathrm{K} / \mathrm{Ca} \\
\text { Aparente }\end{array}$ & \multirow{2}{*}{$\begin{array}{c}\mathrm{K} / \mathrm{Cl} \\
\text { Aparente } \\
=5.0 \mathrm{mg}\end{array}$} & \multirow{2}{*}{\multicolumn{2}{|c|}{$\begin{array}{r}\text { Edad } \\
\text { Aparente }(\mathrm{Ma}) \\
146 \mathrm{KD} 49\end{array}$}} & \multirow[t]{2}{*}{$\begin{array}{l}\text { Error } \\
(\mathrm{Ma})\end{array}$} \\
\hline & \multicolumn{3}{|c|}{ Zona cizalla N Sierrita Blanca } & $\underline{\text { mica blanca }}$ & .009225 & peso $=5.0 \mathrm{mg}$ & & & & \\
\hline A & 600 & 0.3 & 10.3 & 0.0005 & 4.374 & 0.8 & 5 & & 71.37 & \pm 27.58 \\
\hline B & 700 & 0.7 & 3.6 & 0.0012 & 3.002 & 1.1 & 11 & & 49.27 & \pm 11.22 \\
\hline $\mathrm{C}$ & 750 & 1.0 & 6.9 & 0.0018 & 1.943 & 1.3 & 18 & & 32.05 & \pm 7.86 \\
\hline $\mathrm{D}$ & 800 & 1.5 & 45.9 & 0.0027 & 2.531 & 1.6 & 18 & & 41.63 & \pm 4.97 \\
\hline $\mathrm{E}$ & 825 & 1.7 & 60.4 & 0.0031 & 3.226 & 4.4 & 30 & & 52.90 & \pm 4.47 \\
\hline $\mathrm{F}$ & 850 & 3.1 & 73.1 & 0.0056 & 3.016 & 7.8 & 67 & & 49.50 & \pm 4.00 \\
\hline G & 875 & 4.5 & 57.8 & 0.0081 & 3.264 & 12.3 & 105 & & 53.51 & \pm 1.95 \\
\hline $\mathrm{H}$ & 900 & 5.9 & 17.0 & 0.0107 & 3.056 & 10.6 & 78 & & 50.16 & \pm 4.51 \\
\hline I & 925 & 6.7 & 45.7 & 0.0122 & 3.521 & 18.9 & 166 & & 57.66 & \pm 2.80 \\
\hline $\mathrm{J}$ & 950 & 7.2 & 85.6 & 0.0131 & 3.267 & 15.2 & 188 & & 53.57 & \pm 1.35 \\
\hline K & 1000 & 7.2 & 83.3 & 0.0130 & 3.138 & 13.4 & 114 & & 51.48 & \pm 1.00 \\
\hline $\mathrm{L}$ & 1050 & 6.9 & 36.2 & 0.0126 & 3.473 & 15.3 & 93 & & 56.88 & \pm 1.15 \\
\hline M & 1100 & 12.9 & 86.3 & 0.0234 & 3.397 & 21.3 & 174 & & 55.67 & \pm 0.62 \\
\hline $\mathrm{N}$ & 1150 & 17.5 & 72.2 & 0.0318 & 3.215 & 23.0 & 180 & & 52.72 & \pm 0.64 \\
\hline $\mathrm{O}$ & 1200 & 12.4 & 47.5 & 0.0225 & 3.456 & 31.5 & 7 & & 56.62 & \pm 0.61 \\
\hline $\mathrm{P}$ & 1250 & 5.9 & 60.7 & 0.0107 & 3.529 & 10.1 & 68 & & 57.79 & \pm 1.47 \\
\hline Q & 1450 & 1.9 & 15.0 & 0.0035 & 3.227 & 1.6 & 42 & & 52.92 & \pm 4.59 \\
\hline $\mathrm{R}$ & 1650 & 1.7 & 8.2 & 0.0031 & 2.942 & 1.0 & 42 & & 48.31 & \pm 4.33 \\
\hline $\mathrm{S}$ & 1650 & 1.0 & 11.6 & 0.0018 & 5.468 & 0.9 & 34 & & 88.77 & \pm 24.66 \\
\hline Gas Total & & & 59.2 & 0.1814 & 3.308 & 17.3 & 112 & & 54.22 & \\
\hline SB07-1 & Lava an & sitica Cald & ra El Pilar & oclasa & 0.00462 & $0.50 \%$ & $\rho=251.1 \mathrm{mg}$ & & $49 K D 48$ & \\
\hline A & 700 & 0.8 & 11.7 & 0.0078 & 2.652 & 0.48 & 31 & & 21.99 & \pm 1.60 \\
\hline B & 800 & 0.8 & 23.4 & 0.0080 & 2.217 & 0.55 & 39 & & 18.40 & \pm 0.94 \\
\hline $\mathrm{C}$ & 900 & 2.5 & 34.3 & 0.0253 & 1.912 & 0.40 & 50 & & 15.88 & \pm 0.39 \\
\hline $\mathrm{D}$ & 1000 & 5.1 & 46.8 & 0.0511 & 1.899 & 0.20 & 70 & & 15.77 & \pm 0.14 \\
\hline $\mathrm{E}$ & 1100 & 7.3 & 62.4 & 0.0731 & 2.039 & 0.11 & 124 & & 16.93 & \pm 0.16 \\
\hline $\mathrm{F}$ & 1150 & 5.5 & 71.7 & 0.0553 & 2.068 & 0.08 & 229 & & 17.17 & \pm 0.67 \\
\hline G & 1200 & 7.4 & 77.5 & 0.0743 & 2.084 & 0.07 & 478 & & 17.30 & \pm 0.81 \\
\hline $\mathrm{H}$ & 1250 & 27.4 & 75.5 & 0.2740 & 2.030 & 0.07 & 454 & & 16.85 & \pm 0.36 \\
\hline I & 1300 & 13.8 & 79.9 & 0.1375 & 2.089 & 0.07 & 449 & & 17.34 & \pm 0.08 \\
\hline $\mathrm{J}$ & 1350 & 8.7 & 74.5 & 0.0874 & 2.089 & 0.07 & 241 & & 17.34 & \pm 0.11 \\
\hline $\mathrm{K}$ & 1450 & 8.2 & 69.6 & 0.0820 & 2.215 & 0.08 & 197 & & 18.38 & \pm 0.16 \\
\hline $\mathrm{L}$ & 1650 & 10.3 & 72.0 & 0.1029 & 2.165 & 0.07 & 268 & & 17.97 & \pm 0.09 \\
\hline M & 1650 & 2.0 & 50.9 & 0.0204 & 2.074 & 0.07 & 229 & & 17.22 & \pm 0.46 \\
\hline Gas Total & & & 70.2 & 0.9990 & 2.077 & 0.10 & 318 & & 17.24 & \\
\hline $62.9 \%$ del & gas en lo & pasos del p & teau entre los pa & s $1150-1350$ & & Edad & de Meseta $=$ & & 17.32 & \pm 0.10 \\
\hline SB07-1 & Lava an & sítica Cald & ra El Pilar & iz volcánica & $J=0.0$ & $60 \pm 0.50 \%$ & peso $=245$. & $m g$ & \#145KD4 & \\
\hline $\mathrm{A}$ & 700 & 26.7 & 28.1 & 0.7562 & 2.132 & 4.20 & 54 & & 16.69 & \pm 0.42 \\
\hline B & 750 & 14.1 & 65.0 & 0.3999 & 2.336 & 3.15 & 39 & & 18.28 & \pm 1.03 \\
\hline $\mathrm{C}$ & 800 & 11.5 & 62.9 & 0.3265 & 2.340 & 2.19 & 62 & & 18.31 & \pm 0.15 \\
\hline $\mathrm{D}$ & 850 & 9.3 & 58.5 & 0.2617 & 2.292 & 1.34 & 65 & & 17.93 & \pm 0.13 \\
\hline $\mathrm{E}$ & 900 & 8.6 & 54.5 & 0.2419 & 2.313 & 0.88 & 66 & & 18.10 & \pm 0.07 \\
\hline $\mathrm{F}$ & 950 & 8.0 & 51.2 & 0.2255 & 2.342 & 0.71 & 65 & & 18.33 & \pm 0.09 \\
\hline G & 1000 & 6.9 & 48.6 & 0.1959 & 2.366 & 0.62 & 63 & & 18.52 & \pm 0.18 \\
\hline $\mathrm{H}$ & 1050 & 5.2 & 44.8 & 0.1457 & 2.290 & 0.57 & 61 & & 17.93 & \pm 0.10 \\
\hline I & 1100 & 3.3 & 42.9 & 0.0924 & 2.306 & 0.46 & 56 & & 18.04 & \pm 0.24 \\
\hline $\mathrm{J}$ & 1150 & 1.9 & 37.6 & 0.0548 & 2.192 & 0.30 & 44 & & 17.16 & \pm 0.24 \\
\hline $\mathrm{K}$ & 1200 & 1.2 & 28.2 & 0.0335 & 2.173 & 0.20 & 29 & & 17.01 & \pm 1.63 \\
\hline $\mathrm{L}$ & 1250 & 1.0 & 28.1 & 0.0276 & 1.930 & 0.16 & 36 & & 15.12 & \pm 3.01 \\
\hline $\mathrm{M}$ & 1450 & 1.7 & 13.3 & 0.0481 & 1.118 & 0.17 & 32 & & 8.77 & \pm 3.73 \\
\hline $\mathrm{N}$ & 1650 & 0.6 & 22.5 & 0.0175 & 2.556 & 0.14 & 41 & & 19.99 & \pm 0.85 \\
\hline Gas Total & & & 46.9 & 2.8272 & 2.247 & 2.18 & 56 & & 17.59 & \\
\hline
\end{tabular}

Edades calculadas asumiendo un valor inicial $\mathrm{de}^{40} \mathrm{Ar}{ }^{36} \mathrm{Ar}=295.5$.

Las estimaciones de precisión en la edad son al nivel 1-sigma.

Las edades de los pasos individuales no incluyen error en el parametro de irradiación J.

No se calcula error para la edad de gas total.

J: Parámetro de irradiación, para cuantificar el campo neutrónico de las rocas 


\section{Granitos Sierrita Blanca}
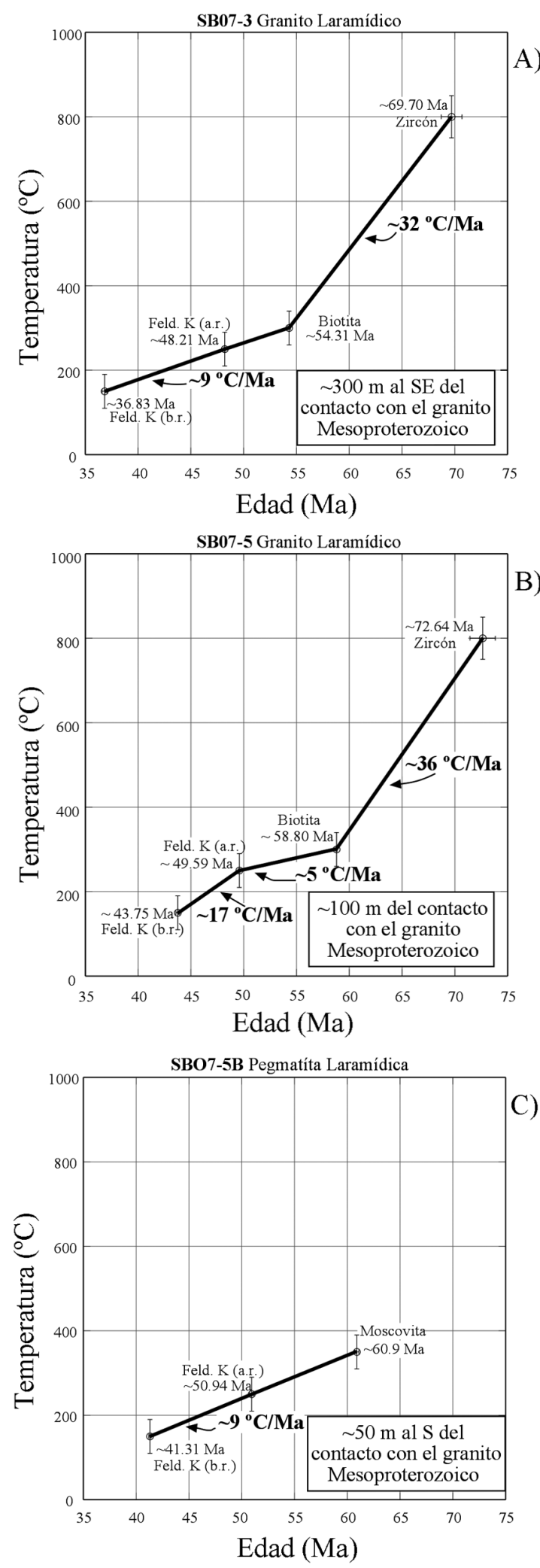

Granitos Murrieta
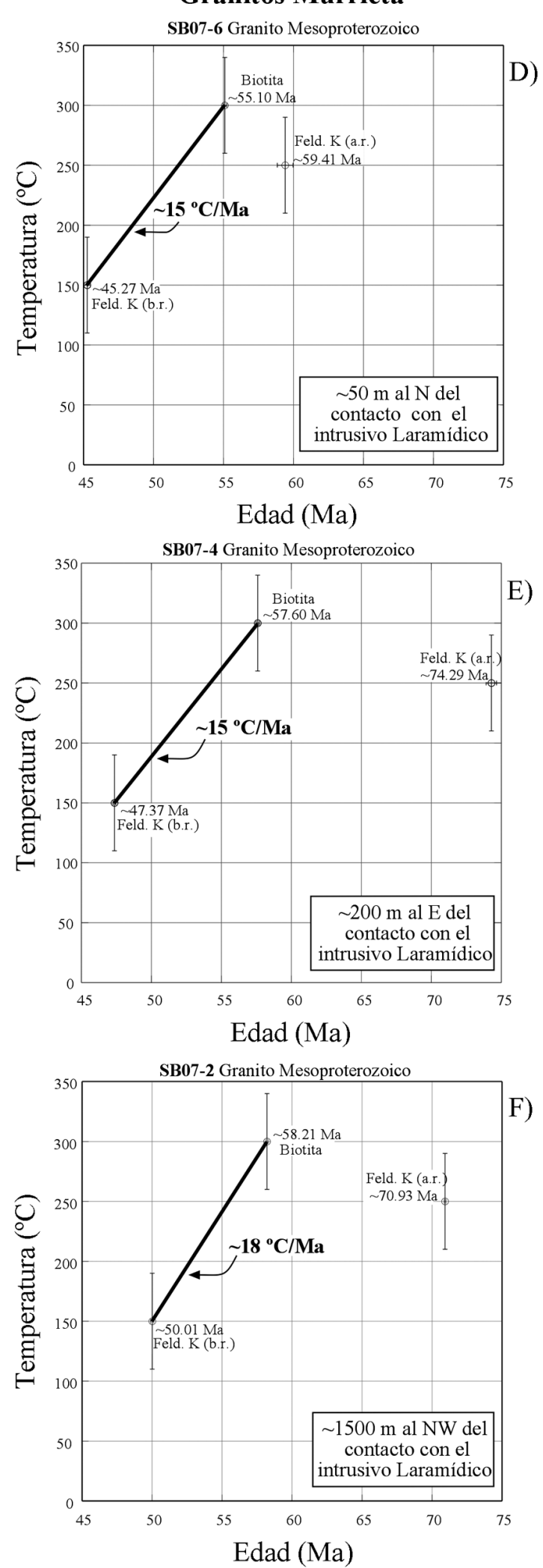

Figura 15. Curvas semi-cuantitativas de enfriamiento a partir de datos geocronológicos de U-Pb en zircones $\mathrm{y}^{40} \mathrm{Ar} /{ }^{39} \mathrm{Ar}$ en diferentes minerales para rocas graníticas de la Sierrita Blanca. A, B y C) Termocronología de los granitos laramídicos Sierrita Blanca, incluyendo una pegmatita tardimagmática de aproximadamente la misma edad ( $\sim 61 \mathrm{Ma}$, moscovita). D, E y F) Termocronología de granitos mesoproterozoicos Murrieta. En cada uno de los gráficos se indica la velocidad de enfriamiento entre varios pares minerales (ej., biotita-feldespato), y a que distancia fueron recolectadas las muestras con respecto al contacto intrusivo-encajonante. 
Tabla 6. Tasas de enfriamiento para granitoides cretácicos de NW de México.

\begin{tabular}{|c|c|c|c|}
\hline Muestra & Par Mineral & Tasa de Enfriamiento & Referencia \\
\hline \multicolumn{4}{|c|}{ Rocas Sierrita Blanca, $N W$ de Sonora } \\
\hline \multirow[t]{2}{*}{ SB07-3 } & Zircón-Biotita & $\sim 32^{\circ} \mathrm{C} / \mathrm{Ma}$ & 1) \\
\hline & Biotita-Feld. K (b.r.) & $\sim 9^{\circ} \mathrm{C} / \mathrm{Ma}$ & 1) \\
\hline \multirow[t]{3}{*}{ SB07-5 } & Zircón-Biotita & $\sim 36^{\circ} \mathrm{C} / \mathrm{Ma}$ & 1) \\
\hline & Biotita-Feld. K (a.r.) & $\sim 5^{\circ} \mathrm{C} / \mathrm{Ma}$ & 1) \\
\hline & Feld. K (a.r.)-Feld. K (b.r.) & $\sim 17^{\circ} \mathrm{C} / \mathrm{Ma}$ & 1) \\
\hline SB07-5B & Muscovita-Feld. K (b.r.) & $\sim 9^{\circ} \mathrm{C} / \mathrm{Ma}$ & 1) \\
\hline SB07-2* & Biotita-Feld. K (b.r.) & $\sim 18^{\circ} \mathrm{C} / \mathrm{Ma}$ & 1) \\
\hline SB07-4* & Biotita-Feld. K (b.r.) & $\sim 15^{\circ} \mathrm{C} / \mathrm{Ma}$ & 1) \\
\hline SB07-6* & Biotita-Feld. K (b.r.) & $\sim 15^{\circ} \mathrm{C} / \mathrm{Ma}$ & 1) \\
\hline \multicolumn{4}{|c|}{ Rocas Batolito Costero de Sonora } \\
\hline \multirow[t]{3}{*}{ K1-03-03 } & Zircón-Biotita & $\sim 85^{\circ} \mathrm{C} / \mathrm{Ma}$ & 2) \\
\hline & Biotita-Feld. K (a.r.) & $\sim 12^{\circ} \mathrm{C} / \mathrm{Ma}$ & 2) \\
\hline & Feld. K (a.r.)-Feld. K (b.r.) & $\sim 36^{\circ} \mathrm{C} / \mathrm{Ma}$ & 2) \\
\hline \multirow[t]{3}{*}{ K1-03-07 } & Zircón-Biotita & $\sim 51^{\circ} \mathrm{C} / \mathrm{Ma}$ & 2) \\
\hline & Biotita-Feld. K (a.r.) & $\sim 6^{\circ} \mathrm{C} / \mathrm{Ma}$ & 2) \\
\hline & Feld. K (a.r.)-Feld. K (b.r.) & $\sim 4^{\circ} \mathrm{C} / \mathrm{Ma}$ & 2) \\
\hline \multirow[t]{3}{*}{ K1-03-15 } & Zircón-Biotita & $\sim 36^{\circ} \mathrm{C} / \mathrm{Ma}$ & 2) \\
\hline & Biotita-Feld. K (a.r.) & $\sim 10^{\circ} \mathrm{C} / \mathrm{Ma}$ & 2) \\
\hline & Feld. K (a.r.)-Feld. K (b.r.) & $\sim 11^{\circ} \mathrm{C} / \mathrm{Ma}$ & 2) \\
\hline \multicolumn{4}{|c|}{ Rocas Baja California } \\
\hline \multirow[t]{4}{*}{ DLC-10 } & Horblenda-Biotita & $\sim 87^{\circ} \mathrm{C} / \mathrm{Ma}$ & 3) \\
\hline & Biotita-Feld. K (a.r.) & $\sim 15^{\circ} \mathrm{C} / \mathrm{Ma}$ & 3) \\
\hline & Biotita-Feld. K (b.r.) & $\sim 19^{\circ} \mathrm{C} / \mathrm{Ma}$ & 3) \\
\hline & Feld. K (a.r.)-Feld. K (b.r.) & $\sim 22^{\circ} \mathrm{C} / \mathrm{Ma}$ & 3) \\
\hline San Pedro Martir & Zircón-Biotita & $\sim 40^{\circ} \mathrm{C} / \mathrm{Ma}$ & 4) \\
\hline \multicolumn{4}{|c|}{ 1) Datos de este trabajo. } \\
\hline \multicolumn{4}{|c|}{$\begin{array}{l}\text { 2) Tasas de enfriamiento calculadas a partir de datos tomados de Ramos-Velázquez et } \\
\text { al. (2008). Las temperaturas de cierre isotópico utilizadas en este artículo son iguales } \\
\text { a las reportadas en este trabajo. }\end{array}$} \\
\hline \multicolumn{4}{|c|}{$\begin{array}{l}\text { 3) Tasas de enfriamiento calculadas a partir de datos tomados de Iriondo et al. (2003). } \\
\text { Utilizando las temperaturas de cierre isotópico reportadas en este trabajo. }\end{array}$} \\
\hline \multicolumn{4}{|c|}{ 4) Tasa de enfriamiento tomada de Ortega-Rivera et al . (1997). } \\
\hline \multicolumn{4}{|c|}{$\begin{array}{l}\text { Feld. K (a.r): Feldespato potásico de alta retención. } \\
\text { Feld. K (b.r): Feldespato potásico de baja retención. }\end{array}$} \\
\hline
\end{tabular}

Se aprecia que los enfriamientos calculados para estas rocas graníticas laramídicas de la Sierrita Blanca tienen similitudes con algunos de los anteriormente estimados para rocas de edades similares (Tabla 6) en la zona NE de Baja California (Ortega-Rivera et al., 1997; Ortega-Rivera, 2003; Iriondo et al., 2003b) y en la zona costera de Sonora (Ramos-Velázquez et al., 2008). Sin embargo, se aprecia una tendencia a que los enfriamientos para granitoides de Baja California, y algunos más antiguos de la zona costera de Sonora, son mucho más rápidos, sobre todo en los primeros estadios de enfriamiento entre la temperatura de cierre del zircón y la biotita y entre la hornblenda y la biotita, donde se alcanzan enfriamientos de hasta $\sim 87^{\circ} \mathrm{C} / \mathrm{Ma}$ (Iriondo et al., 2003b; Ramos-Velázquez et al., 2008) que contrastan fuertemente con los enfriamientos estimados de $\sim 36^{\circ} \mathrm{C} / \mathrm{Ma}$ para las rocas graníticas de Sierrita Blanca. Esto puede ser el resultado de que el frente del arco magmático Cretácico en Baja California y en la zona costera de Sonora se desplazara más rápidamente hacia el $\mathrm{E}$ del continente según progresaba la subducción en el NW de México (ej., Valencia-Moreno et al., 2006). Este desplazamiento (alejamiento) rápido del frente magmático podría resultar en una disminución rápida del gradiente geotérmico que permitiría el enfriamiento rápido de los cuerpos graníticos en los primeros estados de enfriamiento desde la temperatura de cierre del zircón a $\sim 800^{\circ} \mathrm{C}$ hasta los $\sim 300^{\circ} \mathrm{C}$ de la biotita. De la misma manera, el gradiente geotérmico más elevado que presentaría la zona del NW de Sonora, donde se encuentra la Sierrita Blanca, sugeriría enfriamientos más lentos de los cuerpos graníticos. De hecho los enfriamientos calculados en este estudio desde los $\sim 800^{\circ} \mathrm{C}$ a los $\sim 150^{\circ} \mathrm{C}$ sugerirían que el granito Sierrita Blanca necesitó de $\sim 35$ Ma para enfriarse desde los $\sim 72 \mathrm{Ma}$ (edad U-Pb de la muestra SB07-5) hasta los $\sim 37$ $\mathrm{Ma}$ (edad del feldespato de baja temperatura de la muestra SB07-3). Básicamente, este es el tiempo de duración y el rango estimado de edades ( 75-40 Ma) de la orogenia laramide en el NW de Sonora (ej., Iriondo et al., 2005), por lo que se demuestra que el magmatismo y la deformación/ metamorfismo en esta región están íntimamente ligados a este evento orogénico.

La diferencia de edades de cristalización entre las dos muestras laramídicas pudiera estar asociada al enfriamiento preferencial (más rápido) del magma en la zona de contacto con el encajonante mesoproterozoico. Esta interpretación es apoyada por los resultados geocronológicos U-Pb de una muestra de granito laramídico, en la parte sur de la Sierrita Blanca (Izaguirre-Pompa, 2009), algo alejada del encajonante mesoproterozoico $(\sim 150 \mathrm{~m})$, cuya edad en zircones de $69.7 \pm 1.3 \mathrm{Ma}$ es indistinguible de la edad de la muestra SB07-3. Sin embargo, no se puede descartar que esta unidad granítica esté compuesta por múltiples intrusiones relativamente espaciadas en el tiempo, como lo sugieren estudios recientes sobre el ensamblado de cuerpos plutónicos en la Cordillera Norte Americana que se estima puedan ensamblarse en periodos incluso superiores a los $10 \mathrm{Ma}$ (ej., Glazner et al., 2004; Coleman et al., 2004). Por último, destacar que las edades de cristalización U-Pb del granito Sierrita Blanca, son similares a las edades reportadas para granitos laramídicos del NW de Sonora (ej., Iriondo, 2001; Nourse et al., 2005; Jacques-Ayala et al., 2008).

6.2. El granito mesoproterozoico Murrieta y los efectos termales recibidos durante el pulso magmático laramídico

En las tres muestras de granito mesoproterozioco Murrieta analizadas por geocronología U-Pb en zircones se obtuvo, dentro de los límites de error (2 sigma), básicamente la misma edad $(1106 \pm 14 \mathrm{Ma}, 1108 \pm 18$ Ma y $1098 \pm 19$ Ma; ver Tabla 1). El fechamiento del dique de anortosita de la Sierrita Blanca, que corta al granito Murrieta (Figura 
$3 \mathrm{C})$, arrojó una edad ${ }^{207} \mathrm{~Pb} /{ }^{206} \mathrm{~Pb}$ de $1065 \pm 69 \mathrm{Ma}$.

El granito mesoproterozoico Murrieta $(\sim 1.1 \mathrm{Ga})$ se asocia a un pulso magmático presente en el NW de Sonora que se caracteriza por tener miembros graníticos y anortosíticos (magmatismo bimodal; Iriondo et al., 2008). Ocurrencias de estos intrusivos graniticos se tienen en diferentes zonas de Sonora, pero las únicas que están fechadas por $\mathrm{U}-\mathrm{Pb}$ en zircones son las de Quitovac, justo al NE de Sierrita Blanca (Iriondo et al., 2004b), Sierra Los Tanques (Iriondo et al., 2008) y Rancho Aibó (Iriondo et al., 2003a; Farmer et al., 2003; Anderson y Silver, 2005). Manifestaciones de anortositas están presentes en la Sierra Prieta al oeste de la Sierrita Blanca (Izaguirre e Iriondo, 2007) y en El Tecolote, en la región del Rancho Bámuri más hacia el centro sur de Sonora (Espinoza et al., 2003). Así, el granito Murrieta y la anortosita Sierrita Blanca forman parte de esta suite bimodal mesoproterozoica que está asociada espacialmente a las rocas de la provincia paleoproterozoica Yavapai presente en el NW de Sonora (Iriondo y Premo, 2003; Iriondo et al., 2004b, 2008).

A pesar de haber podido obtener la edad de cristalización $\mathrm{U}-\mathrm{Pb}$ de zircones de estas muestras mesoproterozoicas del granito Murrieta, los efectos termales del intrusivo laramídico en estas rocas son evidentes. Algunos de los zircones muestran una pérdida de $\mathrm{Pb}$ que podría estar asociada a la exposición de estas rocas encajonantes al calor y/o fluidos relacionados a la intrusión laramídica. Este reajuste termal de la sistemática de algunos de los zircones es más notorio en la roca recolectada cerca del contacto con la intrusión (SB07-6; Figura 2), y al alejarnos de este, se observa una disminución paulatina de estos efectos, hasta llegar a la muestra con zircones totalmente concordantes y sin ningún tipo de evidencia de pérdida de $\mathrm{Pb}$ (SB07-2; Figura 2). Todas las edades de intersección inferior (Figura 5) para las rocas mesoproterozoicas de la Sierrita Blanca, dentro de los límites de error reportados, podrían explicarse con el evento magmático laramídico de reajuste isotópico.

Las muestras del granito Murrieta también presentan un claro rejuvenecimiento (reajuste isotópico) de las edades ${ }^{40} \mathrm{Ar} /{ }^{39} \mathrm{Ar}$ tanto de la biotita como del feldespato potásico al acercarnos al contacto con el granito laramídico. Las velocidades de enfriamiento calculadas entre la temperatura de cierre isotópico de la biotita y la del feldespato potásico de baja retención para las diferentes muestras son similares entre si, y representan una tasa de enfriamiento de $\sim 15-18^{\circ} \mathrm{C} / \mathrm{Ma}$ (Figuras 15D, E y F). El feldespato de alta retención para estas rocas tiene edades demasiado elevadas (más altas que la biotita) por lo que se supone que el reajuste isotópico durante el evento térmico no ha sido completo.

En líneas generales, este enfriamiento entre biotita y feldespato potásico de baja retención para el granito Murrieta es ligeramente más rápido $\left(\sim 15-18^{\circ} \mathrm{C} / \mathrm{Ma}\right)$ que las estimaciones de tasas de enfriamiento para el intrusivo laramídico Sierrita Blanca $\left(\sim 9-10^{\circ} \mathrm{C} / \mathrm{Ma}\right)$. Sin embargo, a grandes rasgos, el enfriamiento general de área de Sierrita Blanca, fue relativamente coherente, finalizando aparentemente en las zonas más internas del intrusivo laramídico representado, en este caso, por la muestra SB073 (Figura 2).

El resultado obtenido para el estudio del efecto termal de la intrusión laramídica Sierrita Prieta en su encajonate mesoproterozoico (granito Murrieta) sigue un esquema coherente, el esperado, y se compara perfectamente con estudios clásicos de metamorfismo de contacto como el estudio de Hart (1964) y Berger (1975) en el que evaluaron el efecto termal de la aureola de contacto del intrusivo terciario Eldora en su encajonate precámbrico (Fm. Idaho Springs) utilizando diferentes técnicas geocronológicas. Los estudios de $\mathrm{K}-\mathrm{Ar}$ de estas rocas de Colorado, en hornblenda, biotita y feldespato potásico, ilustraron los efectos de pérdida de $\mathrm{Ar}$ a diferentes distancias desde el punto de contacto y pudieron concluir que la fracción de Ar pérdida por cada mineral decrece en función de la distancia al intrusivo pudiéndose apreciar que los diferentes minerales tienen diferentes propiedades de retención del Argón radiogénico (temperaturas de cierre).

Finalmente, destacar que el reajuste isotópico laramídico de la sistemática ${ }^{40} \mathrm{Ar} /{ }^{39} \mathrm{Ar}$ de las rocas encajonates mesoproterozoicas de Sierrita Blanca ilustra muy bien la problemática de utilizar esta técnica geocronológica para determinar la edad de cristalización de rocas plutónicas. En muchas ocasiones las edades de enfriamiento han sido consideradas como aproximaciones a la edad de cristalización, y como se ha mostrado para el granito mesoproterozoico Murrieta, este podría confundirse con un intrusivo laramídico por su edad ${ }^{40} \mathrm{Ar}{ }^{39} \mathrm{Ar}$ en biotita y feldespato potásico.

\subsection{Posibles efectos termales post-laramídicos en la Sierrita Blanca}

Por último, en este estudio de historia termal, se aprecia que el pulso magmático miocénico, representado por lavas andesíticas asociadas al vulcanismo de la Caldera El Pilar en Quitovac (Iriondo et al., 1996), no tuvo ningún efecto termal significativo en las rocas graníticas estudiadas, tanto laramídicas como mesoproterozoicas. A pesar de la gran envergadura de este pulso magmático, como queda manifestado en la Caldera El Pilar (Iriondo et al. 1996), lo más probable es que estas rocas graníticas laramídicas y mesoproterozoicas ya habrían sido exhumadas antes del inicio de este pulso magmático miocénico. La edad de la andesita de Sierrita Blanca de 17.32 \pm 0.10 Ma es similar a las edades reportadas en Quitovac para una colada (17.72 $\pm 0.07 \mathrm{Ma})$ y para un dique $(17.37 \pm 0.07 \mathrm{Ma})$, ambos de composición andesítica (Iriondo et al., 1996; Iriondo, 2001). Estas son rocas calcoalcalinas asociadas a los últimos estadios de subducción de la placa Farallón debajo de la placa Norte Americana en el NW de México (Iriondo et al., 1996). 


\section{Conclusiones y Recomendaciones}

7.1. Edad de cristalización de granitoides de la Sierrita Blanca

Las dos muestras del granito laramídico Sierrita Blanca presentan edades diferentes de cristalización determinadas a partir de geocronología U-Pb en zircones. Estas parecen variar de acuerdo a la distancia que existe con el contacto con las rocas encajonantes. Algunos de los zircones de estas muestras laramídicas presentan evidencias de herencia del Paleoproterozoico y Mesoproterozoico y su procedencia podría fácilmente explicarse con las rocas del Proterozoico existentes en el NW de Sonora.

Se recomienda realizar más fechamientos $\mathrm{U}-\mathrm{Pb}$ para rocas laramídicas de la Sierrita Blanca a fin de discernir si existen varios intrusivos laramídicos con edades contrastantes o bien si estas diferencias en las edades son únicamente el resultado del enfriamiento diferencial del cuerpo granítico desde sus zonas externas a las más internas.

\subsection{Enfriamiento del granito laramídico de la Sierrita} Blanca

Los resultados de historia termal a partir de técnicas geocronológicas U-Pb y ${ }^{40} \mathrm{Ar} /{ }^{39} \mathrm{Ar}$ en la Sierrita Blanca sugieren que los enfriamientos de las rocas graníticas laramídicas han sido relativamente lentos, quizá en parte por los grandes volúmenes magmáticos que representan estas rocas en el NW de México.

De acuerdo con las determinaciones de ${ }^{40} \mathrm{Ar} /{ }^{39} \mathrm{Ar}$ en biotitas y feldespatos potásicos, se observa un enfriamiento monotónico del granito laramídico que inicialmente es relativamente rápido $\left(\sim 36-32^{\circ} \mathrm{C} / \mathrm{Ma}\right)$, aunque en los últimos estadios del enfriamiento el proceso es relativamente lento $\left(\sim 10-9^{\circ} \mathrm{C} / \mathrm{Ma}\right)$. Estos enfriamientos son comparables, aunque quizá un poco más lentos, a los estimados para granitoides laramídicos de otras zonas del NW de México.

Se recomienda intentar reproducir las curvas de enfriamiento con otras muestras de diferentes partes de la Sierrita Blanca. También hacerlo a nivel más regional incluyendo otros intrusivos de supuesta edad laramídica pero quizá de composiciones algo diferentes que pudieran tener mineralogías más variadas, como hornblenda o mica blanca, con el fin de concretar mejor los estadios iniciales del enfriamiento por tener estos minerales temperaturas de cierre isotópico superiores a las de la biotita y el feldespato potásico.

\subsection{Reajuste isotópico laramídico y posterior} enfriamiento del granito Murrieta

Los estudios sobre el efecto termal de los granitos laramídicos en las rocas encajonantes de la Sierrita Blanca que se presentan en este trabajo, son pioneros en México y quizá representan uno de los estudios termocronológicos de carácter semi-cuantitativo más completos para esta fenomenología del reajuste isotópico por el calor asociado a intrusiones graníticas, por realizarse de forma sistemática y utilizando dos sistemáticas isotópicas diferentes (U-Pb y $\left.{ }^{40} \mathrm{Ar} /{ }^{39} \mathrm{Ar}\right)$.

Para las muestras de granito Murrieta $(\sim 1.1 \mathrm{Ga})$ existe un claro rejuvenecimiento tanto de las edades ${ }^{40} \mathrm{Ar} /{ }^{39} \mathrm{Ar}$ de biotita como del feldespato potásico de baja retención según se esté más cerca del granito laramídico de Sierrita Blanca, en donde la sistemática de estos minerales se cierra más tarde al perdurar más el calor asociado al cuerpo ígneo. Estos efectos termales también se aprecian, en menor medida, en la sistemática U-Pb donde se observa pérdida $\mathrm{de} \mathrm{Pb}$ en algunos de los zircones que atribuimos al calor de la intrusión además de que también pueda deberse a la presencia de fluidos calientes en la zona de contacto, como lo evidencia la gran cantidad de pegmatitas laramídicas y la alteración penetrante de la roca encajonante en esa zona.

Las estimaciones de enfriamiento del granito mesoproterozoico Murrieta entre la biotita y feldespato potásico de $\sim 18-15^{\circ} \mathrm{C} / \mathrm{Ma}$ (después de su reajuste laramídico) son, en cierto modo, armónicas con los enfriamientos estimados para estos mismos minerales en las muestras de granito laramídico. Esto sugiere que el enfriamiento general del área de la Sierrita Blanca, después de la intrusión granítica laramídica, fue coherente, finalizando este en las zonas más internas del intrusivo Sierrita Blanca.

Se sugiere iniciar un estudio regional sobre los efectos termales de los magmas laramídicos en las rocas encajonantes para poder cuantificar los efectos del reajuste isotópico a mayor escala. Por otro lado, se recomienda realizar estudios de geoquímica (mayores y trazas) e isótopos ( $\mathrm{Sm}-\mathrm{Nd}$ principalmente) del granito Murrieta para ponerlo en la perspectiva de los estudios del basamento proterozoico del NW de Sonora que se están realizando actualmente.

\subsection{Efectos termales post-laramídicos en la Sierrita Blanca}

Las rocas andesíticas de la parte norte de la Sierrita Blanca, las cuales se cree están relacionadas a un pulso magmático miocénico de gran magnitud presente en la región (Caldera El Pilar), no tuvieron ningún efecto termal significativo en las rocas graníticas laramídicas o mesoproterozoicas estudiadas. Lo más probable es que estas rocas graníticas ya habrían sido exhumadas antes de la existencia de este pulso magmático miocénico.

Se recomienda fechar diques andesíticos, supuestamente miocénicos, que intruyen al granito laramídico Sierrita Blanca para evaluar si cerca de los mismos existió reajuste (rejuvenecimiento) de la sistemática ${ }^{40} \mathrm{Ar} /{ }^{39} \mathrm{Ar}$ de la roca encajonante laramídica y evaluar, recolectando muestras a distintas distancias del dique(s), hasta que distancia de los mismos se aprecian sus efectos termales. Por otro lado, la 
obtención de análisis geoquímicos de elementos mayores, traza e isotópicos serían importantes para determinar el origen de éstos magmas y la potencial participación o no de la placa Farallón en su generación.

\section{Agradecimientos}

La primera autora de este artículo agradece a la Universidad Nacional Autónoma de México (UNAM), en particular al Centro de Geociencias (CGEO) en el Campus Juriquilla, Querétaro, por permitirle el uso de sus instalaciones para llevar a cabo este trabajo. Agradecemos a los proyectos científicos PAPIIT (Clave IN113906) y CONACYT (Clave 52163) otorgados al Dr. Iriondo por apoyarnos con una beca de estudios y en la realización de las determinaciones geocronológicas. De igual manera, se le agradece a la compañía Servicios Industriales Peñoles, S. A. de C. V. por el apoyo logístico dado durante la realización del trabajo de campo en la Sierrita Blanca. Un especial agradecimiento a los estudiantes Andrés Velázquez, Aldo Izaguirre y Harim Arvizu por su valiosa ayuda en el transcurso de la elaboración de la cartografía geológica y la separación de minerales para estudios geocronológicos. Un agradecimiento también a Juan Tomás Vásquez por su ayuda en la elaboración de las secciones delgadas en el Laboratorio de Laminación del CGEO. Agradecemos el apoyo de George Gehrels y Víctor Valencia para la obtención de los datos de U-Pb en el Laboratorio LaserChron de la Universidad de Arizona en Tucson, Arizona. También estamos muy agradecidos con Ryan McAleer por su paciencia y apoyo en nuestra estancia en el Laboratorio de Termocronología ${ }^{40} \mathrm{Ar} /{ }^{39} \mathrm{Ar}$ del U.S. Geological Survey en Reston, Virginia. De igual manera, agradecemos a Dan Miggins y Heather Lowers del U.S. Geological Survey en Denver, Colorado, por su ayuda en la obtención de las imágenes de cátodoluminiscencia (SEM-CL) de los zircones. Por último, agradecemos a Margarita LópezMartínez y a dos revisores anónimos por sus sugerencias para mejorar sustancialmente el manuscrito.

\section{Referencias}

Alexander, E.C., Jr., Mickelson, G.M., Lanphere, M.A., 1978, Mmhb-1: a new ${ }^{40} \mathrm{Ar} /{ }^{39} \mathrm{Ar}$ dating standard, en Zartman, R.E., (ed.), Short papers of the Fourth International Conference, Geochronology, Cosmochronology, and Isotope Geology: U.S. Geological Survey, Open-File Report, 78-701, 6-8.

Anderson, T.H., Schmidt, V.A., 1983, The evolution of Middle America and the Gulf of Mexico-Caribbean Sea region during Mesozoic time: Geological Society of America Bulletin, 94, 94-966.

Anderson, T.H., Silver, L.T., 1977, Geochronometric and stratigraphic outlines of the Precambrian rocks of northwestern Mexico: Geological Society of America Abstracts with Programs, 9, 880.

Anderson, T.H., Silver, L.T., 1978, The nature and extent of Precambrian rocks in Sonora, Mexico [abs.], en Roldán-Quintana, J., Salas, G.A., (eds.), Primer Simposio sobre la Geología y Potencial Minero en el Estado de Sonora, Hermosillo, Resúmenes: Instituto de Geología,
Universidad Nacional Autónoma de México, 9-10.

Anderson, T.H., Silver, L.T., 1979, The role of the Mojave-Sonora Megashear in the tectonic evolution of northern Mexico, en Anderson, T.H., Roldán-Quintana, J., (eds.), Geology of northern Sonora: Hermosillo, Universidad Nacional Autónoma de México, Instituto de Geología, 59-68.

Anderson, T.H., Silver, L.T., 2005, The Mojave-Sonora Megashear: Field and analytical studies leading to the conception and evolution of the hypothesis, en Anderson, T.H., Nourse, J.A., McKee, J.W., Steiner, M.B., (eds.), The Mojave-Sonora megashear hypothesis: Development, assessment, and alternatives: Geological Society of America Special Paper 393, 1-50.

Berger, G.W., $1975,{ }^{40} \mathrm{Ar} /{ }^{39} \mathrm{Ar}$ step heating of thermally overprinted biotite, hornblende and potassium feldspar from Eldora, Colorado: Earth and Planetary Science Letters, 26, 387-408.

Campbell, P.A., Anderson, T.H., 2003, Structure and kinematics along a segment of the Mojave-Sonora megashear: A strike-slip fault that truncates the Jurassic continental magmatic arc of southwestern North America: Tectonics, 22(6), 1-21.

Cebula, G.T., Kunk, M.J., Mehnert, H.H., Naeser, C.W., Obradovich, J.D., Sutter, J.F., 1986, The Fish Canyon Tuff: A potential standard for the ${ }^{40} \mathrm{Ar} /{ }^{39} \mathrm{Ar}$ and fission track dating methods: Terra Cognita, 6(2), 139-140.

Cerca, M., 2004, Deformación y magmatismo Cretácico tardío - Terciario temprano en la zona de la Plataforma Guerrero Morelos: Tesis Doctoral, Universidad Nacional Autónoma de México, Centro de Geociencias, Posgrado en Ciencias de la Tierra, 175 p., 1 mapa.

Chávez-Cabello, G., 2005, Deformación y mecanismos cenozoicos en el sur de la cuenca de Sabinas, Coahuila, México: Tesis Doctoral, Universidad Nacional Autónoma de México, Centro de Geociencias, Posgrado en Ciencias de la Tierra, $313 \mathrm{p}$.

Coleman, D.S., Gray, W., Glazner, A.F., 2004, Rethinking the emplacement and evolution of zoned plutons: Geochronologic evidence for incremental assembly of the Tuolumne Intrusive Suite, California: Geology, 32(5), 433-436.

Coney, P.J., 1976, Plate tectonics and the Laramide orogeny, en Woodward, L.A., Northrop, S.A., (eds.), Tectonics and Mineral Resources of Southwestern North America: New Mexico Society Special Publication, 6, 5-10.

Cooper, G.A., Arellano, A.R.V., 1946, Stratigraphy near Caborca, northwest Sonora, Mexico: American Association of Petroleum Geologists Bulletin, 30(4), 606-610.

Dalrymple, G.B., Alexander, E.C., Lanphere, M.A., Kraker, G.P., 1981, Irradiation of samples for ${ }^{40} \mathrm{Ar} /{ }^{39} \mathrm{Ar}$ dating using the Geological Survey TRIGA reactor: U.S. Geological Survey Professional Paper, $1176,55 \mathrm{p}$.

Damon, P.E., Livingston, D.E., Giletti, B.J., 1961, Extension of the older Precambrian of the southwest into Sonora, Mexico: Geological Society of America Abstracts with Programs, 68, 158-159.

Damon, P.E., Livingston, D.E., Mauger, R.L., Gilletti, B.J., Alor, P., 1962, Edad del Precámbrico Anterior y de otras rocas del zócalo de la región de Caborca-Altar de la parte noroccidental del Estado de Sonora: Boletín Instituto de Geología, Universidad Nacional Autónoma de México, 64, 11-64.

Damon, P.E., Mauger R.L., Bikerman M., 1964, K-Ar dating of Laramide plutonic and volcanic rocks within the Basin and Range province of Arizona and Sonora, en Sastry, M.V.A., Bhatia, S.B., (eds.), Cretaceous-Tertiary Boundary Including Volcanic Activity: 22th IGC, India, Part 3 Proccedings of Section 3, 45-55.

Deino, A.L., 2001, Users manual for Mass Spec 5.02: Berkeley Geochronology Center Special Publication, 1a, 119 p.

Dickinson, W.R., Klute, M.A., Hayes, M.J., Janecke, S.U., Lundin, E.R., Mckittrick, M.A., Olivares, M.D., 1988, Paleogeographic and paleotectonic setting of Laramide sedimentary basins in the central Rocky Mountain region: Geological Society of America Bulletin, 100, 1023-1039.

Enríquez-Castillo, M.A., 2008, Termocronología U-Pb y ${ }^{40} \mathrm{Ar} /{ }^{39} \mathrm{Ar}$ de intrusivos de la Sierrita Blanca, NW Sonora: Ejemplo de interacción termal entre magmas graníticos laramídicos y las rocas encajonantes 
del basamento metaígneo Mesoproterozoico: Tesis de Licenciatura, Linares, N.L., Universidad Autónoma de Nuevo León, 74p.

Espinoza, I., Iriondo, A., Premo, W.R., Paz-Moreno, F., Valencia-Moreno M., 2003, Geochemistry and SHRIMP U-Pb zircon geochronology of anorthositic rocks at Sierra El Tecolote in the Caborca block, northwestern Sonora, Mexico: Geological Society of America, Cordilleran Section, 99th Annual Meeting, Abstracts with Programs, 35(4), 84 .

Farmer, G.L., Bowring, S.A., Espinoza, I., Matzel, J., 2003, Isotopic evidence on the nature of Precambrian basement and overlying sedimentary rocks, Caborca, Sonora: Geological Society of America Cordilleran Section, 99th Annual Meeting, Abstracts with Programs, 35(4), 67.

Farmer, G.L., Bowring, S.A., Matzel, J., Espinoza Maldonado, G., Fedo, C., Wooden, J., 2005, Paleoproterozoic Mojave province in northwestern Mexico? Isotopic and $\mathrm{U}-\mathrm{Pb}$ zircon geochronologic studies of Precambrian and Cambrian Crystalline and sedimentary rocks, Caborca, Sonora, en Anderson, T.H., Nourse, J.A., McKee, J.W., Steiner, M.B., (eds.), The Mojave-Sonora megashear hypothesis: Development, assessment, and alternatives: Geological Society of America Special Paper 393, 183-198.

Fleck, R.J., Sutter, J.F., Elliot, D.H., 1977, Interpretation of discordant ${ }^{40} \mathrm{Ar} /{ }^{39} \mathrm{Ar}$ age spectra of Mesozoic tholeiites from Antarctica: Geochimica et Cosmochimica Acta, 41, 15-32.

Gaber, L.J., Foland, K.A., Corbató, C.E., 1988, On the significance of argon release from biotite and amphibole during ${ }^{40} \mathrm{Ar}{ }^{39} \mathrm{Ar}$ vacuum heating: Geochimica et Cosmochimica Acta, 52, 2457-2465.

Gans, P.B., 1997, Large-magnitude Oligo-Miocene extension in southern Sonora: implications for the tectonic evolution of northwest Mexico: Tectonics, 16, 388-408.

Gehrels, G., Valencia, V., Pullen, A., 2006, Detrital zircon geochronology by Laser-Ablation Multicollector ICPMS at the Arizona LaserChron Center, en Olszewski, T.D. (ed.), Geochronology Emerging Opportunities: Paleontological Society, 12, 67-76.

Glazner, A.F., Bartley, J.M., Coleman, D.S., Gray, W., Taylor, R.Z., 2004, Are plutons assembled over millions of years by amalgamation from small magma chambers?: GSA Today, 14, 4-11.

Hanson, G.N., Simmons, K.R., Bence, A.E., $1975,{ }^{40} \mathrm{Ar} r{ }^{39} \mathrm{Ar}$ spectrum ages for biotite, hornblende and muscovite in a contact metamorphic zone: Geochimica et Cosmochimica Acta, 39, 1269-1277.

Harrison, T.M., McDougall, I., 1980a, Investigation of an intrusive contact, northwest Nelson, New Zealand-I. Thermal Chronological and isotopic constraints: Geochimica et Cosmochimica Acta, 44, 1985-2003.

Harrison, T.M., McDougall, I., 1980b, Investigation of an intrusive contact, northwest Nelson, New Zealand-II. Diffusion of radiogenic and excess ${ }^{40} \mathrm{Ar}$ in hornblende revealed by ${ }^{40} \mathrm{Ar} /{ }^{39} \mathrm{Ar}$ age spectrum análisis: Geochimica et Cosmochimica Acta, 44, 2005-2020.

Hart, S.R., 1964, The petrology and isotopic-mineral age relations of a contact zone in the Front Range, Colorado: Journal of Geology, $72,493-525$

Haugerud, R.A., Kunk, M.J., 1988, Ar/Ar*, a computer program for reduction of ${ }^{40} \mathrm{Ar} /{ }^{39} \mathrm{Ar}$ data: U.S. Geological Survey, Open File Report, 88-261, $68 \mathrm{p}$.

Haxel, G.B., Tosdal, R.M., May, D.J., Wright, J.E., 1984, Latest Cretaceous and early Tertiary Orogenesis in south-central Arizona: Thrust Faulting, regional metamorphism, and granitic plutonism: Geological Society of America Bulletin, 95, 631-653.

Heaman, L., Parrish, R., 1991, U-Pb geochronology of accessory minerals, en Heaman, L., Ludden, N., (eds.), Short course handbook on applications of radiogenic isotope systems to problems in geology: Mineralogical Association of Canada, 19, 59-102.

INEGI, Instituto Nacional de Estadística, Geografía e Informática, 2003, Carta Topográfica escala 1:50,000, H12A34, "El Tullido", Sonora, México.

Iriondo, A., 2001, Proterozoic basements and their laramide juxtaposition in NW Sonora, Mexico: Tectonic constraints on the SW margin of Laurentia: Ph.D. Thesis, University of Colorado at Boulder, USA, $222 \mathrm{p}$.
Iriondo, A., Premo, W.R., 2003, The Caborca Block: an inhomogeneous piece of Paleoproterozoic crust in Sonora: Geological Society of America, Cordilleran Section, 99th Annual Meeting, Abstracts with Programs, 35(4), 67.

Iriondo, A., Premo, W.R., 2010, Las rocas cristalinas Proterozoicas de Sonora y su importancia para la reconstrucción del margen continental SW de Laurencia: La pieza mexicana del rompecabezas de Rodinia, en Calmus, T., (ed.), La geología de Sonora, Publicaciones Especiales, Instituto de Geología, Universidad Nacional Autónoma de México (en prensa).

Iriondo, A., Atkinson, W.W., Jr., Martínez-Torres, L.M., 1996, El Pilar Caldera: an example of Early Miocene calc-alkaline magmatism in the Quitovac area, norwestern Sonora, Mexico: Geological Society of America, Abstracts with Programs, 28, 441-442.

Iriondo, A., Miggins, D., Premo, W.R., 2003a, The Aibo-type ( 1.1 Ga) granitic magmatism in NW Sonora, Mexico: Failed continental rifting of Rodinia?: Geological Society of America Cordilleran Section Abstracts with Programs, 35(4), 84.

Iriondo, A., Kunk, M.J., Winick, J.A., Consejo de Recursos Minerales, $2003 \mathrm{~b},{ }^{40} \mathrm{Ar}{ }^{39} \mathrm{Ar}$ dating studies of minerals and rocks in various areas in Mexico: USGS/CRM Scientific Collaboration (Part I): U.S. Geological Survey Open File Report, OF-03-020, 79 p.

Iriondo, A., Kunk, M.J., Winick, J.A., Consejo de Recursos Minerales, $2004 \mathrm{a},{ }^{40} \mathrm{Ar}{ }^{39} \mathrm{Ar}$ dating studies of minerals and rocks in various areas in Mexico: USGS/CRM Scientific Collaboration (Part II): U.S. Geological Survey Open File Report, OF-04-1444, 46 p.

Iriondo, A., Premo, W.R., Martínez-Torres, L.M., Budahn, J.R., Atkinson, W.W., Jr., Siems, D.F., Guarás-González, B., 2004b, Isotopic, geochemical, and temporal characterization of Proterozoic basement rocks in the Quitovac region, northwestern Sonora, México: Implications for the reconstruction of the southwestern margin of Laurentia: Geological Society of America Bulletin, 116, 154-170.

Iriondo, A., Martínez-Torres, L.M., Kunk, M.J., Atkinson, W.W., Jr., Premo, W.R., McIntosh, W.C., 2005, Northward Laramide thrusting in the Quitovac region, northwestern Sonora, Mexico: Implications for the juxtaposition of Paleoproterozoic basement blocks and the MojaveSonora megashear hypothesis, en Anderson, T.H., Nourse, J.A., McKee, J.W., Steiner, M.B., (eds.), The Mojave-Sonora megashear hypothesis: Development, assessment, and alternatives: Geological Society of America Special Paper 393, 631-669.

Iriondo, A., Kamenov, G.D., Foster, D.A., 2008, The Sierra Los Tanques $\sim 1.1$ Ga granite in NW Sonora: another example of Mesoproterozoic plutonism along the Mexican Yavapai province: Geological Society of America Abstracts with Programs, 40(6), Abstract 145-12.

Izaguirre-Pompa, A., 2009, El basamento Paleoproterozoico ( 1.71-1.68 Ga) Yavapai en el área Mina La Herradura en el NW de Sonora: Sus implicaciones para el desarrollo del margen magmático continental Mesozoico-Cenozoico del NW de México: Tesis de Maestría, Querétaro, Qro, Universidad Nacional Autónoma de México, 201 p.

Izaguirre, A., Iriondo, A., 2007, Mesoproterozoic ( 1.2 Ga) quartzite and intruding anorthosite $(\sim 1.08 \mathrm{Ga})$ from Sierra Prieta, NW Sonora: Mexican additions to the Precambrian history of SW Laurentia: Ore and Orogenesis, A symposium honoring the career of William R. Dickinson, Programs with Abstracts, 147.

Jacques-Ayala, C., Barth, A.P., Jacobson, C.C., Roldán-Quintana, J., 2008, Tectonically transported Laramide granitoids in the Caborca area: 1er. Congreso sobre la Evolución Geológica y Ecológica del Noroeste de México, Disco de Resúmenes. Resumen, 8.8.

Koenken, P.J., 1976, Petrology of anorthosites from two localities in northwestern Sonora, Mexico: M.S. Thesis, University of Southern California, Los Angeles, USA, 97 p.

Kunk, M.J., Sutter, J.F., Naeser, C.W., 1985, High-precision ${ }^{40} \mathrm{Ar} /{ }^{39} \mathrm{Ar}$ ages of sanidine, biotite, hornblende, and plagioclase from the Fish Canyon Tuff, San Juan Volcanic Field, south central Colorado: Geological Society of America Abstracts with Programs, 17, 236.

Lovera, M.O., Grove, M., Harrison, T.M., 2003, Termocronometría por el método de argón en K-Feldespatos: GEOS, 23(2), 105.

Ludwig, K.R., 2003, ISOPLOT, Version 3.00: A geochronological Toolkit for Microsoft Excel: Berkeley Geochronology Center Special 
Publication, $4,70 \mathrm{p}$.

McDougall, I., Harrison, T.M., 1999, Geochronology and thermocronology by the ${ }^{40} \mathrm{Ar} /{ }^{39} \mathrm{Ar}$ Method: Oxford University Press, $269 \mathrm{pp}$.

Molina-Garza, R.S., Iriondo, A., 2005, La megacizalla Mojave-Sonora: la hipótesis, la controversia y el estado actual de conocimiento: Revista de la Sociedad Geológica Mexicana, Volumen Conmemorativo del Centenario Grandes Fronteras Tectónicas de México, Tomo LVII, $1,1-26$.

Nourse, J.A, Premo, W.R., Iriondo, A., Stahl, E.R., 2005, Contrasting Proterozoic basament complexes near the truncated margin of Laurentia, northwestern Sonora-Arizona international border region, en Anderson, T.H., Nourse, J.A., McKee, J.W., Steiner, M.B., (eds.), The Mojave-Sonora megashear hypothesis: Development, assessment, and alternatives: Geological Society of America Special Paper 393, 123-182.

Ortega-Rivera, A., 2003, Geochronological constraints on the tectonic history of the Peninsular Ranges batholith of Alta and Baja California: Tectonic implications for western México: Geological Society of America Special Paper 374, 297-335.

Ortega-Rivera, A., Farrar, E., Hanes, J.A., Archival, D.A., Gastil, R.G., Kimbrough, D.L., Zentilli, M., López-Martínez, M., Féreaud, D., Ruffet, G., 1997, Chronological constrain on the thermal and tilting history of the Sierra San Pedro Mártir pluton, Baja California, México, from $\mathrm{U} / \mathrm{Pb},{ }^{40} \mathrm{Ar} /{ }^{39} \mathrm{Ar}$, and fission-track geochronology: Geological Society of America Bulletin, 109, 728-745.

Ramos-Velázquez, E., Calmus, T., Valencia, V., Iriondo, A., ValenciaMoreno, M., Bellon, H., 2008, U-Pb and ${ }^{40} \mathrm{Ar} /{ }^{39} \mathrm{Ar}$ geochronology of the coastal Sonora batholith: New insights on Laramide continental arc magmatism: Revista Mexicana de Ciencias Geológicas, 25(2), 314-333.

SGM, Servicio Geológico Mexicano, 2002, Carta Geológico-Minera Puerto Peñasco, Sonora H12-1: Servicio Geológico Mexicano, Secretaría de Economía, México D.F.

Stacey, J.S., Kramers, J.D., 1975, Approximation of terrestrial Lead isotope evolution by a two-stage model: Earth and Planetary Science Letters, 26, 207-221.

Steiger, R.H., Jäger, E., 1977, Subcommission on geochronology: Convention on the use of decay constants in geo- and cosmochronology: Earth and Planetary Science Letters, 36, 359-362.

Valencia-Moreno, M., Iriondo, A., González-León, C., 2006, Temporal constraints on the eastward migration of the Late Cretaceous-early Tertiary magmatic arc of NW Mexico based on new ${ }^{40} \mathrm{Ar} /{ }^{39} \mathrm{Ar}$ hornblende geochronology of granitic rocks: Journal of South American Earth Sciences, 22, 22-38.

Manuscrito recibido: Septiembre 19, 2009.

Manuscrito corregido recibido: Octubre 19, 2009.

Manuscrito aceptado: Octubre 22, 2009. 